\title{
The effects of oocytes on Smad signaling pathways in granulosa cells
}

\author{
Efthimia Rafaelia Christoforou
}

A thesis submitted to the Victoria University of Wellington in partial fulfillment of the requirements for the degree of Master of Biomedical Science

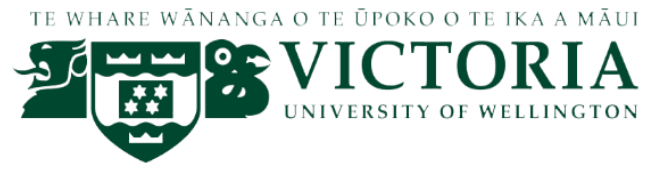

Victoria University of Wellington

Te Whare Wānanga o te Ūpoko o te Ika a Māui 


\section{Abstract}

It is well established that two oocyte-secreted growth factors (OSF), namely growth differentiation factor 9 (GDF9) and bone morphogenetic protein 15 (BMP15) regulate the growth of ovarian follicles and ovulation rate. Moreover, it has been reported that the gene expression ratio of Gdf9:Bmp15 varies between species and may, at least in part, influence litter size in mammals. Generally, poly-ovulatory and mono-ovulatory species express a high and low ratio of $G d f 9: B m p 15$, respectively. Intriguingly pigs, a poly-ovulatory species, have a low GDF9: BMP15 ratio and are the exception to this rule. To further our understanding of species differences in oocyte-secreted growth factors (OSF), and how this impacts follicular growth, oocytes and follicular cells (granulosa cells; GC) from a range of species that differ in litter size were cultured together. The aims of this study were to perform same- and cross-species co-incubations of oocytes with GCs to elucidate species-specific effects of OSF on (i) GC proliferation rate, (ii) expression levels of GC type I and type II receptors and (ii) activation of Smad signaling pathways in rats, sheep, pigs and red deer. The methodologies utilised were tritiated thymidine incorporation assays, qPCR and Western blotting, respectively.

The co-incubation studies revealed in general, that rat GC are more proliferative than GCs from any other species tested, especially with time in culture. Moreover deer oocytes, which express negligible GDF9 mRNA, are unable to stimulate proliferation in rat GCs to the same extent as oocytes from the other species. This supports previous studies that suggest that rat GC only require GDF9 to proliferate, whilst both BMP15 and GDF9 are able to stimulate the GCs of sheep. This may illustrate that these two OSF play divergent roles in folliculogenesis dependant on the species.

Interestingly, deer oocytes decreased Bmpr1b mRNA expression in rat GC but increased BMPR1B mRNA expression in pig GC. This may suggest that whilst the rat and pig are both poly-ovulatory species, their GCs respond in different ways to negligible amounts of GDF9, compared to BMP15. Although deer oocytes differentially affected receptor expression levels in GCs of various species, they were able to increase Smad 1/5/8 levels in both rat and deer GCs, illustrating that the BMP15 secreted by deer oocytes utilise this signaling pathway. 
The cross-species incubations of rat GCs with either rat, sheep or pig oocytes stimulated proliferation to a high extent. However, sheep oocytes concomitantly increased $\operatorname{Tgf} \beta r 1$ expression, and increased Smad 2/3 in rat GCs, whilst rat and pig oocytes did not. This suggests that OSF from different species may elicit proliferation by utilising different type I receptors and signaling pathways.

In summary, this study illustrated that GCs of rat were different to that of the other species tested due to their suspected inability to respond to the proliferative actions of BMP15. Moreover, species-specific differences exist in the ability of OSFs to stimulate GC proliferation and activate downstream signaling pathways. 


\section{Acknowledgements}

First and foremost, I would like to express my heartfelt thanks to my supervisor, Dr Janet Pitman, for giving me the opportunity to work on this project. Janet's constant help, encourangement and patience throughout have been most invaluable. I will also always be grateful to her for encouranging me to persue further study. I would also like to thank the Reproductive Biology group, and in particular Professor Ken McNatty, for useful discussions and advice. Thank you to Sarah Sczelecki, for assisting me throughout this project, in the collection of oocytes, and for the troubleshooting of Western blots. Thank you also to Adrian Bibby, for guidance in proliferation assays. I am privileged to have been a member of the Reproductive Biology group, whose welcoming environment helped me throughout my research, as everyone was always keen to answer questions, and also sometimes volunteer their help in oocyte collections.

I would like to express my gratitude to everyone who helped me in obtaining the ovaries required for this research. Thank you to the Department of Psychology at Victoria University of Wellington, and Dr Bronwyn Kivell. Thank you also to the Taylor Preston meat processing plant in Ngauranga; Cabernet Foods, Kintyre Meats Ltd in Gladstone, and the Venison Packers Feilding Ltd meat processing plant in Feilding for also providing ovaries and being so accommodating of our hectic schedules.

I would also like to acknowledge the Royal Society of NZ and the Marsden fund (Contract 13-VUW-153), for providing the funding for this research.

Last but not least, I would like to thank my friends, my cousins and my aunties and uncles, for their encouragement and understanding when things got busy. I would especially like to thank my parents, Demetrius and Maria, for encouraging my study and their unfailing support. 


\section{Table of Contents}

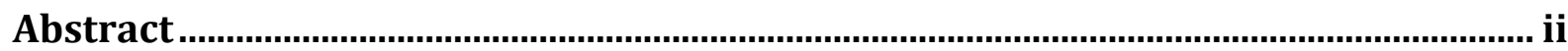

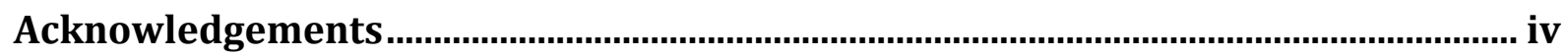

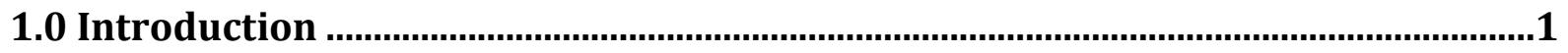

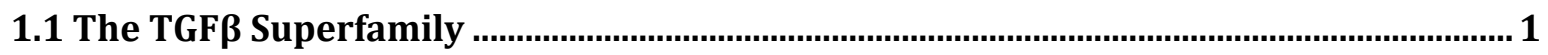

1.1.1 Molecular Forms of the TGF $\beta$ Superfamily Members .......................................................... 1

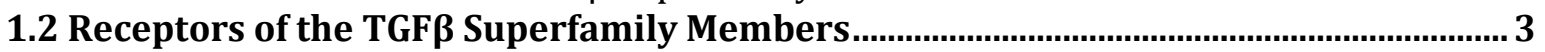

1.3 Growth Differentiation Factor 9 \& Bone Morphogenetic Protein 15 ............................... 4

1.3.1 Protein Structures of GDF9 \& BMP15 ………............................................................................ 4

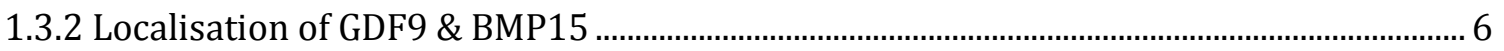

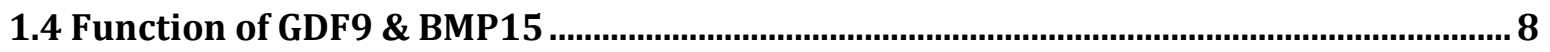

1.4.1 Information from Sheep Mutants and Mouse Knockouts ………........................................ 8

1.4.2 Roles of GDF9 and BMP15 in Folliculogenesis ...................................................................11

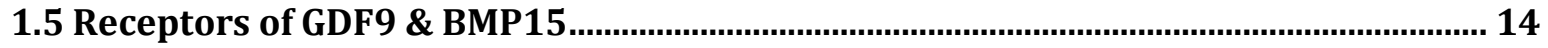

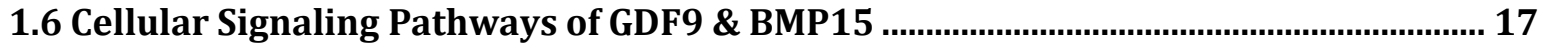

1.6.1 Smad Signaling Pathways...............................................................................................................

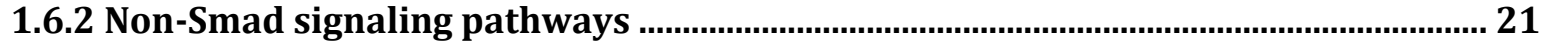

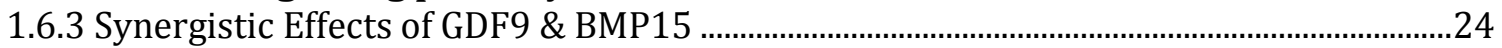

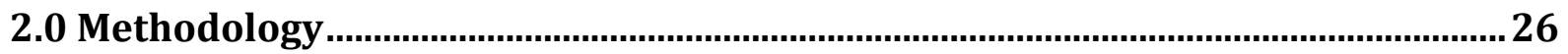

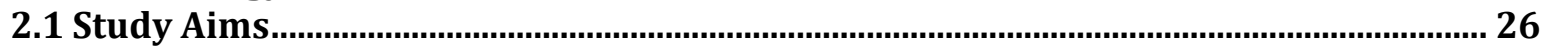

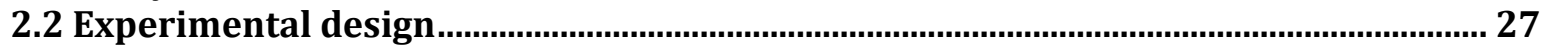

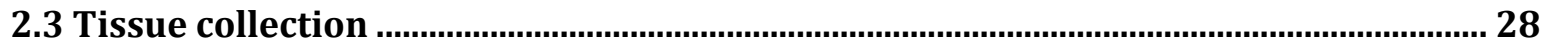

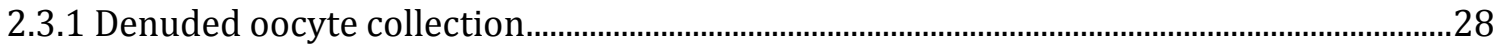

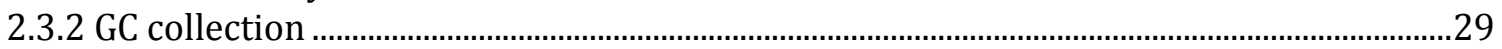

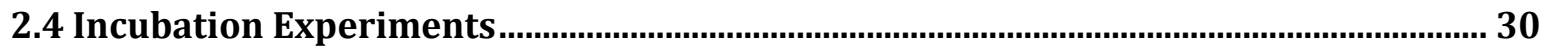

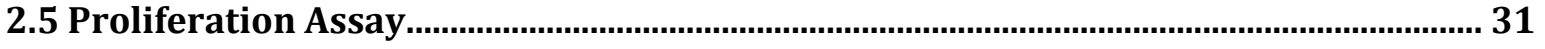

2.6 GC sample preparation for qPCR and Western Blots..................................................... 31

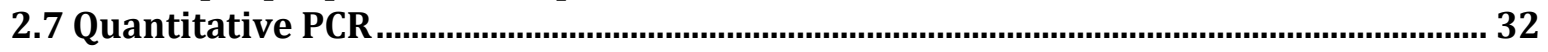

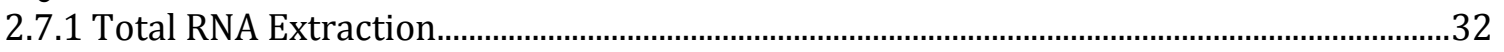

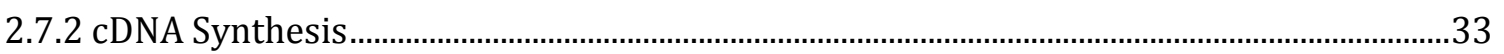

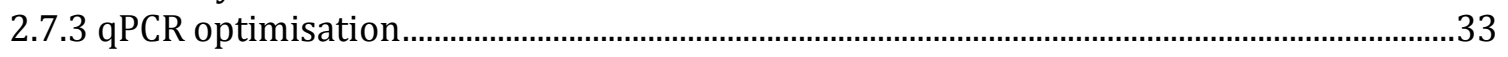

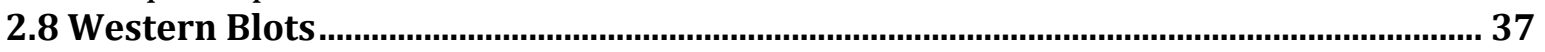

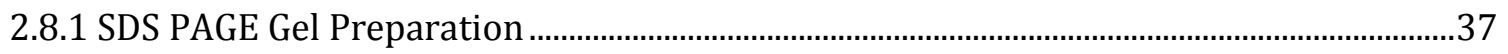

2.8.2 Sample Preparation ..............................................................................................................

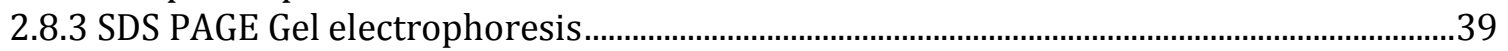

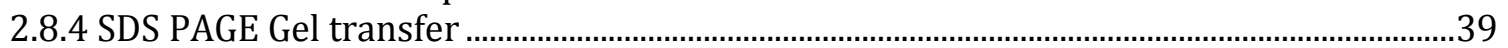

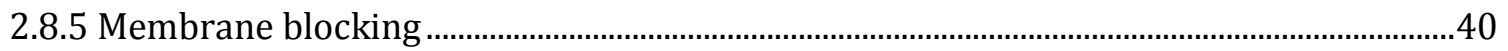

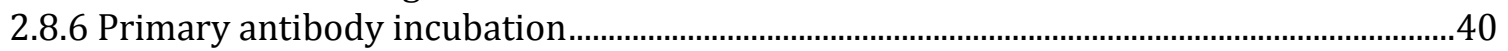

2.8.7 Secondary antibody incubation........................................................................................... 41

2.8.8 Western blot development ...........................................................................................

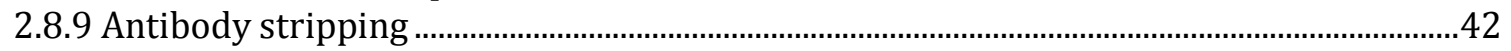

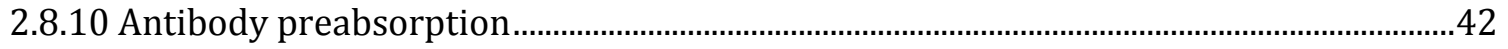

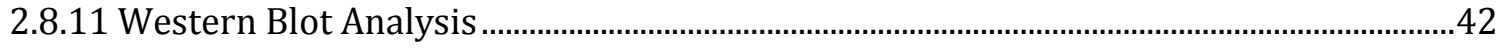

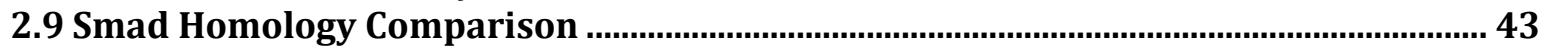

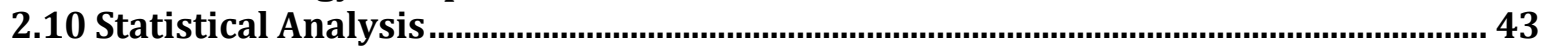

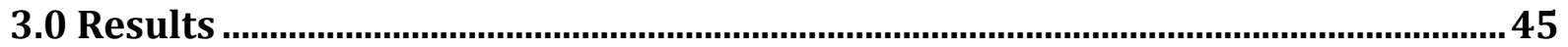


3.1 Effects of incubation time on GC proliferation rate ..........................................................

3.2 Effects of oocyte co-incubations on GC proliferation rate .............................................50

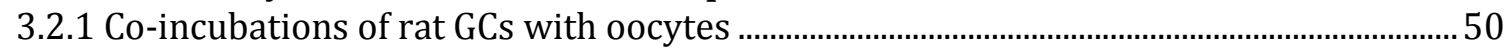

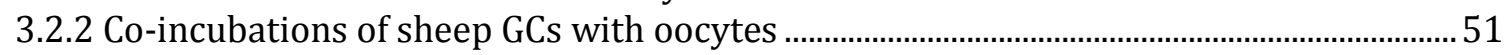

3.2.3 Co-incubations of pig GCs with oocytes …………………………………........................ 52

3.2.4 Co-incubations of deer GCs with oocytes ........................................................................... 53

3.5 Effects of cell viability and species on GC proliferation rate .............................................54

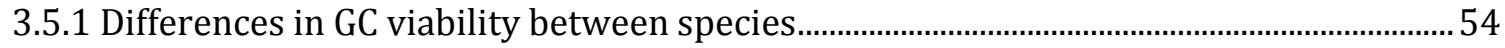

3.5.2 Differences in basal GC proliferation rate between species................................................. 55

3.5.3 Effects of GC viability on basal proliferation rate …………………………......................... 56

3.6 Effects of oocyte co-incubation on GC-derived gene expression .......................................57

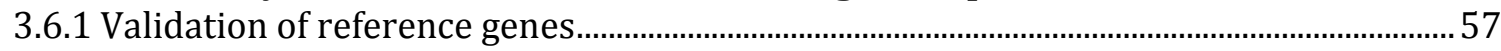

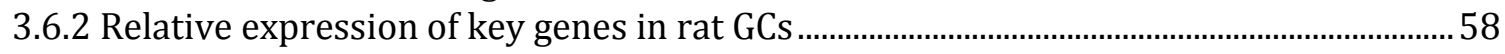

3.6.3 Relative expression of key genes in sheep GCs ..................................................................... 58

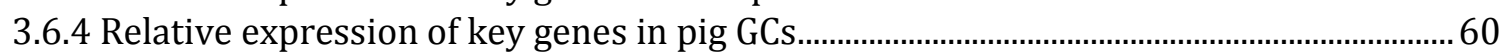

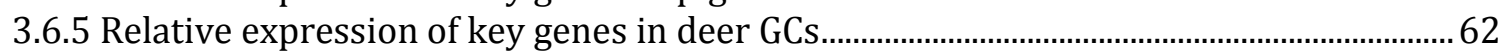

3.7 Effects of oocyte co-incubation on Smad protein levels in GCs......................................63

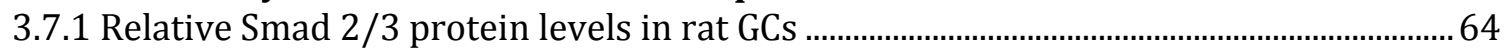

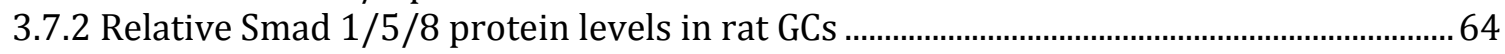

3.7.3 Relative Smad 2/3 protein levels in deer GCs .......................................................................67

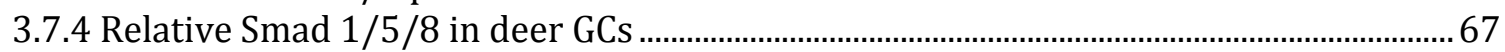

3.8 Validation of Smad 2/3 and Smad 1/5/8 antibodies .................................................... 70

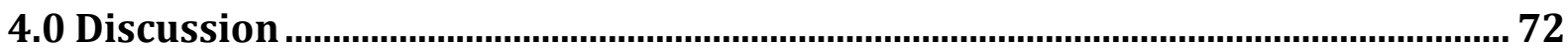

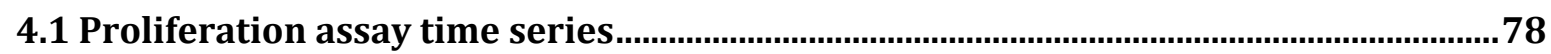

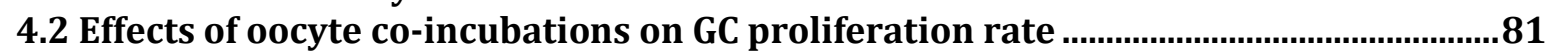

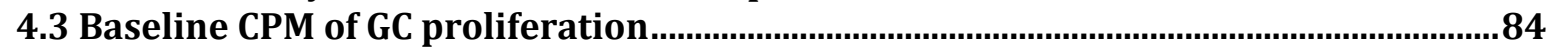

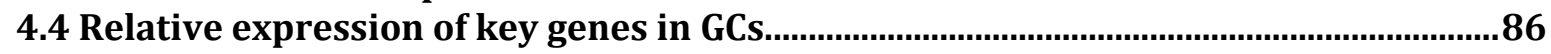

4.5 Effects of oocyte co-incubation on Smad protein levels in GCs.......................................90

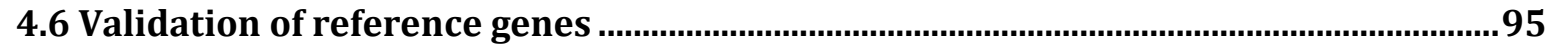

4.7 Validation of Smad 2/3 and Smad 1/5/8 antibodies.................................................95

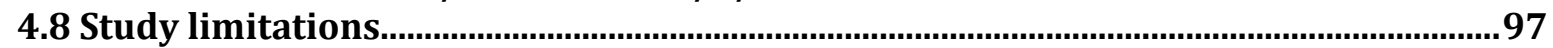

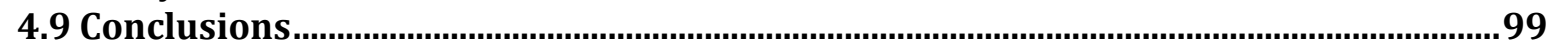

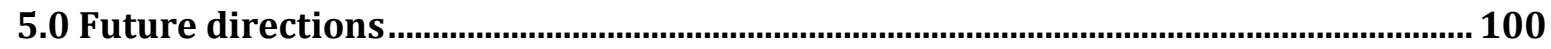

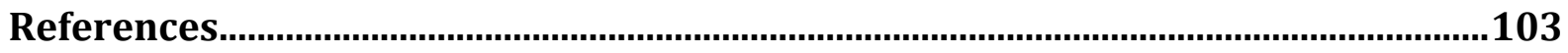

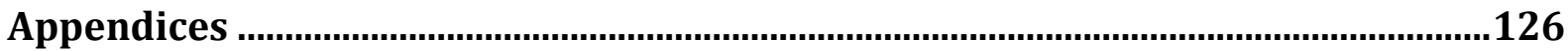

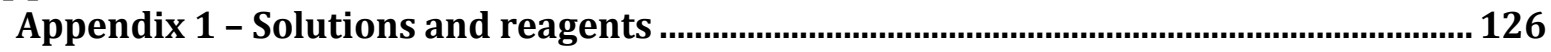

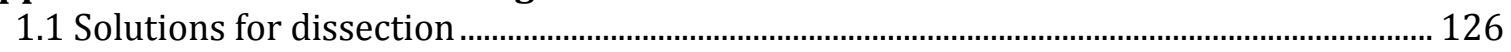

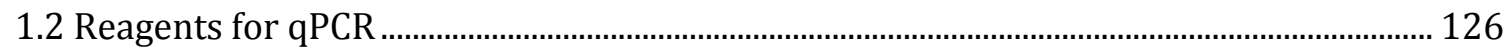

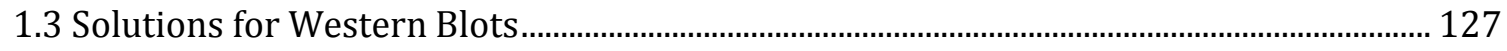

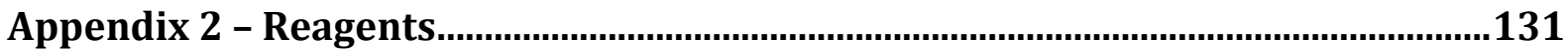

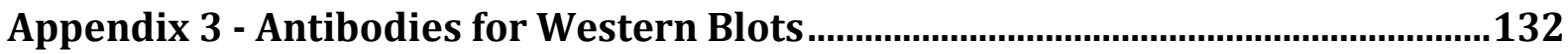




\section{List of Figures}

Figure 1.1: Paracrine signaling between oocyte secreted factors and follicular somatic cells 16

Figure 1.2: Smad structure and function. 18

Figure 2.1: Experimental design of cross-incubations of granulosa cells and oocytes from the four test species. 27

Figure 3.11: Fold change in proliferation rate of rat, sheep, pig and deer GC with time in culture. 46

Figure 3.12: Tritiated thymidine incorporation of rat, sheep, pig and deer GC with time in culture. 48

Figure 3.13: Proliferation rate of rat, sheep, pig and deer GC after 16 hours in culture.. 49

Figure 3.2.1: Proliferation rate of rat GC co-incubated with oocytes. .................................. 51

Figure 3.2.2: Proliferation rate of sheep GC co-incubated with oocytes. .............................. 52

Figure 3.2.3: Proliferation rate of pig GC co-incubated with oocytes..................................... 53

Figure 3.2.4: Proliferation rate of deer GC co-incubated with of deer oocytes................... 54

Figure 3.5.1: Cell viability of rat, sheep, pig and deer GC at time of collection................... 55

Figure 3.5.2: Basal proliferation rate of rat, sheep, pig and deer GC..................................... 55

Figure 3.5.3: Correlation between GC viability and basal proliferation rate........................ 56

Figure 3.6.1: PPIA and RPL19 expression in rat, sheep, pig and deer GC samples............. 57

Figure 3.6.2: Gene expression levels in rat GC co-incubated with oocytes............................59

Figure 3.6.3: Gene expression levels in sheep GC co-incubated with oocytes...................... 60

Figure 3.6.4: Gene expression levels in pig GC co-incubated with oocytes.......................... 61

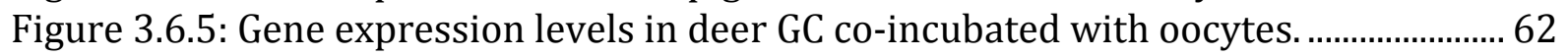

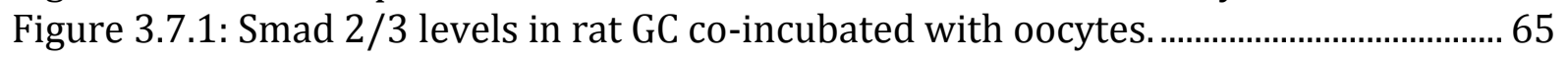

Figure 3.7.2: Smad 1/5/8 levels in rat GC co-incubated with oocytes. ...................................66

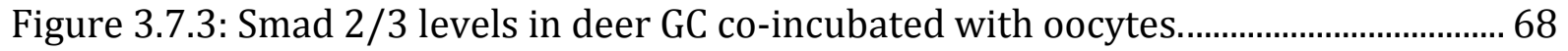

Figure 3.7.4: Smad 1/5/8 levels in deer GC co-incubated with oocytes.................................69

Figure 3.8: Western blots testing Smad2/3 and 1/5/8 antibody specificity....................... 71 


\section{List of Tables}

Table 2.7.3.1: Nucleotide sequences and NCBI accession numbers for forward and reverse rat, sheep, pig and deer primers and TaqMan probes.

Table 2.7.3.2: Optimised forward and reverse rat, sheep, pig and deer primer concentrations and Taqman probes. 36

Table 2.7.3.3: Amplification efficiencies of rat, sheep, pig and deer genes. .37

Table 2.8.1: Table of reagents for $13.5 \%$ separating gel and $4 \%$ stacking gel recipes......38

Table 2.8.6: Optimised antibody concentrations.

Table 2.9.1: Homology of Smad proteins between species.

Table 4.1.1: Expression of OSFs and GC receptors in the four different species..................74

Table 4.4.1: The effect of oocytes on TGF $\beta R 1$ mRNA levels in GCs in mono-ovulatory and poly-ovulatory species

Table 4.4.2: The effect of oocytes on BMPR1B mRNA levels in GCs in mono-ovulatory and poly-ovulatory species.

Table 4.4.3: The effect of oocytes on BMPR2 mRNA levels in GCs in mono-ovulatory and poly-ovulatory species. 


\section{List of abbreviations}

ActRI

ActRIB

ActRII

ActRIIB

ACVR1

ACVR1B

ACVR1C

ACVRL1

ACVR2A

ACVR2B

ALK

ALK5

ALK6

$\mathrm{AMH}$

ANOVA

AROM

BAMBI

BIMEL

BMP15

BMP1B

BMPR2

cDNA

COC

Co-Smad

CPM

$\mathrm{C}_{\mathrm{T}}$

DTT

ERK1/2

FAST

FecXI

GC

GDF9

GDNF

hCG

I-Smad

IVF

IVM

LAP

LH

LSD

MAPK

MH

mRNA

NCBI

$\mathrm{NF}-\kappa \mathrm{B}$

OOX
Activin receptor type I

Activin receptor type I B

Activin receptor type II

Activin receptor type II B

Activin A receptor type 1

Activin A receptor type 1B

Activin A receptor type $1 \mathrm{C}$

Activin A receptor type II like I

Activin A receptor type IIA

Activin A receptor type IIB

Activin receptor like kinase

Activin receptor like kinase-5 (aka TGF $\beta$ R1)

Activin receptor like kinase-6 (aka BMPR1B)

Anti-Mullerian hormone

Analysis of variance

Aromatase

BMP and activin membrane bound inhibitor

BCL-2-interacting mediator of cell death-extra long

Bone morphogenetic protein 15

Bone morphogenetic protein 1B

Bone morphogenetic protein receptor 2

Complimentary deoxyribonucleic acid

Cumulus-oocyte complex

Common mediator Smad

Counts per minute

Cycle threshold

Dithiothreitol

Extracellular signal-regulated kinases

Forkhead activin signaling transducer

Fecundity gene Inverdale on $\mathrm{X}$ chromosome

Granulosa cell

Growth differentiation factor 9

Glial cell-derived neurotrophic factor

Human chorionic gonadotropin

Inhibitory Smad

In vitro fertilisation

In vitro maturation

Latency-associated peptide

Luteinising hormone

Least significant difference

Mitogen-activated protein kinase

Mad-homology domain

messenger Ribonucleic acid

National Center for Biotechnology Information

Nuclear factor- $\kappa \mathrm{B}$

Oocytectomised-cumulus cell complex 
Oocyte secreted factor

PCNA

Phosphate buffered saline

PI3K

Proliferating cell nuclear antigen

qPCR

Phosphatidylinositol-3-kinase

RPL19

Quantitative polymerase chain reaction

R-Smad

Ribosomal protein L19

RTK

SARA

StAR

SDS

SBE

SEM

SMAD

Receptor activated Smad

Receptor protein tyrosine kinase

Smad anchor for receptor activation

Steroidogenic acute regulatory protein

Sodium dodecyl sulfate

Smad binding element

Standard error of the mean

Smurf

Similar to mothers against decapentaplegic protein

TGF $\beta$

Smad ubiquitination regulatory factor

Transforming growth factor $\beta$ 


\subsection{Introduction}

Growth differentiation factor 9 (GDF9) and bone morphogenetic protein 15 (BMP15) are members of the transforming growth factor- $\beta$ (TGF $\beta$ ) superfamily. Interestingly, they appear to utilise distinct signaling pathways, firstly binding a common Type 2 receptor and then recruiting unique Type 1 receptors to activate different down-stream Smad proteins. The biological actions of these two oocyte-secreted growth factors facilitate ovarian follicular development and regulate ovulation rate and litter size in mammals. The expression, secretion and biological activity of both GDF9 and BMP15 have been reported to be specific to each mammalian species tested. The aim of this study was to cross-incubate oocytes with granulosa cells of different species to observe the regulation of granulosa cell proliferation and downstream signaling by speciesspecific oocyte secreted factors, namely GDF9 and BMP15.

\subsection{The TGF $\beta$ Superfamily}

\subsubsection{Molecular Forms of the TGF $\beta$ Superfamily Members}

The transforming growth factor- $\beta$ (TGF $\beta$ ) superfamily includes over 30 structurally related polypeptides such as TGF- $\beta$ s, activins, inhibins, growth differentiation factors and bone morphogenetic proteins, which are conserved across species (Massague, 1998, Chang et al, 2002, ten Dijke et al, 2002, Shi and Massague, 2003, Mueller and Nickel, 2012). The cellular processes that this superfamily of structurally-related ligands are involved in include development (Jones et al, 1996, Dudley et al, 1995, Luo et al, 1995, Winnier et al, 1995, Celá et al, 2016), wound healing (Carrington et al, 2006, Sefat et al, 2014, Yang et al, 2016), immune surveillance (Rich et al, 1995, Tiemessen et al, 2003, Takai et al, 2010), and reproductive function (Yan et al, 2001, Juengel et al, 2009, Gao et al, 2015). Using possible phylogenetic relationships, the members of the superfamily have been classified into five groups (INH $\alpha$, MIS, TGF $\beta$ s, BMPs and INH $\beta$ s), as well as several subgroups (Burt, 1992). As reviewed by Knight and Glister (2006), analysis of additional structural characteristics allows the further classification of subfamilies. These include the TGF $\beta$ (including TGF $\beta 1$, TGF $\beta 2$, and TGF $\beta 3$ ), the activin/inhibin, the glial cell-derived neurotrophic factor (GDNF), the bone morphogenetic protein (BMP) 
and the growth and differentiation factor (GDF) subfamilies. The BMP and GDF subfamilies comprise of at least 20 and nine members, respectively.

TGF $\beta$ superfamily members are translated as prepropeptide precursors prior to their processing and secretion (Chang et al, 2002). Several experiments have detected the secretion of latent TGF $\beta$, with its biological activation being observed upon release from its latent form through acidification (Pircher et al, 1984, Lawrence et al, 1985, Pircher et al, 1986). Thus, it was hypothesised that latent TGF $\beta$ is comprised of TGF $\beta$ noncovalently associated with its precursor (Lawrence et al, 1985, Wakefield et al, 1988), a dimer now known as the latency associated peptide (LAP) (Chang et al, 2002). Inactive TGF $\beta$ also contains a latent TGF $\beta$ binding protein (LTBP), which is comprised of TGF $\beta 1$ bound to a complex of components which are disulfide-linked (Miyazono et al, 1988). The integrin $\alpha_{v} \beta_{6}$ is able to recognise an amino acid sequence on LAP. However for $\alpha_{v} \beta_{6}$ mediated activation of TGF $\beta$, LTBP-1 is required, with this process being LTBP isoform specific (Annes et al, 2004).

As reviewed by Taylor et al (2003), proprotein convertases (PC) are a family of endoproteases, which cleave at basic motifs, changing the precursor molecule to an active protein. Such proprotein convertases include PC1, PC2, PC4, PC6B, furin and LPC, with the convertases' predicted substrates including TGF $\beta$ superfamily members. The expression of the proprotein convertases PC1 and PC2 in a recombinant vaccinia virus vector allows the processing of proopiomelanocortin at pairs of basic residues (Benjannet et al, 1991). The pro-protein convertase furin is able to convert pro-TGF $\beta 1$ into its mature monomer and pro-region (Dubois et al, 1995), having been verified as an endogenous TGF $\beta 1$ convertase (Dubois et al, 2001). In comparison, furin inefficiently cleaves TGF $\beta 2$, with the tertiary structure of the LAP regions influencing the ability of furin to to cleave TGFßs (Kusakabe et al, 2007).

The prodomains of the TGF $\beta$ family are described as having low to unrelated sequence homology, with their length varying from 169 to 433 residues (Shi et al, 2011). Although the pro-domain of TGF $\beta$ is poorly conserved across various family members, the mature 
region is more highly conserved. Seven cysteine residues within the mature region are present in almost all members of the family (Lee, 1990, Daopin et al, 1992, Kingsley, 1994). The pro-regions of several members of the TGF $\beta$ superfamily, such as activin $A$ and TGF $\beta 1$, are important in aiding the folding, disulfide bond formation and export of their homodimers (Gray and Mason, 1990). Analysis of the crystal structure of TGF $\beta 2$ illustrates that this protein's overall structure consists of two finger-like $\beta$ strands and loops, attached to a $\alpha 3$ helix. The core structure is expected to be shared amongst members of the TGF $\beta$ superfamily (Daopin et al, 1992), with BMP2, BMP7 and the TGF $\beta$ s sharing a cysteine-knot motif core, described as a palm, and finger-like $\beta$ sheets (Scheufler et al, 1999).

\subsection{Receptors of the TGF $\beta$ Superfamily Members}

Members of the TGF $\beta$ superfamily act through the binding of receptors that have intrinsic serine/threonine kinase activity (Chang et al, 2002). As reviewed in Massague, (1998), and Chang et al, (2002), the receptors of the TGF $\beta$ superfamily have two subfamilies, the type I and type II receptors. In mammalian species, the type I receptors are subdivided into three groups. The three groups include: 1) activin receptor-like kinase 5 (ALK5; also known as TGFßR1), ALK4 (also known as ACVR1B) and ALK7; 2) ALK3 (also known as BMPR1A) and ALK6 (also known as BMPR1B) and: 3) ALK1 and ALK2.

Cloning of the TGF $\beta$ type I receptor revealed an open reading frame of 509 amino acids, divided into a 363-and 123-amino acid cytoplasmic and extracellular domain, respectively. The core protein of this receptor is around $55 \mathrm{kDa}$ (Ebner et al, 1993). The TGF $\beta$ type II receptor has also been isolated and cloned, illustrating that it is a $\sim 80 \mathrm{kDa}$ protein (Lin et al, 1992). The type I and II receptors share sequence similarity in their extracellular domains, both having three cysteines upstream of their transmembrane domain (Ebner et al, 1993). TGF $\beta$ receptor I has a unique glycine/serine-rich sequence known as the GS-domain. Mutational analysis has demonstrated that the presence of the amino acids serine and threonine in the GS-domain of TGF $\beta$ receptor I functions in phosphorylation and signaling (Wrana et al, 1994, Wieser et al, 1995). For example, 
TGF $\beta 1$ is able to elicit phosphorylation of Ser165 of TGF $\beta$ receptor I, and the GS domain of this receptor, which is required for signaling (Souchelnytskyi et al, 1996).

The TGF $\beta$ type II receptor contains functional kinase domains, and is constitutively active, evidenced by high phosphorylation without the addition of TGF $\beta$ (Lin et al, 1992, Wrana et al, 1994, Souchelnytskyi et al, 1996). Thus, its autophosphorylating activity is not activated through ligand binding (Wrana et al, 1994). TGF $\beta$ binds to receptor II; it is recognised by receptor I, which in turn is phosphorylated by receptor II. A signaling cascade then begins after receptor I propagates the signal to the following substrates (Wrana et al, 1994). Furthermore, the binding of TGF $\beta$ to the type II receptors may require the type I receptor, which could also be important for transport of the type II receptor to the cell surface. Stoichiometric ratios between the type I and II TGF $\beta$ receptors may further mediate TGF $\beta$ binding (Ebner et al, 1993).

TGFßIII (betaglycan) has membrane proteoglycan properties and its binding site resides in the 100-120 kDa core polypeptide (Cheifetz et al, 1988). The TGF $\beta$ receptor type III does not have a recognisable kinase domain, however, it does mediate TGF $\beta$ binding to the type II receptor, which is especially important for TGF 32 (Lin et al, 1992, Brown et al, 1999, Shi and Massague, 2003). Betaglycan also acts as a co-receptor with ActRII for inhibin. It is able to bind inhibin with high affinity, as well as forming crosslinked complexes, mediating the functional antagonism of activin signaling (Lewis et al, 2000).

\subsection{Growth Differentiation Factor 9 \& Bone Morphogenetic Protein 15}

\subsubsection{Protein Structures of GDF9 \& BMP15}

Human, murine and ovine GDF9 spans approximately $2.5 \mathrm{~kb}$, containing 1 intron and 2 exons (Incerti et al, 1996; Bodensteiner et al, 1999). Overall, the structure of BMP15 is similar to that of other TGF $\beta$ superfamily members, and is most closely related to GDF9, with the two sharing high sequence homology (Dube et al, 1998). BMP15 also has two exons, separated by one intron, encoding a pre-propeptide of 393 amino acids. Its secondary structure is comprised of one $\alpha$-helix and two fingers, with two anti-parallel $\beta$-strand segments (Liao et al, 2003, Galloway et al, 2000). 
GDF9 shows close homology to other known members of the TGF $\beta$ superfamily, with the presence of a $\mathrm{COOH}$-terminal region. The $\mathrm{COOH}$-terminal region of BMP15 shares 53\% homology with that of GDF9. GDF9 however lacks the conserved cysteine residue common between other TGF $\beta$ family members, instead having six cysteine residues and four potential N-glycosylation sites (McPheron and Lee, 1993, Bodensteiner et al, 1999). Similarly to GDF9, BMP15 also lacks this cysteine, with a serine residue being present instead of the fourth conserved cysteine (Laitinen et al, 1998). The fourth cysteine residue in most TGF $\beta$ superfamily members forms a disulfide bond, covalently linking the two subunits (Vitt et al, 2001).

The post-translational processing of GDF9 and BMP15 affect the biological activity of these proteins. BMP signaling is likely regulated through the activity of proprotein convertase activity (Constam and Robertson, 1999). For example, GDF9 and BMP15 are more susceptible to proteolytic cleavage as individual homodimers compared to proprotein heterodimers. This is illustrated as the co-expression of these two proteins significantly impaired the processing of these proproteins. This may be due to endopeptidases having a decreased ability to cleave the proproteins (Liao et al, 2003).

In the mouse and human, a possible five $\mathrm{N}$-linked glycosylation sites have been observed for BMP15. Between the two species, three of these glycosylation sites are conserved. However, BMP15 differs between the two species in that upstream of the first conserved cysteine, mouse BMP15 has two additional cysteines (Dube et al, 1998). Discrepancies in BMP15 glycosylation occur between species, which may also affect their biological activity. For example, the treatment of the mature proteins with the endoglycosidase PNGase F, which releases N-linked oligosaccharides, has revealed that whilst mouse BMP15 contains N-glycosylation sites, the mature protein of human BMP15 does not (Hashimoto et al, 2005). The biological activity of GDF9 and BMP15 is also affected by protein phosphorylation, with GDF9 and BMP15 being the first phosphoproteins to be observed in the TGF $\beta$ superfamily, as phosphorylation is needed for their bioactivity (McMahon et al, 2008b). 
Interactions between the pro and mature regions of TGF $\beta$ superfamily proteins are crucial in the assembly of homodimers and protein secretion (Gray and Mason, 1990, Walton et al, 2009). When transfected 293H cells secreted BMP15 and GDF9, GDF9 homodimers were observed, however BMP15 homodimers were absent, with BMP15 being observed as monomeric proregion, mature, and multimeric protein forms (McIntosh et al, 2008). Previous studies demonstrated that when expressed individually, BMP15 and GDF9 were able to form non-covalent homodimers, however when coexpressed, GDF9: BMP15 heterodimers were observed (Liao et al, 2003). Utilising granulosa cell (GC) and cumulus cell expansion assays, Peng et al (2013) showed that GDF9: BMP15 heterodimers were the most bioactive ligands in humans and mice, compared with mouse GDF9 homodimers, or human BMP15 homodimers. These heterodimers are thought to act through ALK 4/5/7 and bone morphogenetic receptor type 2 (BMPR2), activating the Smad2/3 pathway. However, due to BMP15 and GDF9 mature regions not forming covalent dimers, equilibrium between monomers, heterodimers and homodimers may occur, influencing results. Thus it can also not be assumed that cooperative effects of GDF9 and BMP15 in studies monitor the actions of two homodimers (Mottershead et al, 2013).

\subsubsection{Localisation of GDF9 \& BMP15}

Expression of GDF9 and BMP15 mRNA is present exclusively in oocytes in sheep and murine species (Bodensteiner et al, 1999, Galloway et al, 2000, Crawford et al, 2012, Laitinen et al, 1998, Mester et al, 2014). Conversely, studies indicate the expression of GDF9 and BMP15 in the GC of several other species such as the pig, goat and primates (Duffy, 2003, Silva et al, 2005, Prochazka et al, 2004, Paradis et al, 2009). In rat oocytes, Gdf9 is expressed from the one-layer primary follicle stage, however the most intensive immunostaining was observed in primary and preantral follicles, compared to antral follicles (Jaatinen et al, 1999). In sheep however, GDF9 is first expressed in primordial (type 1) follicles (Bodensteiner et al, 1999). Immunohistochemistry studies indicate the presence of porcine GDF9 in follicles at all developmental stages of folliculogenesis (Sun et al, 2010). 
It is demonstrated through the use of Northern blot and in situ hybridisation that the mRNA expression pattern for Bmp15 is similar to that of Gdf9 in mice, whereby Bmp15 expression also begins at the one layer primary follicle stage, and is expressed throughout follicular development to ovulation (Dube et al, 1998, Jaatinen et al, 1999). In sheep, BMP15 mRNA is expressed exclusively in the oocyte from the type II, or primary stage of folliculogenesis (Galloway et al, 2000). Furthermore in the porcine follicle, BMP15 mRNA expression is present in primordial follicles onward (Sun et al, 2010), with the abundance of BMP15 mRNA decreasing from the recruitment phase of folliculogenesis to the post-LH surge (Paradis et al, 2009). Thus in summary, these studies together demonstrate that the timing of expression of GDF9 and BMP15 during folliculogenesis is species-specific.

GDF9 and BMP15 both bind BMPR2 (Vitt et al, 2002), with oocytes and GC from all mammalian species studied expressing BMPR2 mRNA, indicating the presence of an autocrine/paracrine system in the ovary (Shimasaki et al, 1999, Wilson et al, 2001, Glister et al, 2004, Paradis et al, 2009). Through in situ hybridisation, it was observed that BMPR1B (ALK6) is expressed in the oocyte and granulosa cells in sheep (Wilson et al, 2001). This localisation pattern of receptor gene expression is similar in the rat; with in situ hybridisation experiments illustrating the localisation of BMPR1B mRNA to both oocytes and granulosa cells in the rat follicle (Shimasaki et al, 1999). The TGFBR1 (ALK5) gene is expressed in the oocyte, granulosa cells and theca interna of sheep (Feary et al, 2007). Rat GC express $\operatorname{Tg} f \beta r 1$, which is required for GDF9 signaling. This is demonstrated through $\mathrm{Tg} f \beta r 1$, siRNA transfection into GCs decreasing GDF9 signaling (Mazerbourg et al, 2004). Both TGF $\beta R 1$, and BMPR1B have been found in porcine oocytes and GC (Paradis et al, 2009, Sun et al, 2010). Thus, as seen through localisation patterns in the follicle, BMP15 and GDF9 and their receptors are crucial for ovarian function. 


\subsection{Function of GDF9 \& BMP15}

\subsubsection{Information from Sheep Mutants and Mouse Knockouts}

There are species differences in the required dose of BMP15 and GDF9 for folliculogenesis. The importance of BMP15 on GC function differs between high and low ovulation rate species. For example, ovine GC require ovine GDF9 and ovine BMP15 to stimulate GC proliferation. In comparison, rat GC require only rat GDF9 and not BMP15 to proliferate (Lin et al, 2012). This illustrates how low ovulation rate species such as sheep require both GDF9 and BMP15 for folliculogenesis, however BMP15 is not as crucial for rodents. The species differences in the required dose of BMP15 and GDF9 have been demonstrated in a variety of experiments using animals with natural mutations, knockout models and immunisation.

The importance of GDF9 in high ovulation rate species, and in female fertility, has been demonstrated in knockout mice models. Homozygous GDF9-knockout (GDF9-/) mice, with a targeted deletion of exon 2 encoding the mature region of GDF9, are infertile, with hypoplastic ovaries. Infertility is due to an arrest in folliculogenesis; however mice are hypergonadotrophic. Due to altered negative feedback of gonadal hormones, a three-fold elevation in FSH serum levels and a two-fold elevatation in luteinising hormone (LH) serum levels were measured in these mice compared to the wild type (Dong et al, 1996). GDF9 is required for the formation of corpora lutea and the formation of normal follicles past the primary one layer follicle stage (Dong et al, 1996). However, despite follicle growth arresting at the type $3 \mathrm{~b}$ stage, mouse oocytes deficient in GDF9 grow at a faster rate compared to control oocytes. The oocytes from these GDF9 homozygous mutant mice also acquired meiotic competence in a manner similar to heterozygous control mice. Many of these GDF9 deficient oocytes were unable to complete maturation in vitro, whilst spontaneously activating, suggesting their inability to maintain meiotic arrest (Carabatsos et al, 1998). In summary, these results illustrate that in the mouse, which is a poly-ovulatory species, GDF9 is a requirement for early folliculogenesis (Dong et al, 1996). 
Whilst GDF9 is a requirement for fertility in females, demonstrated in homozygous mutant mice, homozygous BMP15-knockout (BMP15\%/-) mice were subfertile, showing a reduced ovulation rate. Whilst ovaries from GDF9-/- mice were small due to early perturbation in folliculogenesis, in comparison, the ovarian histology of BMP15\% mice is normal. Thus, while BMP15 is important in mice fertility, it is not as crucial as GDF9 (Yan et al, 2001). In contrast to this, oocyte-specific overexpression of BMP15 in mice led to accelerated follicle development, with GCs displaying a higher mitotic index compared to wild type mice. Interestingly, these transgenic mice had a normal litter size (McMahon et al, 2008a). To determine the importance of BMP15 on ovulation quota, the molecular characteristics of BMP15 have been compared in high and low ovulating species. Mouse BMP15 was not detected in conditioned media when cells were transfected with a BMP15 expression vector. However, this absence may be due to the post-translational processing of mouse BMP15, as mouse BMP15 proprotein was present in transfected cells similarly to the expression of human BMP15 proprotein. This lack of secreted mouse BMP15 is likely due to the pro-region impairing secretion through defective post-translational processing (Hashimoto et al, 2005). However, the secretion of mouse BMP15 from transfected 293H cells has been observed in another study (McIntosh et al, 2008), which may be due to differences in experimental protocol. Therefore mouse knockout models illustrating the lesser importance of BMP15 compared to GDF9 in mouse folliculogenesis are supported by a lack of secreted mouse BMP15 mature protein being observed.

Similarly to mice, GDF9 is also required for folliculogenesis in low ovulation rate species, such as the sheep. This has been concluded through the discovery of several genetic lines of sheep that exhibit natural mutations in GDF9. In both Cambridge and Belclare breeds, the mutation of GDF9 in these ewes is associated with sterility. The sterility phenotype is observed in sheep homozygous for a variant in GDF9 $\left(\mathrm{Fec}^{H}\right)$, illustrating the importance of GDF9 in sheep fertility (Hanrahan et al, 2004). Natural mutations in BMP15 have been discovered in sheep also, including the Hanna, Inverdale, Belclare and Cambridge sheep (Davis et al, 1991, Galloway et al, 2000, Hanrahan et al, 2004). Similarly to natural mutations in GDF9, homozygous mutations in BMP15 in Belclare and Cambridge sheep also cause sterility (Hanrahan et al, 2004). The Inverdale gene in 
sheep, with the locus named "FecX", is an X-linked prolifacy gene. As the Fec $X^{I}$ locus is orthologous to human BMP15 and that such mutations are reported to lead to a loss of BMP15 function, BMP15 was concluded to be essential in sheep fertility (Galloway et al, 2000). Indeed, homozygous carriers of the Inverdale gene have nonfunctional ovaries, with no follicular activity observed (Davis et al, 1991). Some ewes may also develop abnormal nodular structures, which contain granulosa-like cells due to BMP15 deficiencies (Braw-Tal et al, 1993). Moreover, this was also observed in Hanna sheep, which are unrelated but also exhibit a BMP15 mutation resulting in the same phenotype (Galloway et al, 2000). Moreover, the immunisation of ewes against either GDF9 or BMP15 peptide both cause an arrest in folliculogenesis and induced anovulation (Juengel et al, 2002), suggesting that this immunisation induces a similar phenotype to ewes with natural homozygous mutations in GDF9 and BMP15, as described previously. Thus, in mammalian species such as the sheep, which display a low ovulation rate phenotype, both GDF9 and BMP15 are required for normal follicular development.

Sheep with heterozygous mutations in GDF9 and BMP15 however display a contrasting phenotype to their homozygous counterparts. Heterozygous mutations in GDF9 and BMP15 increasing ovulation rate in Cambridge and Belclare sheep (Hanrahan et al, 2004). Furthermore, sheep heterozygous for both BMP15 and GDF9 mutations have an increased ovulation rate, suggesting the additive effects of BMP15 and GDF9 (Hanrahan et al, 2004). An increased ovulation rate is also observed in Inverdale sheep that are heterozygous for $\mathrm{FecX}^{I}$ (Galloway et al, 2000). Heterozygous Inverdale ewes have a significantly larger proportion of nonatretic follicles with granulosa cells responsive to LH/human chorionic gonadotropin (hCG) compared to wild type ewes. In contrast, the follicular sensitivity to FSH does not differ between the heterozygous and wild type genotypes (McNatty et al, 2009). Thus, the BMP15 mutation in heterozygous Inverdale ewes leads to a higher ovulation rate due to earlier acquisition of LH responsiveness by GC (McNatty et al, 2009). In a similar manner to natural heterozygous mutations in sheep, ovulation rate can be increased in ewes through immunisation also. Antibodies blocking the $\mathrm{N}$ terminal region of both BMP15 and GDF9 can inhibit the paracrine actions of these proteins. In this manner, decreasing the amount of BMP15 or GDF9 increases ovulation rate up to a minimum threshold (McNatty et al, 2007). An increased 
ovulation rate is also observed using short-term (partial) immunisation against BMP15 and GDF9, without effecting fertilisation or embryo survival (Juengel et al, 2004b).

In addition to the natural mutations in GDF9 and BMP15 observed in sheep, the mutation of these proteins' receptors also impact fertility in ewes. Booroola ewes have a segregating autosomal gene $(F e c B)$, which is present on sheep chromosome 6 (Montgomery et al, 1993, Wilson et al, 2001). In humans this corresponds to chromosome 4q22-23, which contains the BMPR1B gene. Thus BMPR1B, which is the type I receptor for BMP15, is a candidate gene for FecB in sheep (Montgomery et al, 1993, Mulsant et al, 2001, Wilson et al, 2001). The presence of this mutation in sheep increases ovulation and has an additive effect, whereby ovulation rate increases by approximately 1.6 corpora lutea per cycle with each copy an ewe has (Wilson et al, 2001).

\subsubsection{Roles of GDF9 and BMP15 in Folliculogenesis}

Several studies illustrate the importance of GDF9 in early follicle growth and differentiation. Treatment with GDF9 increases follicular diameter of preantral follicles from rats. Conversely, this was not observed when non-bioactive amino-terminal tagged GDF9 was used (Hayashi et al, 1999). Furthermore in mice, the deletion of an oocytespecific homeobox gene, Nobox, caused a down-regulation of Gdf9 mRNA expression, and an inability of follicles to transition from the primordial stage, in addition to accelerated oocyte loss (Rajkovic et al, 2004). Studies in Bmp15\% and $\mathrm{Gdf9} \mathrm{9}^{+/-}$mice demonstrate that BMP15 and GDF9 also play important roles in both cumulus expansion and maintaining cohesive interaction between cumulus cells and oocytes (Yan et al, 2001). During folliculogenesis, GDF9 and BMP15 are both potent mitogenic stimulators of GC proliferation. This has been demonstrated through mitogenic bioassays, where GDF9 promoted a dose-dependent increase in DNA synthesis in GC (Gilchrist et al, 2006). BMP15 is reported to stimulate cumulus cell expansion, as well as being a potent stimulator of DNA synthesis and kit ligand (KL) expression in GC (Otsuka and Shimasaki, 2002). 
In addition to their proliferative effects during follicular development, GDF9 and BMP15 also impact steroidogenesis in the follicle. Whilst GDF9 stimulates the proliferation of GC, it simultaneously inhibits GC differentiation induced by FSH and suppresses FSHstimulated oestradiol and progesterone production (Vitt et al, 2000). In human GC cell lines, BMP15, but not GDF9, treatment suppressed progesterone production through the suppression of steroidogenic acute regulatory protein (StAR) and Smad 1/5/8 signaling pathways. Thus, the oocyte prevents premature luteinisation through its regulation of progesterone production (Chang et al, 2013). Other studies support the role of BMP15 in reducing both basal progesterone secretion and basal oestradiol levels in human GC (Prapa et al, 2015). In comparison, GDF9 does not affect basal progesterone production, but does inhibit 8-Br-cAMP-stimulated StAR protein expression and progesterone synthesis (Yamamoto et al, 2002). Therefore, GDF9 and BMP15 stimulate follicular proliferation whilst simultaneously preventing premature differentiation of the follicle, as implicated through their actions on steroidogenesis.

Whilst stimulating follicular development, oocyte-secreted factors also display antiapoptotic actions in the ovarian follicle, thus promoting follicular survival. In GCs at an early stage of follicular development, GDF9 is able to attenuate apoptosis induced by ceramide (Orisaka et al, 2006). A similar effect is observed with BMP15, which is able to decrease apoptosis in porcine cumulus cells in a dose-dependent manner (Zhai et al, 2013). The secretion of BMPs from the oocyte itself also decreased cumulus cell apoptosis, illustrated through an increased cumulus cell apoptosis following oocyte removal. Thus the oocyte creates an anti-apoptotic gradient, with apoptosis within the cumulus cells of a cumulus cell-oocyte complex (COC) being greater in the outer layers, farthest from the oocyte (Hussein et al, 2005). Oocyte-secreted factors decreased the expression of the proapoptotic BCL-2-interacting mediator of cell death-extra long (BIMEL) protein, in the cumulus cells of pigs. In particular, treatment of oocytectomisedcumulus cell complexes (OOX) with GDF9 produced similar BIMEL protein levels (Wang et al, 2013a). These anti-apoptotic capabilities displayed by TGF $\beta$ superfamily members have also been studied through their signaling proteins, the Smads. In this manner, the targeting of the inhibitory Smad, Smad7, through siRNA increases Bcl-2 and decreases 
Bax RNA levels, which is indicative of the inhibition of apoptosis in porcine GCs (Liu et al, 2014).

As discussed in an earlier section, the importance of BMP15 to folliculogenesis and fertility differs in high or low ovulation species. Similarly, the expression levels of GDF9 mRNA also differ in low and high ovulating species, with ratios of GDF9: BMP15 being the same within species, but different between species. For example, GDF9 mRNA expression levels were found to be higher in high ovulation rate species such as the mouse and rat, compared to low ovulation rate species, such as cows and deer. Conversely, the pig, which is a high ovulation rate species, had a low ratio of GDF9: BMP15 mRNA in oocytes (Crawford and McNatty, 2012). Other studies also indicate that the oocyte itself is of importance in the determination of ovulation rate in mammalian species. For example, high ovulation rate mutant female mice were generated through an oocyte-specific deletion of T synthase, an enzyme that generates core 1-derived 0glycans (Williams and Stanley, 2008). Furthermore, the high ovulation rate phenotype of mutant mice deficient in core 1 -derived $O$-glycans was associated with an increase in the GDF9:BMP15 expression ratio at diestrus (Grasa et al, 2015).

TGF $\beta$ superfamily member expression, as well as expression of their receptors and signaling molecules have also been evaluated in human follicles. Expression levels of GDF9, BMP15, BMPR2, and Smad4 mRNA have differed in primordial to late secondary stage follicles, illustrating their importance in early human folliculogenesis (Kristensen et al, 2014). The importance of these oocyte-secreted factors in follicular development is further validated through the study of humans displaying natural mutations in these TGF $\beta$ superfamily members. It has been hypothesised that similarly to mutations of BMP15 in sheep causing hyperproliferacy phenotypes (Galloway et al, 2000, Hanrahan et al, 2004), mutations in BMP15 may cause dizygotic twinning. However, although there was evidence between a BMP15 variant and dizygotic twinning, after correction for multiple testing, there was no significant association (Zhao et al, 2008). Mutations in GDF9 have been identified in humans also, such as insertion/deletions and missense alterations, which are related to a higher incidence of dizygotic twinning compared to controls (Montgomery et al, 2004, Palmer et al, 2006). Taken together, these studies 
demonstrate the likely importance of GDF9, compared to BMP15, in regulating twinning in humans. As well as increasing ovulation rate in humans, GDF9 and BMP15 mutations can also negatively impact fertility. Heterozygous non-conservative substitutions in the pro-region of BMP15 have been identified to cause a reduction in GC growth, and be associated with familial ovarian dysgenesis (Pasquale et al, 2004). Alterations in GDF9 and BMP15 have also been associated with premature ovarian failure in women (Laissue et al, 2006).

In human GC, BMP15 also preferentially binds the BMPR1B and BMPR2 receptors, illustrated through the use of affinity-labeling with [125I]-BMP15 (Pulkki et al, 2012). A homozygous mutation that causes loss of function of BMPR1B has been attributed to causing ovarian dysfunction in a human patient (Demirhan et al, 2005). Furthermore, recently it has been shown that a decrease in BMPR1B receptor density is correlated with an age-induced decrease of the ovarian reserve in IVF patients during preovulatory follicle maturation and dominant follicle selection (Regan et al, 2016). Thus BMPR1B, being the receptor for BMP15 signaling, also plays a concomitant role in human fertility.

\subsection{Receptors of GDF9 \& BMP15}

Crystallographic structural analysis predicts that TGF $\beta$ superfamily ligand dimers bind two type I and two type II receptors forming a complex (Nickel et al, 2001, Hart et al, 2002, Allendorph et al, 2006). To aid in the understanding of ligand: receptor interactions, the structures of the type I and type II receptors have been assessed through protein crystallography. The BMPR2 core structure is comprised of a threefinger toxin fold, similar to other TGF $\beta$ family receptor ectodomains (Mace et al, 2006). The N-glycosylation pattern of BMPRII has also been studied, showing that asparagines in the ligand-binding domain of BMPRII are glycosylated, aiding in the ability of this receptor to bind BMP2 (Lowery et al, 2014). The TGFßR1 core region of the catalytic domain is comprised of a canonical protein kinase fold, a C lobe involved in substrate recognition and an N lobe, which is required for ATP binding. Structural analysis of TGF $\beta$ R1's unphosphorylated cytoplasmic domain in complex with the immunophilin 
FKBP12 illustrates that FKBP12, an inhibitor of TGF $\beta$ signaling, is able to bind to two highly conserved residues, Leu-195 and Leu-196, located at the N-terminal of the GS2 helix (Huse et al, 1999). The specificity of the TGF $\beta$ superfamily ligands to their type I receptors is dependent upon ligand and receptor structure, as illustrated with a single residue in the pre-helix loop of GDF5 being responsible for this ligand's specificity to its receptor, BMPRIB (Nickel et al, 2005).

Both GDF9 and BMP15 require BMPR2 for their downstream signaling (Moore et al, 2003, Vitt et al, 2002). This has been validated through a co-precipitation study, as the BMPR2 ectodomain directly interacts with GDF9 (Vitt et al, 2002). Furthermore, the BMPR2 extracellular domain is the most effective in the inhibition of BMP15 bioactivity (Soyun et al, 2001). In addition to GDF9 and BMP15 several other TGF $\beta$ superfamily members such as inhibins, BMP2, BMP6, BMP10, GDF2, GDF5, GDF6 and GDF7 also display an affinity for BMPR2 (Ebisawa et al, 1999, Wiater et al, 2003, Mazerbourg et al, 2005, Scharpfenecker et al, 2007, Kirkbride et al, 2008), illustrating the promiscuity of this receptor. 


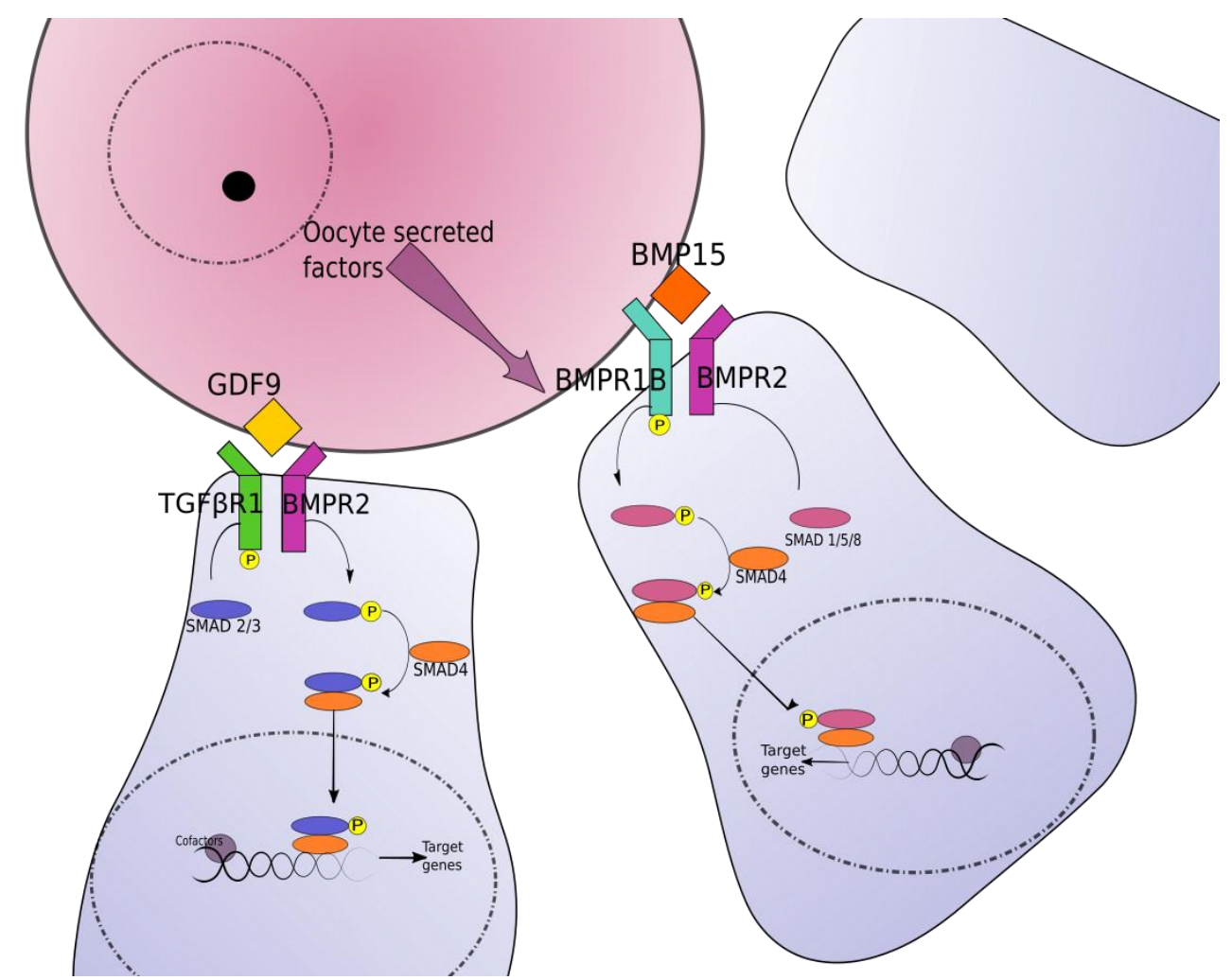

Figure 1.1: Paracrine signaling between oocyte secreted factors and follicular somatic cells.

Paracrine signaling between oocytes and GCs involves interactions between oocyte secreted factors, their receptors, and downstream signaling molecules. Oocytes secrete a range of oocyte secreted factors, two of which are the TGF $\beta$ superfamily members GDF9 and BMP15. Follicular somatic cells such as cumulus cells and GCs express several type I (including TGF $\beta R 1$ and BMPR1B) and type II (including BMPR2) receptors. Smads are intracellular signaling proteins, involved in the signal transduction of oocyte secreted factors. Ligands bind receptor serine/threonine kinases, forming a hetero-tetrameric receptor complex. GDF9 binds BMPR2/TGFßR1, whilst BMP15 binds BMPR2/BMR1B. The GS-domain of the type I receptors is phosphorylated by the type II receptor, creating a pS-x-pS motif which acts as a docking site for receptor-regulated Smads (Smads 2/3 and Smads 1/5/8). In the basal state, Smads are constantly being shuttled in and out of the nucleus. The activation of TGF $\beta R 1$ and BMPR1B leads to phosphorylation at the $C$ terminus of Smad 2/3 and Smad 1/5/8 respectively. Both Smad 2/3 and Smad $1 / 5 / 8$ associate with the common Smad4. This complex moves into the nucleus, whereby they interact with specific DNA motifs and encode transcriptional activators. Figure modified from Gilchrist et al (2008) and descriptions from Massague et al (2005) and Gilchrist et al (2008). 
Using a CAGA-luciferase reporter, it has been illustrated that the action of GDF9 is mediated by the type I receptor, TGFßR1 (Mazerbourg et al, 2004, Kaivo-Oja et al, 2005). Conversely, the type I receptor for BMP15 has been demonstrated to be BMPR1B, as it's extracellular domain co-immunoprecipitates with BMP15 (Moore et al, 2003). However much cross-reactivity is observed among various BMP ligands and their type-I receptors, as reviewed in Shimasaki et al (2004). For example, whilst TGF $\beta R 1$ binds GDF9, this receptor also interacts with several other ligands including GDF8, GDF11, TGF $\beta 1$ and TGF $\beta 2$ (Goumans et al, 2003, Rebbapragada et al, 2003, Andersson et al, 2006, Townsend et al, 2011). Similarly, BMPR1B also binds GDF5, GDF6, GDF7, BMP4, BMP10 and AMH in addition to BMP15 (ten Dijke et al, 1994, Nishitoh et al, 1996, Gouedard et al, 2000, Mazerbourg et al, 2005), illustrating the overall promiscuity of these type I and type II receptors.

\subsection{Cellular Signaling Pathways of GDF9 \& BMP15}

\subsubsection{Smad Signaling Pathways}

In 1995, the gene Mothers against decapentaplegic (Mad) was identified in Drosophila melanogaster (Sekelsky et al, 1995). Similarly in Caenorhabditis elegans, sma-2, sma-3 and sma-4 genes are homologous to the Mad gene product in Drosophila (Savage et al, 1996). These molecules were described as having a relative molecular mass of 42-62 kDa (Chen et al, 1997, Wu et al, 2001b, Hu et al, 2003, Nahar-Gohad et al, 2015). Subsequently, related genes were identified in invertebrates also, and through merging the terms Sma and Mad, were given the nomenclature of Smad (Derynck et al, 1996). Smad proteins are crucial constituents of the signaling cascade, which are activated by members of the TGF $\beta$ family. They are recruited to the TGF $\beta$ receptor complex as the first step in the TGF $\beta /$ Smad signalling pathway, and accumulate in the nucleus, where they are able to regulate the expression of genes (Dennler et al, 1999, ten Dijke et al, 2002, Schmierer and Hill, 2005). Thus, Smads are responsible for signal transmission from transmembrane serine/threonine kinase receptors to the nucleus (Tsukazaki et al, 1998). The nucleocytoplasmic shuttling of Smads is dynamic, with the shuttling of Smads to the nucleus quantitatively reflecting the strength of the extracellular TGF $\beta$ signal (Schmierer et al, 2008). 


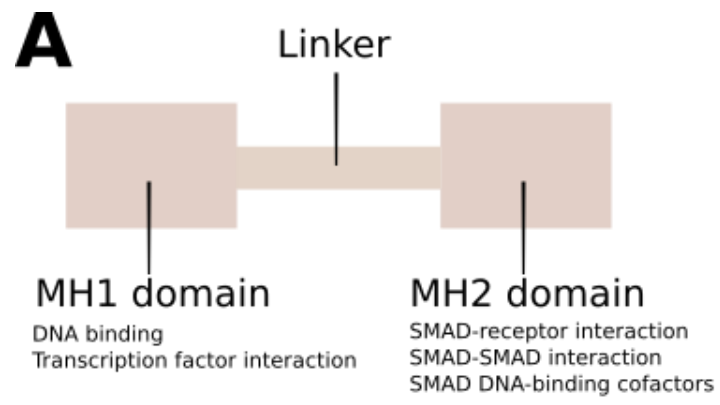

B

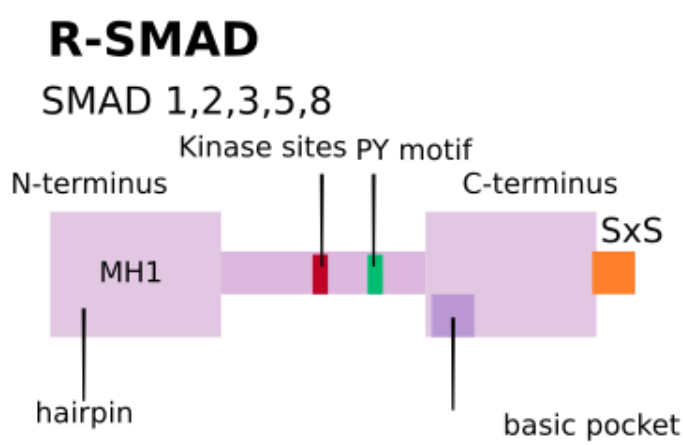

\section{Co-SMAD \\ SMAD 4}
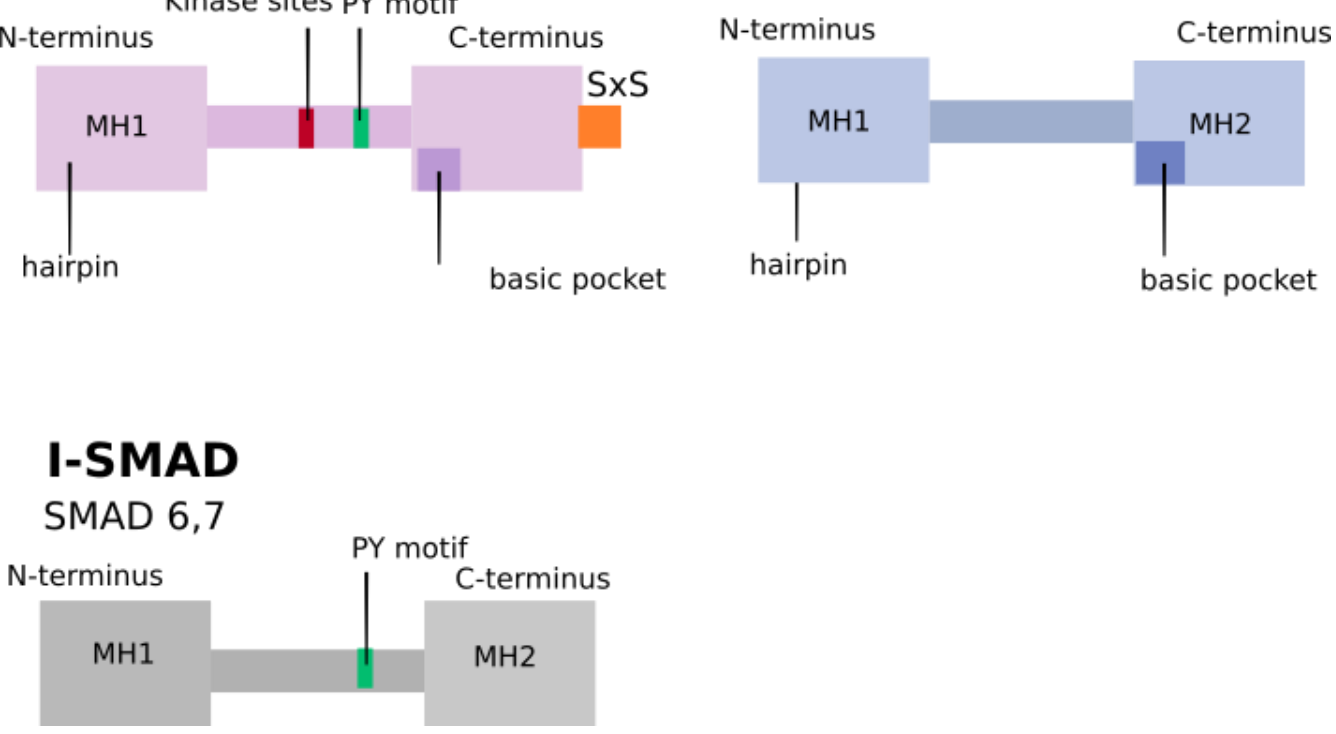

Figure 1.2: Smad structure and function.

(A) The basic structure of Smad proteins consists of an $\mathrm{N}$-terminal and $\mathrm{C}$-terminal, known as Mad-homology domains, $\mathrm{MH} 1$ and $\mathrm{MH} 2$ domains respectively. A prolinerich linker region, which is variable in sequence and size, links the MH1 and MH2 domains together. Whilst the MH1 domain is involved in DNA binding, the MH2 domain is involved in protein-protein interactions. (B) R-Smad, Co-Smad and ISmad structure: There are three categories of SMADs including inhibitory, common-mediator and receptor-activaed SMADs, with seven mammalian Smad proteins falling under these categories. The $\beta$-hairpin present on the MH1 domain of R-Smads and Co-Smads is involved in DNA binding. The linker region of $R$ Smads contains kinase sites allowing phosphorylation by CDKs, MAPKs and various other kinases. The PY motif (PPXY) on R and I-Smads is involved in interactions with Smurf ubiquitin ligases. On the MH2 domain in R-Smads a basic pocket interacts with type I receptors and the SxS motif (orange square), whilst the basic pocket in Co-Smads interacts with the SxS motif only. Modified from Massague and Wotton (2000) and Massague et al, (2005). 
Three classes of Smad proteins have been identified: the inhibitory Smads (I-Smads), the common-mediator Smads (Co-Smads), and the receptor-activated Smads (R-Smads, including Smad1, 2, 3, 5, and 8) (Shia and Massague, 2003). Apart from the I-Smads (Smad6 and Smad7), two regions of homology exists at the amino terminals, known as the Mad-homology domain (MH1), and carboxy terminals (MH2) (Heldin et al, 1997, Massague, 1998). Co-Smads and R-Smads (except Smad2) recognise Smad binding elements via MH1 domains (ten Dijke et al, 2002).

Once TGF $\beta$ superfamily members, such as TGF $\beta$ bind to heteromeric complexes of transmembrane Ser/Thr kinases, Smad2 and Smad3 are phosphorylated on their C terminus residues (Dennler et al, 1999). SARA (Smad anchor for receptor activation) is a protein that recruits Smad2 to the TGF $\beta$ receptor, directly interacting with the MH2 domain of Smad 2 and 3 (Tsukazaki et al, 1998). A cytoplasmic protein, promyelocytic leukaemia tumour suppressor, is essential in modulating TGF $\beta$ signaling, as it is required for the association of Smad2/3 with SARA (Lin et al, 2004). Once phosphorylated, receptor regulated Smads form heterocomplexes with the co-mediator Smad; For example Smad2 forms a heterodimer with Smad4 (Wu et al, 2001a). When Smad3 is phosphorylated, it has a greater propensity for the formation of a heterotrimer with Smad4 (Chacko et al, 2001).

The MH1 domain of Smad3 and Smad4 is able to specifically bind DNA. Smad2 and Smad 4 are able to recognise an 8 bp palindromic sequence termed the Smad binding element (SBE). Tandem repeats of SBE allow for transcriptional activation (Zawel et al, 1998). Whilst Smad3 acts as a transcription factor, binding to the CAGA box, Smad2 does not bind (Dennler et al, 1998). This difference may be due to differences in the Nterminal MH1 domain, where Smad2 contains two more stretches of amino acids (Dennler et al, 1999). Smads also bind GC-rich sequences, which confer BMP responsiveness. Multimerisation of GGCGCC palindromic sequence as well as the CAGC and CGCC motifs is required to generate a BMP/Smad-dependent specific enhancer (Korchynskyi and ten Dijke, 2002). 
As reviewed in Massagué and Wotton (2000), Smads interact with DNA-binding Smad cofactors, allowing high-affinity binding to DNA. There are a multitude of Smad cofactors; some of which are specific for TGF- $\beta$ superfamily member signaling. A 30zinc finger protein (OAZ) exclusively cooperates with BMP-activated Smads, leading to the activation of the Xvent-2 promoter (Hata et al, 2000). Furthermore, Sox5 is also involved in the activation of BMP target genes, acting as a cofactor for R-Smads in embryos and explants (Nordin and LaBonne, 2014). In TGF- $\beta$ signaling, Olig1 is a helixloop-helix Smad cofactor, which interacts with Smad3 (Motizuk et al, 2013). Conversely, in Nodal signaling, E proteins act as signaling cofactors, associating with Smad 2 and 3 (Yoon et al, 2011). Not all Smad cofactors are likely to be involved in GC proliferation, as cofactor expression is often tissue-specific. For example, OAZ is not usually expressed in smooth muscle cells and myoblasts (Ku et al, 2005). Thus, the specificity of the Smadcofactor complex formation in various tissues acts as a determinant of TGF $\beta$ signaling specificity (Massagué and Wotton, 2000).

The signaling of the TGF $\beta$ superfamily can be modified at several levels. Extracellular antagonists can block ligand binding, and include noggin, gremlin and chordin (Kaivooja et al, 2006). BMP and activin membrane bound inhibitor (BAMBI) is an antagonist that associates with TGF $\beta$ family receptors, inhibiting BMP, activin and TGF $\beta$ signaling. Inhibition is mediated by its intracellular domain, which prevents the formation of receptor complexes (Onichtchouk et al, 1999).

Targeted ubiquitination of Smads acts as a control of cellular responses to TGF $\beta$ signals. Smurf1 is an E3 ubiquitin ligase, which interacts with Smads that are specific for the BMP pathway. It is able to trigger ubiquitination, inactivating Smads (Zhu et al, 1999). Furthermore, Smurf2 is involved in the ubiquitin-mediated degradation of Smad2, thereby also regulating TGF $\beta$ signaling (Lin et al, 2000). Epidermal growth factor and hepatocyte growth factor receptor protein tyrosine kinases (RTKs) cause Erk-mediated phosphorylation, which is inhibitory, preventing nuclear accumulation of Smad1 (Kretzschmar, 1997). Oncogenic Ras is able to inhibit TGF $\beta$ and Smad signaling through phosphorylation, inhibiting the nuclear accumulation of Smad2 and Smad3 (Kretzschmar et al, 1999). Lastly, Smad6 and Smad7 (I-Smads) are inhibitors of TGF $\beta$ 
signaling, interacting with the TGF $\beta$ receptor, and preventing the phosphorylation and activation of Smads (Hayashi et al, 1997, Imamura et al, 1997).

The Smad proteins are crucial in the cellular signaling pathways of both GDF9 and BMP15. GDF9 stimulates the phosphorylation of both Smad2 and Smad3 (Mazerbourg et al, 2004). Addition of BMP15 to rat and human GC causes transient phosphorylation and activation of the Smad1/5/8 pathway. In comparison, weak activation of Smad2 was observed with BMP15 stimulation (Moore et al, 2003). Smad5, 1 and 8 are the downstream signal mediators for several BMPs (Chang and Matzuk, 2001).

The importance of these cellular pathways in fertility and folliculogenesis is demonstrated experimentally through the use of knockout mice. A null mutation in the TGFß1 gene leads to almost complete infertility in mice, with disrupted ovulation, oocyte development, and corpus luteum function being observed. Furthermore, the proestrus surge in LH was not observed in these mice (Ingman et al, 2006). Using a Smad3-deficient mouse model, it was observed that these mice had decreased fertility in comparison to wild type mice. Thus, Smad3 may regulate the growth of primordial follicles to the antral stage, as fewer preantral follicles were present in the ovaries of Smad 3\%- mice. This reiterates the importance of Smad3 in the growth of ovarian follicles and in female fertility (Tomic et al, 2002). An ovarian conditional knockout of Smad4 shows subfertility in mice and disrupted steroidogenesis resulting in increased serum progesterone levels. Premature luteinisation of granulosa cells and cumulus cell defects were also observed (Pangas et al, 2006). Thus, these studies illustrate the essential role the Smad signaling pathway plays in transmitting the signal induced by oocyte secreted factors during folliculogenesis.

\subsubsection{Non-Smad signaling pathways}

In addition to the Smad signaling pathway, oocyte secreted factors also act through several non-Smad signaling pathways, described herein. Similarly to the Smad signaling pathway, these pathways are also involved in folliculogenesis and GC proliferation (Yang and Roy, 2006, Reader et al, 2008). The TGF $\beta$ /BMP signaling pathway is dependent 
upon the cross-communication with several signaling pathways (Engel et al, 1999, Reader et al, 2011 Sasseville et al, 2010), one of which is the mitogen-activated protein kinase (MAPK) pathway (Kretzschmar et al, 1997). MAPKs are evolutionary conserved signal transducing enzymes. Regulation of MAPK activity occurs through MAPK, MAPK kinase and MAPKK kinase, which form a cascade (Chang and Karin, 2001). Four signaling cascades share the MAPK signaling pathway; these include Jun amino-terminal kinases (JNK1/2/3), the extracellular signal-related kinases (ERK1/2), p38-MAPK and ERK5 (Sun et al, 2015).

Cross-communication between Smad and non-Smad signaling pathways principally occurs due to Smad proteins making several contacts with other proteins as well as the various targets the TGF $\beta$ superfamily members have (Guo and Wang, 2009). Smad1 is a mediator of BMP signaling, but is also targeted by mitogenic growth factor signaling. The ERK family of MAPKs phosphorylates Smad1, inhibiting its nuclear accumulation. ERK phosphorylation of Smad1 occurs at the linker region, in contrast to BMP stimulated phosphorylation at the C-terminal serines, which causes Smad1 nuclear accumulation (Kretzschmar et al, 1997). Smad2 activates gene transcription by cooperating with DNA binding proteins such as forkhead activin signaling transducer (FAST). Activation of the JNK cascade blocks the ability of Smad2 to activate FAST proteins (Pessah et al, 2001). However, the interconnection between the Smad and MAPK pathway is more complex than MAPK having an antagonistic effect. For example, phosphorylation of Smad3 mediated by JNK facilitates Smad3 nuclear accumulation as well as its phosphorylation by T $\beta$ RI (Engel et al, 1999). Furthermore, the transcriptional responses caused by TGF $\beta$ induced Smad3 phosphorylation is decreased by p38 inhibition, suggesting that the p38 cascade and Smad signaling pathway act in unison to activate gene expression in the nucleus (Abécassis et al, 2004).

Epidermal growth factor (EGF) is able to induce the activation of the MAPK signaling pathway (Wu et al, 1993). Oocyte secreted factors, such as GDF9 and BMP15, promote epidermal growth factor receptor (EGFR) expression in cumulus cells. This is illustrated as the removal of oocytes from COCs decreases Egfr expression in cumulus cells and reduces MAPK3/1 activation (Su et al, 2008). Conversely, TGF $\beta 1$ has a negative 
interaction with EGF, whereby alone, TGF $\beta 1$ and EGF stimulate GC DNA synthesis, however together an attenuation of DNA synthesis is observed. EGF with TGF $\beta 1$ causes an attenuation of TGF $\beta 1$-induced activation Smad3 phosphorylation. Conversely TGF $\beta 1$ or EGF1 stimulate MAPK1 activation, implicating both of these pathways in GC DNA synthesis (Yang and Roy, 2006). The MAPK pathway is also required for BMP15-induced mitosis of GC, as upon the addition of an ERK1/2 phosphorylation inhibitor GC proliferation was decreased (Moore et al, 2003). In a similar manner to BMP15, MAPK signaling has also been implicated in GDF9-induced GC proliferation. The action of GDF9, which induced GC proliferation and cumulus cell expansion, can be inhibited through the use of an MEK inhibitor (Su et al, 2002, Sasseville et al, 2010). The ERK1/2 pathway is important in maintaining the Ser208 phosphorylation of Smad3 at its linker region, illustrating an interaction between these two pathways (Sasseville et al, 2010). Thus the MAPK pathway is likely to interact with the Smad signaling pathway and is required for BMP15 and GDF9 induced folliculogenesis. However, a p38 MAPK inhibitor, although causing a partial inhibition of tritiated thymidine uptake by ovine GDF9 and BMP15, also suppressed thymidine uptake in control cultures, suggesting that this signaling pathway is non-specific (Reader et al, 2011).

As reviewed in Pahl (1999), the Rel/NF-kB family of transcription factors includes RelA (p54), RelB, c-Rel, p50/p105, and p52/p100. These dimers bind to $\kappa B$ sites and regulate gene expression. Members of the TGF $\beta$ superfamily directly can elicit NF- $\kappa B$ pathway activation in a variety of cells. For example, TGF $\beta$, Mullerian Inhibiting Substance (MIS), BMP2 and BMP4 are all capable of stimulating the activation of NF- $\mathrm{BB}$ in osteoclasts, cancer cells and the human cornea, respectively (Gingery et al, 2008, Hoshiya et al, 2003, Mohan et al, 1998). In several types of cells the activation of NF- $\kappa B$ blocks apoptosis. However, NF- $\kappa B$ may inhibit or promote apoptosis depending on the cell type and the inducer type (Barkett and Gilmore, 1999). In particular, the NF- $\kappa B$ pathway plays a critical role in the regulation of GC apoptosis. Early growth response (EGR1) modulates apoptosis, with its expression increasing in the aging mouse ovary and with follicular atresia. This overexpression of EGR1 elicits the promotion of apoptosis in GC, which occurs through the NF- $\kappa B$ pathway (Yuan et al, 2016). However, not all studies are in concordanance with the pro-apoptotic capabilities of NF- $\kappa$ B in GC. Activation of the NF- 
$\kappa B$ pathway is implicated in cadmium-induced apoptosis in GC. However, inhibition of

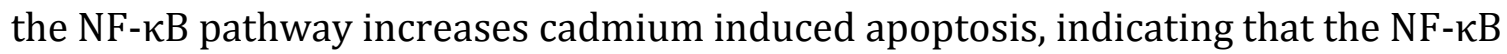
may prevent porcine GC apoptosis under these conditions (Wang et al, 2013b).

\subsubsection{Synergistic Effects of GDF9 \& BMP15}

BMP15 and GDF9 are known to have cooperative effects during folliculogenesis. A synergistic effect is observed when adding low doses of both GDF9 and BMP15, as observed by GC proliferation, compared to the addition of GDF9 and BMP15 separately. This synergistic effect was also demonstrated in cumulus cells, and in suppressing FSHstimulated progesterone production (McNatty, 2005bc, Mottershead et al, 2012). The cooperative effects of GDF9 and BMP15 in stimulating GC proliferation are inhibited by blocking the extracellular domain of BMPR2 by fusing to the IgG Fc region, seen as an inhibition in thymidine incorporation. This suggests that this receptor modulates these cooperative effects (Edwards et al, 2008, McIntosh et al, 2008). Furthermore, a BMP15 proregion antibody was able to immunoneutralise BMP15/GDF9 synergism, demonstrating that the cooperative actions of recombinant mouse GDF9 and BMP15 involve the proregion of BMP15 (McIntosh et al, 2008).

The synergistic effects of GDF9 and BMP15 have also been studied by observing which cellular signaling pathways these proteins activate. GDF9 and BMP15 alone showed minimal Smad3 activation. However, synergistically there was a substantial activation. In comparison, Smad1/5/8 showed high activation with BMP15 alone, but no synergistic effect was observed in activation. Therefore, GDF9 and BMP15 synergism is seen when observing Smad3 pathway activation, and this response was inhibited using the SB431542 inhibitor (Mottershead et al, 2012). This was also demonstrated by Reader et al (2011) through an inhibitor of the SMAD2/3 pathway, which prevented ${ }^{3} \mathrm{H}$ thymidine incorporation by granulosa cells by ovine and murine GDF9 and BMP15. This was not observed with the Smad 1/5/8 pathway inhibitor. Thus, ovine and murine GDF9 and BMP15 stimulated ${ }^{3} \mathrm{H}$-thymidine uptake in GC is dependent on the Smad 2/3 signalling pathway, rather than the Smad 1/5/8 pathway. The synergistic effects of GDF9 and BMP15 also activate a variety of non-Smad signaling pathways. Using recombinant mouse GDF9 and human BMP15 together with pathway inhibitors, 
Mottershead et al, (2012) observed that the synergistic actions of these proteins were dependent on ERK1/2 and SRC kinase signaling. In rat GC, recombinant ovine GDF9 and BMP15 act through the p38-MAPK and NF- $\mathrm{kB}$ pathways. In contrast, recombinant murine GDF9 and BMP15 cause rat GC proliferation through the ERK-MAPK and JNK signaling pathways (Reader et al, 2011). Human recombinant GDF9 and BMP15 act through the NF- $\kappa B$ and JNK signaling pathways (Reader et al, 2016). Thus, the non-Smad signaling pathways activated through the synergistic actions of GDF9 and BMP15 vary depending on the species.

In summary, GDF9 and BMP15 are crucial in folliculogenesis, however as illustrated, there are differences in the importance of expression of these two proteins in high and low ovulating species. This may also be studied through the cellular signaling pathways utilised by these proteins, namely the Smad proteins (Smads 1, 2, 3, 5 and 8), which are a fundamental part of signaling. 


\subsection{Methodology}

\subsection{Study Aims}

The factors that regulate ovulation rate in species are unknown, but several studies point towards the oocyte itself being of importance (Williams and Stanley, 2008, Crawford and McNatty, 2012, Grasa et al, 2015). Although GDF9 and BMP15 both impact folliculogenesis, differences in the importance of expression of these two proteins in high and low ovulating species have been illustrated (Crawford and McNatty, 2012). GDF9 and BMP15 signal through intracellular signaling proteins, known as the Smads (Dennler et al, 1999, ten Dijke et al, 2002, Schmierer and Hill, 2005). Thus, the difference in the expression and importance of GDF9 and BMP15 in mono-ovulatory and polyovulatory species may be indirectly studied through the Smads (Smad 1, 2, 3, 5 and 8). Oocyte secreted factors, such as GDF9, have been implicated in the management of fertility, influencing embryo generation (Li et al, 2014). New insights into the interactions between oocyte secreted factors and their signaling pathways may ultimately improve in vitro maturation (IVM) methodologies, which are currently less efficient than hormone-stimulated in vitro fertilisation (IVF) systems (Gilchrist, 2011). This study will further our understanding of differences in ovulation rate in various species with the inclusion of both the pig, a non-rodent poly-ovulatory species, and the deer, a strict mono-ovulatory species. Despite these ovulation rate differences, both species express high levels of BMP15 in the oocyte (Crawford and McNatty, 2012). This study will investigate the species differences in the bioactivity of oocyte secreted factors (OSFs) on GCs.

The aims of this study were, through cross-species co-incubations of oocytes and GC, to determine the (i) proliferative effects, (ii) expression levels of key genes and (iii) Smad signaling activation of oocyte secreted factors on GC of rat, sheep, pig and red deer.

Specifically, the cross-species effects of oocyte secreted factors on (i) GC proliferation rate were determined using a tritiated thymidine incorporation assay (ii) GC expression 
levels of $B M P R 2$, TGFBR1, and BMPR1B mRNA were determined using qPCR and (iii) GC levels of unphosphorylated and phosphorylated Smads 1, 2, 3, 5 and 8 were measured using Western blotting.

\subsection{Experimental design}

Preliminary experiments were conducted to determine the incubation time that produced the maximum proliferation rate (i.e. tritiated thymidine uptake) in rat, sheep, pig and deer GC. Activin A, which is known to act through the Smad2/3 pathway (Baker and Harland, 1996, Dennler et al, 1998), was used as a positive control. Three to five replicate experiments were performed for each species, whereby oocytes from each species were incubated with GC from their corresponding species.

Following the preliminary experiments, same- and cross-species co-incubations using GC and oocytes from rats, sheep, pig and red deer were conducted in every possible combination (Figure 2.1). For each incubation run, GC samples were collected following incubation with ooctyes for determination of proliferation rate, expression levels of key growth factor receptor genes and relative amounts of phosphorylated and unphosphorylated Smad proteins. The number of replicate experiments performed for the proliferation assays, gene expression and protein measurements were three to five, five to seven, and three, respectively.

\begin{tabular}{l|llllllll} 
GC & Rat & Rat & Rat & Rat & Sheep & Sheep & Sheep & Sheep \\
\hline Oocytes & Rat & Sheep & Pig & Deer & Rat & Sheep & Pig & Deer
\end{tabular}

\begin{tabular}{l|llllllll} 
GC & Pig & Pig & Pig & Pig & Deer & Deer & Deer & Deer \\
\hline Oocytes & Rat & Sheep & Pig & Deer & Rat & Sheep & Pig & Deer
\end{tabular}

Figure 2.1: Experimental design of cross-incubations of granulosa cells and oocytes from the four test species. 


\subsection{Tissue collection}

In accordance with the 1999 Animal Welfare Act (Part 6) of New Zealand, ovaries were collected from prepubertal female Sprague Dawley rats obtained from the Psychology Department (Victoria University of Wellington). Rats were euthanised with $\mathrm{CO}_{2}$ gas, and thereafter, cervical dislocation was performed. To maintain sterility, the abdomen was dowsed in 70\% ethanol prior to dissection. Upon removal, rat ovaries were placed in dissection media (see Appendix One) that had been previously warmed to $37^{\circ} \mathrm{C}$ for transport back to the laboratory. Sheep, deer and pig ovaries were obtained from Ngauranga Meatworks (Wellington, NZ), Venison Packers Feilding Ltd (Feilding, NZ), and Cabernet Foods, Kintyre Meats Ltd (Gladstone, NZ), respectively. Sheep ovaries were transported in a plastic bag at room temperature to the laboratory. Pig and deer ovaries were transported in $0.9 \%$ saline pre-warmed to $37^{\circ} \mathrm{C}$ in a flask, with transportation taking two and three hours, respectively. Upon arrival, extraneous connective and fatty tissues were removed from the ovaries. For sterilisation purposes, rat ovaries were briefly placed in pre-warmed ethanol and washed twice in dissection media. Sheep, pig and deer ovaries were also immersed briefly in $70 \%$ ethanol to rid the ovarian surface of possible bacterial contamination and then washed twice in $0.9 \%$ saline. During oocyte retrieval, rat ovaries were kept in dissection media, and sheep, deer and pig ovaries were kept in $0.9 \%$ saline, in a $37^{\circ} \mathrm{C}$ water bath.

\subsubsection{Denuded oocyte collection}

Rat ovaries were placed in $3.5 \mathrm{~cm}$ petri dishes whilst sheep, deer and pig ovaries were placed in petri dishes filled with dissection media. Using a dissection microscope, visible follicles on rat ovaries were punctured using a 30-gauge needle. For sheep, pig and deer ovaries, a 20 -gauge needle attached to a $1 \mathrm{~mL}$ syringe was used to puncture visible follicles. Media was often injected into the follicles of sheep, pig and deer ovaries to encourage detachment of the COC from its follicular surroundings. Isolated denuded oocytes and COCs were transferred into a clean petri dish containing dissection media. COCs were denuded by aspirating with a $1 \mathrm{~mL}$ syringe, or vigorous pipetting, until the majority of cumulus cells were removed. When collecting large quantities of oocytes, oocytes were temporarily stored in a petri dish with incubation media (see Appendix 
One) in a $37^{\circ} \mathrm{C}$ (for rat) or $39^{\circ} \mathrm{C}$ (for sheep, pig and deer) incubator whilst the remaining oocytes were collected.

\subsubsection{GC collection}

The GCs of rats, sheep, pigs and deer were collected once all COCs and denuded oocytes had been collected. It is possible that the cells remaining contained a small proportion of cell types other than GC, such as theca cells. The GC preparations were aspirated twice with a 20-gauge needle attached to a $1 \mathrm{~mL}$ syringe to disperse any clumps of GC and transferred into a $10 \mathrm{~mL}$ falcon tube and centrifuged at $453 \mathrm{~g}$ for 5 minutes, at $20^{\circ} \mathrm{C}$. Collection media was removed taking care not to disrupt the pellet containing GC. Cells were washed once in $1 \mathrm{~mL}$ incubation media (Appendix 1.1). After the final wash, the GC were then evenly resuspended by pipetting in incubation media, ensuring no clumps were visible in the media. Thereafter, a $50 \mu \mathrm{L}$ aliquot of GCs was removed and mixed gently with $5 \mu \mathrm{L}$ of $0.4 \%$ trypan blue (Gibco Life Technologies, USA). An aliquot of $10 \mu \mathrm{L}$ was pipetted under a cover slip on a hemocytometer with a $0.1 \mathrm{~mm}$ depth (Improved Neubauer, BS 74B Hawksley). Under a Leica DM1000 microscope, the number of live (clear) and dead (blue) cells with GC morphology were counted and recorded. The morphological characteristics used to distinguish GCs were the presence of a nucleus and a cytoplasm with a granular appearance. The concentration of cells within the preparation was determined using the equation below and the cell suspension was diluted further in incubation media so that 1,000 live cells were present in $1 \mu \mathrm{L}(20,000$ in $20 \mu \mathrm{L})$.

Number of cells $/ \mathrm{mL}=$ live cell count $\mathrm{x} 10,000 \mathrm{x}$ dilution factor $\mathrm{x}$ volume

If fewer than 1,000 live cells per $\mu \mathrm{L}$ were present, the falcon tube containing the GCs was centrifuged again and a smaller volume of incubation media was added so that the cell concentration was 20,000 viable cells $/ 20 \mu \mathrm{L}$. 


\subsection{Incubation Experiments}

All incubation experiments were performed in an incubator with $5 \% \mathrm{CO}_{2}$ at $37{ }^{\circ} \mathrm{C}$ (for rat) or $39{ }^{\circ} \mathrm{C}$ (for sheep, pig and deer). From this point onwards, the term $\mathrm{CO}_{2}$ incubator will be used.

\subsubsection{Preliminary time series incubation experiments}

The 96-well plates (Jetbiofil) were used for all incubation experiments. For the preliminary time series experiments, $55 \mu \mathrm{L}$ of incubation media was added to three to five wells within the first row of each plate and used as the baseline from which each result was normalised against. Three to five wells within the second row of each plate contained $20 \mu \mathrm{L}$ of 20,000 viable rat GC together with $35 \mu \mathrm{L}$ of incubation media. Three to five wells within the third row of each plate contained $20 \mu \mathrm{L}$ of 20,000 viable rat GCs together with 32 rat denuded oocytes, with a final volume of $55 \mu \mathrm{L}$. As the positive control, three to five wells in the final row of each plate contained $20 \mu \mathrm{L}$ of 20,000 live rat GCs, $34 \mu \mathrm{L}$ of incubation and $1 \mu \mathrm{L}$ of Activin A (final concentration of $10 \mathrm{ng} / \mathrm{mL}$; Accession \# P08476, R \& D systems). This plate set-up regimen was repeated for GC and denuded oocyte of the other species also (i.e. sheep, pig and deer). Following the addition of cells, plates were placed in a $\mathrm{CO}_{2}$ incubator. The rat cells were incubated for either $0,4,8,12$ or 16 hours, whilst sheep, pig and deer cells were incubated for either 8 , 12 or 16 hours. The rationale behind the incubation times for the rat was determined by previous literature, whereby an 18 hour incubation has been previously used in similar studies employing tritiated thymidine uptake in GC (McNatty et al, 2005b, McNatty et al, 2005c). Therefore, a maximum incubation time of 16 hours was used for all species. However, shorter incubation times of four hour increments were also tested in the time series experiments to determine both basal proliferation rate at 0 hours and the relationship of time in culture and proliferation rate. Fewer time points were used for the sheep, pig and deer experiments due to time limitations in oocyte retrieval.

\subsubsection{Same- and cross-species incubation experiments}

For the experiments involving cross-incubations of GC and denuded oocyte from different species, the first row of each plate contained $55 \mu \mathrm{L}$ of incubation media. Three 
to five wells within the second, third and fourth rows of each plate contained $20 \mu \mathrm{L}$ of 20,000 viable GCs from one species in $35 \mu \mathrm{L}$ of incubation media. In the third and fourth rows, 32 denuded oocytes of either of the four species were added to the wells containing the GCs and the second row contained wells with GCs alone. Whilst all experiments were set up in an identical manner, the experiments destined for gene expression and Western blot analyses were performed on separate 96-well plates than those destined for proliferation analyses.

\subsection{Proliferation Assay}

Following the stipulated incubation period (variable for the preliminary experiments and 16 hours for all other experiments), 96-well plates were removed from the incubator for the addition of tritiated thymidine (NET35501MC, Perkin Elmer). Tritiated thymidine was diluted 1:25-fold in incubation media and $10 \mu \mathrm{L}(\sim 0.4 \mu \mathrm{Ci})$ was added to each well. The plate was returned to the $\mathrm{CO}_{2}$ incubator for a further 6 hours. Thereafter, the plate was removed for cell harvesting. Briefly, the radiolabelled cellular contents of the 96-well plates were transferred onto a glass fibre filter mat (1450 micro $\beta$ fibre filter, $90 \times 120$ mm printed filter mat, Perkin Elmer, MA, USA) using the 'Pulse Wash' programme of a Wallac Harvester (TOMTEC). The filter mat was carefully dried in a microwave oven (1500W, 2-3 minutes), and then placed into a sample bag (Perkin Elmer, MA, USA). An aliquot of $4.5 \mathrm{ml}$ of $\beta$-scintillation fluid (SC/9200.21, Perkin Elmer Life Sciences) was added inside the sample bag and the bag edges were completely sealed with heat (Wallac heat sealer; Perkin Elmer). The bag was maneuvered such that the filter mat was evenly immersed in the $\beta$-scintillation fluid. The bag containing the filter mat was placed into the Wallac micro $\beta$ trillux scintillation counter (1450 LSC and Luminescence counter, Perkin Elmer) and $\beta$ particle emissions at positions corresponding to a 96-well plate format were measured on the filter mat in counts per minute (CPM).

\subsection{GC sample preparation for qPCR and Western Blots}

Following a 16 hour incubation period, 96-well plates were removed from the $\mathrm{CO}_{2}$ incubator and placed on ice to dislodge the cells from the well bottom. This was aided by 
mechanical pipetting of media over the well bottom and the resultant cell suspension was placed into a $3.5 \mathrm{~cm}$ petri dish. Any ruptured (absent) denuded oocytes were noted to account for any discrepancies in results, and oocytes were removed from GC. For gene expression analyses, the GC were then transferred into eppendorf tubes and pelleted by centrifugation at $800 \mathrm{~g}$ for four minutes. The pellet was washed with $200 \mu \mathrm{L}$ of PBS, pelleted by centrifugation and excess PBS was removed.

For Western blot samples, the media was carefully removed without disturbing the pellet. An aliquot of $1 \mu \mathrm{l}$ of 10x protease inhibitor (Ref \# 04693159001, Roche) was added to the GC pellet. All qPCR and Western blot samples were snap frozen and stored at $-80^{\circ} \mathrm{C}$ until further use.

\subsection{Quantitative PCR}

\subsubsection{Total RNA Extraction}

Total RNA was isolated from samples containing 20,000 GC using an ArrayPure ${ }^{\mathrm{TM}}$ Nanoscale RNA Purification Kit (Cat \# MCR85102, Epicentre), following the manufacturer's instructions. For each GC sample, $1 \mu \mathrm{L}$ of $5 \mu \mathrm{g} / \mu \mathrm{L}$ Proteinase $\mathrm{K}$ was diluted into $30 \mu \mathrm{L}$ of Nano-scale Lysis Solution. Thirty $\mu \mathrm{L}$ of this solution was added to each GC sample and then incubated at $65^{\circ} \mathrm{C}$ for 15 minutes. After samples were placed on ice for 5 minutes, $18 \mu \mathrm{L}$ of MPC Protein Precipitation Reagent was added and briefly vortexed. Samples were centrifuged at $12,000 \mathrm{~g}$ for 7 minutes at $4{ }^{\circ} \mathrm{C}$ and the supernatant was transferred to a clean Eppendorf tube. Total RNA was precipitated with the addition of $50 \mu \mathrm{L}$ of isopropanol. Following a 30 second vortex, the RNA was pelleted by centrifugation at $12,000 \mathrm{~g}$ for 5 minutes at $4{ }^{\circ} \mathrm{C}$. Residual isopropanol was removed and the RNA pellet was air-dried. The pellet was then re-suspended in $20 \mu \mathrm{L}$ of Dnase I solution, which was prepared using $1 \mu \mathrm{L}$ of Rnase-Free Dnase I with $40 \mu \mathrm{L}$ of $1 \mathrm{X}$ Dnase Buffer. Thereafter samples were incubated for 30 minutes at $37^{\circ} \mathrm{C}$. After the addition of $20 \mu \mathrm{L}$ of $2 \mathrm{X}$ Nanoscale Lysis Solution and brief vortexing, $20 \mu \mathrm{L}$ of MPC Protein Precipitation reaction was added. Following centrifugation at $12,000 \mathrm{~g}$ for 5 minutes at $4{ }^{\circ} \mathrm{C}$, the supernatant was transferred to a clean Eppendorf tube. Total RNA was again precipitated with the addition of $50 \mu \mathrm{L}$ of isopropanol and the RNA was pelleted by centrifuging at $12,000 \mathrm{~g}$ 
for 5 minutes at $4{ }^{\circ} \mathrm{C}$. The pellet was washed with $50 \mu \mathrm{L}$ of $70 \%$ ethanol, and centrifuged at $12,000 \mathrm{~g}$ for 3 minutes. The residual ethanol was removed and the pellet air-dried for 5 minutes. Total RNA was resuspended in $10 \mu \mathrm{L}$ Dnase free water and vortexed for one minute. The RNA samples were then either frozen at $-80{ }^{\circ} \mathrm{C}$ for further processing, or used immediately for cDNA synthesis.

\subsection{2 cDNA Synthesis}

Complementary DNA was synthesised from GC RNA using the SuperScript VILO cDNA Synthesis Kit (Cat \# 11754-250, Invitrogen, Life Technologies) following the manufacturer's instructions. Briefly, in a $200 \mu \mathrm{L}$ PCR tube (Scientific Specialities Inc, USA), $4 \mu \mathrm{L}$ of $5 \mathrm{X}$ VILO reaction mix, $2 \mu \mathrm{L}$ of 10X SuperScript enzyme mix, $10 \mu \mathrm{L}$ of isolated GC RNA and $4 \mu \mathrm{L}$ of DEPC-treated water were added and mixed thoroughly. The synthesis of cDNA was performed on a Corbett Rotor-Gene 6000 (Corbett Research Ltd) under the following conditions: $25^{\circ} \mathrm{C}$ for 10 minutes, $42{ }^{\circ} \mathrm{C}$ for 120 minutes and $85^{\circ} \mathrm{C}$ for 5 minutes.

\subsection{3 qPCR optimisation}

Primers and Taqman probes (for some genes) for rat, sheep, pig and deer Tgfßr1, Bmpr1b, Bmpr2, Rpl19 (reference) and Ppia (reference) genes were designed using Beacon Designer 8.13 (Premier Biosoft; see Table 2.7.3.1). Primers were synthesised by Life Technologies (New Zealand) and Taqman probes were manufactured by Sigma Proligo (Australia).

Optimisation of the qPCR was completed using various concentrations of forward and reverse primers for each gene to determine the optimal primer concentrations. Combinations of 100, 200, 300 and $500 \mathrm{nM}$ forward and reverse primers were tested. Reaction mixes containing $26 \mu \mathrm{L}$ Brilliant SYBR Green qPCR master mix (Cat \# 600828, Agilent technologies), the appropriate concentration of forward and reverse primers (Table 2.7.3.2), $1.04 \mu \mathrm{L}$ of GC cDNA, and UltraPure $\mathrm{dH}_{2} \mathrm{O}$ to a final volume of $52 \mu \mathrm{L}$ were prepared in $0.2 \mathrm{~mL}$ PCR tubes. For those genes in which Taqman probe chemistry were used, 100, 200, 300 and $500 \mathrm{nM}$ concentrations of probes were tested. Reaction mixes 
containing $26 \mu \mathrm{L}$ Brilliant Multiplex qPCR master mix (Cat \# 600553, Agilent technologies), the optimal concentrations of forward and reverse primers (Table 2), the appropriate concentrations of Taqman probe (Table 2.7.3.2), 1.04 $\mu \mathrm{L}$ of GC cDNA, and UltraPure $\mathrm{dH}_{2} \mathrm{O}$ to a final volume of $52 \mu \mathrm{L}$ were prepared in $0.2 \mathrm{~mL}$ PCR tubes. Duplicates of $25 \mu \mathrm{L}$ reactions were then added to strip-tubes (QartaBio), loaded into a RotorGene 6000 (Corbett) and subjected to the following conditions: $95{ }^{\circ} \mathrm{C}$ for 10 minutes, and then 40 cycles of $95^{\circ} \mathrm{C}$ for 15 seconds, and $60{ }^{\circ} \mathrm{C}$ for 60 seconds.

PCR efficiencies were determined using serial dilutions ( 1 to $1: 128$ ) with $02.08 \mu \mathrm{L}$ of cDNA, to generate an efficiency value and an $\mathrm{R}^{2}$ value (Table 2.7.3.3). The PCR efficiency of all genes measured in this study was $>75 \%$.

Following optimisation of all gene sets, gene expression levels were then measured in samples collected for qPCR. Similar reaction mixes were prepared as described above in accordance with genes either quantified using SYBR Green or Taqman qPCR chemistry. SYBR Green qPCR chemistry was utilised for the genes PPIA, RPL19 of all species and deer BMPR2. Taqman qPCR chemistry was utilised for every other gene as well as the $R P L 19$ gene of the sheep, pig and rat. Taqman reactions were performed in quadraplex (rat and sheep TGFBR1, BMPR1B, BMPR2, RPL19), triplex (pig BMPR1B, BMPR2, RPL19), duplex (deer TGF $\beta R 1, B M P R 1 B$ ) and singleplex (pig TGFBR1). For SYBR green chemistry, $26 \mu \mathrm{L}$ Brill SYBR Green qPCR master mix, $1.04 \mu \mathrm{L}$ of cDNA, forward and reverse primers at the optimised concentrations (Table 2.7.3.2) were added to a $200 \mu \mathrm{L}$ PCR tubes, and UltraPure $\mathrm{H}_{2} \mathrm{O}$ was added to a final volume of $52 \mu \mathrm{L}$. For Taqman chemistry, $26 \mu \mathrm{L}$ Brill SYBR Green qPCR master mix, $1.04 \mu \mathrm{L}$ of cDNA, forward and reverse primers at the optimised concentrations (Table 2.7.3.2), and Taqman probe(s) at the optimised concentration(s) (Table 2.7.3.2) were added to $200 \mu \mathrm{L}$ PCR tubes, and UltraPure $\mathrm{H}_{2} \mathrm{O}$ was added to a final volume of $52 \mu \mathrm{L}$. Again, for each sample, $25 \mu \mathrm{L}$ of the reaction mix was aliquoted in duplicate into strip-tubes. Gene expression levels from five-seven replicates of each experimental group (collected randomly over multiple experiments) were analysed. The gene, RPL19, was used as the reference gene for sample normalisation however an additional reference gene, $P P I A$, was also measured to ensure parallelism of the two reference genes for each sample. Additionally a calibrator sample 
was present at the beginning and end of every reaction run. Thus, the Ct value of Rpl19 for each sample was subtracted from every sample's Ct value for each gene, obtaining a $\Delta \mathrm{Ct}$ value. Thereafter, the Ct value of the calibrator sample for each gene was subtracted from the $\Delta \mathrm{Ct}$ value resulting in the $\Delta \Delta \mathrm{Ct}$ value. To deduce the relative difference in mRNA expression levels for each gene between GC samples, the equation of $2^{(-\Delta \Delta C T)}$ was calculated (Livak \& Schmittgen, 2001).

Table 2.7.3.1: Nucleotide sequences and NCBI accession numbers for forward and reverse rat, sheep, pig and deer primers and TaqMan probes.

\begin{tabular}{|c|c|c|c|}
\hline Gene & $\begin{array}{l}\text { Accession } \\
\text { Number }\end{array}$ & Primers & Taqman probe \\
\hline \multicolumn{4}{|l|}{ Rat } \\
\hline \multirow[t]{2}{*}{ Bmpr2 } & NM_080407 & F-CGTCAACTTCACTGAGAA & ССАССТССТGATACAACACСАСТС \\
\hline & & R-TGCCAAAGCAATGATTATAG & \\
\hline \multirow[t]{2}{*}{$\operatorname{Tgf} \beta r 1$} & NM_012775 & F-TGCTGATGGTCTATATCTG & TAACCGCACTGTCATTCACCACC \\
\hline & & R-TGCCCTCTGAAATGAAAG & \\
\hline \multirow[t]{2}{*}{ Bmpr1b } & NM_001024259 & F-GGACAGAGATTTTGTTGATG & AGCCTTACTCATATCTGTGACTGTCTGT \\
\hline & & $\begin{array}{l}\text { R- } \\
\text { CCTGAAGTAACAGAATAAAATAATG }\end{array}$ & \\
\hline \multirow[t]{2}{*}{ Rpl19 } & NM_031103 & F-CAGGAAGCTGATCAAAGA & CGGAAGCCTGTGACTGTCCAT \\
\hline & & R-CTTCCCTATGCCCATATG & \\
\hline \multirow[t]{2}{*}{ Ppia } & NM_017101 & F-CTTTGACTTGCGGGCATTT & - \\
\hline & & R-GAACTTCAGTGAGAGCAGAGAT & \\
\hline \multicolumn{4}{|l|}{ Sheep } \\
\hline \multirow[t]{2}{*}{ BMPR2 } & NM_001306123 & F-GGACTTGTGTAATGTCAAC & САССТCCAGACACAACACСАCTC \\
\hline & & R-GATGCCAATGCAATGATTA & \\
\hline \multirow[t]{2}{*}{$T G F \beta R 1$} & XM_012120354 & F-GCCAGTTGTATCTTCCATA & AGCACTATCATTACAGCATAACCACAGG \\
\hline & & R-CACTGTATCCTGACTCAAG & \\
\hline \multirow[t]{2}{*}{$B M P R 1 B$} & NM_001009431 & F-GGCGCTTTAAAATAGAGATAA & TACСТCСАТССТСАССGCСТ \\
\hline & & R-CGCATACCTAAGACACAA & \\
\hline \multirow[t]{2}{*}{ RPL19 } & XM_004012836 & F-GACGATACCGTGAATCTAA & CATGTATCACAGCCTGTACCTGAAGG \\
\hline & & R-CAGCTTGTGGATATGTTC & \\
\hline \multirow[t]{2}{*}{ PPIA } & XM_015095354 & F-TTACTTAACCACCAGACCAT & - \\
\hline & & R-CGAGAGCACAAAGATTATAGG & \\
\hline \multicolumn{4}{|l|}{ Pig } \\
\hline \multirow[t]{2}{*}{ BMPR2 } & NM_001204900 & F-CACAGATTTGTGTAATGTCA & ССТCСAGACACAАСАССАСТСАG \\
\hline & & R-ATGCCAGAGCAATGATTA & \\
\hline \multirow[t]{2}{*}{$T G F \beta R 1$} & AF_317296 & F-CACTCATGTTGATGGTCTA & TGCCATAACCGTACAGTCATTCACC \\
\hline & & R-AAGGGCGATCTAATGAAG & \\
\hline$B M P R 1 B$ & AF_432128 & & CATCCAGAAGTGACCACAGGCAT \\
\hline
\end{tabular}




\begin{tabular}{|c|c|c|c|}
\hline \multirow[t]{2}{*}{ RPL19 } & XM_003131509 & F-GAAGCTGATCAAAGATGG & АCССTTCCGCTTACCGATGC \\
\hline & & R-CCAAGTTACCTTCTCAGG & \\
\hline \multirow[t]{2}{*}{ PPIA } & XM_013985800 & F-ACCGTCTTCTTCGACATC & - \\
\hline & & R-TGAGCAGTCACTTCTTGG & \\
\hline \multicolumn{4}{|l|}{ Deer } \\
\hline \multirow[t]{2}{*}{ BMPR2 } & $\mathrm{N} / \mathrm{A}$ & F-GCAACAAAGATAAATAACTATTTG & CCAGACAGAAGAAGAGTTGCCTTACATT \\
\hline & & R-CCCAAACACAGTGTAGTA & \\
\hline \multirow[t]{2}{*}{$T G F \beta R 1$} & $\mathrm{~N} / \mathrm{A}$ & F-GATCCTTAGGTTTACCATTG & AACAGCAACTTCTTCTCCTCTCCATT \\
\hline & & R-CCATGAACGTTCTTCTCTA & \\
\hline \multirow[t]{2}{*}{$B M P R 1 B$} & $\mathrm{~N} / \mathrm{A}$ & F-CTGAGTTTAGAAGGTGAATC & TGGTCAGCAGCCTCAGCATT \\
\hline & & R-CACAGTTCTTGGATGTTG & \\
\hline \multirow[t]{2}{*}{ RPL19 } & $\mathrm{N} / \mathrm{A}$ & F-CTGGATGAGGAGGATGAGA & - \\
\hline & & R-ATGTGGCGGTCAATCTTC & \\
\hline \multirow[t]{2}{*}{ PPIA } & $\mathrm{N} / \mathrm{A}$ & F- TCAGCAGAGGAGCAAGAC & - \\
\hline & & R-CACTGTCCTTTGTCCATTAGAG & \\
\hline
\end{tabular}

Table 2.7.3.2: Optimised forward and reverse rat, sheep, pig and deer primer concentrations and Taqman probes.

\begin{tabular}{|c|c|c|c|c|}
\hline & \multirow[t]{2}{*}{ Gene } & \multicolumn{2}{|c|}{ Primer (nM) } & \multirow[t]{2}{*}{ TaqMan Probe (nM) } \\
\hline & & Forward & Reverse & \\
\hline \multirow[t]{5}{*}{ Rat } & Bmpr2 & 300 & 300 & 200 \\
\hline & $\operatorname{Tgf} \beta r 1$ & 300 & 500 & 100 \\
\hline & Bmpr1b & 300 & 500 & 100 \\
\hline & Rpl19 & 300 & 300 & 200 \\
\hline & Ppia & 300 & 300 & - \\
\hline \multirow[t]{5}{*}{ Sheep } & BMPR2 & 500 & 200 & 100 \\
\hline & $T G F \beta R 1$ & 300 & 200 & 300 \\
\hline & $B M P R 1 B$ & 300 & 300 & 100 \\
\hline & RPL19 & 300 & 500 & 100 \\
\hline & PPIA & 500 & 300 & - \\
\hline \multirow[t]{5}{*}{ Pig } & $B M P R 2$ & 300 & 200 & 200 \\
\hline & $T G F \beta R 1$ & 300 & 200 & 200 \\
\hline & $B M P R 1 B$ & 300 & 200 & 200 \\
\hline & RPL19 & 200 & 200 & 100 \\
\hline & PPIA & 300 & 300 & - \\
\hline \multirow[t]{5}{*}{ Deer } & BMPR2 & 500 & 300 & 300 \\
\hline & $T G F \beta R 1$ & 300 & 200 & 200 \\
\hline & $B M P R 1 B$ & 200 & 200 & 300 \\
\hline & RPL19 & 300 & 200 & - \\
\hline & PPIA & 300 & 500 & - \\
\hline
\end{tabular}


Table 2.7.3.3: Amplification efficiencies of rat, sheep, pig and deer genes.

\begin{tabular}{|c|c|c|c|}
\hline & Gene & $\mathbf{R}^{2}$ & Efficiency \\
\hline \multirow[t]{5}{*}{ Rat } & Bmpr2 & 0.98 & 0.90 \\
\hline & $T g f \beta r 1$ & 0.98 & 0.93 \\
\hline & Bmpr1b & 0.98 & 0.87 \\
\hline & Rpl19 & 0.99 & 0.84 \\
\hline & Ppia & 0.99 & 0.99 \\
\hline \multirow[t]{6}{*}{ Sheep } & BMPR2 & 0.97 & 0.78 \\
\hline & $T G F \beta R 1$ & 0.98 & 0.85 \\
\hline & $B M P R 1 B$ & 0.98 & 0.77 \\
\hline & RPL19 & 0.99 & 0.81 \\
\hline & PPIA & 0.98 & 0.97 \\
\hline & BMPR2 & 0.99 & 0.81 \\
\hline \multirow[t]{4}{*}{ Pig } & TGF $\beta R 1$ & 0.99 & 0.79 \\
\hline & $B M P R 1 B$ & 0.97 & 0.86 \\
\hline & RPL19 & 0.99 & 0.79 \\
\hline & PPIA & 0.99 & 0.87 \\
\hline \multirow[t]{5}{*}{ Deer } & BMPR2 & 0.99 & 0.89 \\
\hline & $T G F \beta R 1$ & 0.98 & 0.97 \\
\hline & $B M P R 1 B$ & 0.99 & 0.86 \\
\hline & RPL19 & 0.99 & 0.93 \\
\hline & PPIA & 0.98 & 0.99 \\
\hline
\end{tabular}

\subsection{Western Blots}

\subsubsection{SDS PAGE Gel Preparation}

A 13.5\% acrylamide gel was prepared by combining the components in Table 2.8.1 (reagents listed in Appendix 2). The Mini-PROTEAN Tetra Electrophoresis System (BioRad) was used in gel preparation. After the gel solution was thoroughly mixed, it was pipetted between two glass plates, with an in-built $0.75 \mathrm{~mm}$ spacer, held in place by a Tetra Cell casting stand and clamps. A layer of water was pipetted above the solution, which was left to polymerise for at least one hour at room temperature. The top layer of water was then removed and the gel was blotted dry. Thereafter, the stacking gel was prepared (Table 2.8.1) and pipetted on top of the separating gel. A 10-well comb was inserted, and the gel was left to polymerise for over 30 minutes. Following complete 
polymerisation, the gels were either used immediately or stored at $4^{\circ} \mathrm{C}$ for later use in a pre-wet plastic bag with the combs in place and wrapped in damp paper towels.

Table 2.8.1: Table of reagents for $13.5 \%$ separating gel and $4 \%$ stacking gel recipes.

\begin{tabular}{ccc}
\hline Components & $\mathbf{1 3 . 5 \%}$ Separating gel & 4\% Stacking gel \\
\hline Milli Q water & $2.85 \mathrm{~mL}$ & $3.0 \mathrm{~mL}$ \\
1.5 M Tris-HCl (pH 8.8) & $2.5 \mathrm{~mL}$ & - \\
0.5 M Tris-HCl (pH 6.8) & - & $1.25 \mathrm{~mL}$ \\
$10 \%(w / v)$ SDS & $100 \mu \mathrm{L}$ & $50 \mu \mathrm{L}$ \\
$30 \%$ Bis-acrylamide mix & $4.5 \mathrm{~mL}$ & $0.65 \mathrm{~mL}$ \\
$10 \%(w / v)$ Ammonium persulphate & $50 \mathrm{~mL}$ & $25 \mu \mathrm{L}$ \\
TEMED & $5 \mu \mathrm{L}$ & $5 \mu \mathrm{L}$ \\
\hline
\end{tabular}

\subsubsection{Sample Preparation}

The GC samples collected for Western Blotting were removed from $-80{ }^{\circ} \mathrm{C}$ storage and placed on ice to ensure the proteins were maintained in their phosphorylated state. The negative control present in all Western blots was a recombinant deer GDF9 preparation that had been previously produced in-house (Swinerd, 2016). Two positive controls that were present in all Western blots were 20,000 live sheep GCs treated with either recombinant deer GDF9 or deer BMP15 (produced in-house; Swinerd, 2016). Both the negative and positive controls were prepared in a manner similar to that of the samples. For each GC sample, phosphatase inhibitor ( $4 \mu \mathrm{l}$; final concentration of $1 \mathrm{x}$, Appendix 1.3), was immediately added to each GC sample which contained $\sim 3 \mu \mathrm{l}$ of media, followed by $12 \mu \mathrm{l}$ of lysis buffer (Appendix 1.3) and a 1:1 ratio of reducing loading buffer (Appendix 1.3), for a final volume of $40 \mu \mathrm{l}$. Each GC sample was then thoroughly vortexed to complete cell lysis, briefly centrifuged and split into two aliquots, so that each sample contained $\sim 10,000$ previously-viable GCs. Negative controls were prepared in a similar manner, with $1 \mu \mathrm{l}$ of GDF9, $1 \mu \mathrm{l}$ McCoy's media, $2 \mu \mathrm{l}$ phosphatase inhibitor, 6 
$\mu \mathrm{L}$ lysis buffer, and reducing loading buffer in a 1:1 ratio per sample. Samples were firmly sealed in eppendorf tubes and placed in a $95{ }^{\circ} \mathrm{C}$ water bath for 5 minutes for denaturation.

\subsubsection{SDS PAGE Gel electrophoresis}

Gels were assembled inside a running cassette (BioRad), and placed in a cell, which was filled with 1x running buffer (Appendix 1.3). Aliquots $(20 \mu \mathrm{l})$ of sample were loaded into each well and $3 \mu \mathrm{l}$ of ladder (Precision Plus Proteins Dual Colour Standards, 1610374, Bio-Rad) was added into the two outer wells. The gel was electrophoresed at $150 \mathrm{~V}$ for approximately 1 hour, or until the blue dye had reached the bottom of the gel.

\subsubsection{SDS PAGE Gel transfer}

A Criterion ${ }^{\mathrm{TM}}$ Blotter (Bio-Rad) was used to transfer proteins from the gel onto a nitrocellulose membrane (Cat\# 10600004, Amersham Protran, GE Healthcare). The stacking gel was removed from the PAGE gel and thereafter the transfer cassette was assembled in the following manner:

Black side of cassette (bottom)

Scotch-brite pad

2x Blotting paper

Gel

Membrane

2x Blotting paper

Scotch-brite pad

Red side of cassette (top)

The scotch-brite pads, blotting papers and membrane were presoaked in transfer buffer (Appendix 1.3) prior to assembly. The cassette was placed into an electrode module in 
the correct orientation with a stirrer and ice pack placed inside, and the tank filled with transfer buffer. The protein was transferred at $100 \mathrm{~V}$ for one hour at $4{ }^{\circ} \mathrm{C}$. Following the transfer, the cassette was disassembled, and the membrane was placed in a square petri dish. The ladder bands that were visible to the naked eye were marked with a pencil, and the membrane was washed twice for 10 minutes in membrane washing buffer (Appendix 1.3).

\subsubsection{Membrane blocking}

A blocking step was used to prevent non-specific binding of antibodies to the membrane. For blots on which antibodies for phosphorylated proteins would be used, $5 \% \mathrm{w} / \mathrm{v}$ BSA (Cat \# ABRE, MP Biomedicals) in membrane washing buffer was used. For blots on which antibodies for unphosphorylated proteins would be used, $5 \% \mathrm{w} / \mathrm{v}$ milk powder in membrane washing buffer was used. Each membrane was incubated in the blocking solution for one hour with gentle agitation at room temperature.

\subsubsection{Primary antibody incubation}

Each membrane, which contained proteins from 10,000 previously-viable GC per lane or the controls or the ladder, were firstly incubated with phosphorylated Smad 2/3 (Santa Cruz, Lot\# D1216) and 1/5/8 (Cell Signaling, Lot\#13820) antibodies, prior to being stripped and then being incubated with unphosphorylated Smad 2/3 (Santa Cruz, Lot\# B1313) and 1/5/8 (Santa Cruz, Lot \# C2216) antibodies (see Appendix 3 for antibody details). Finally an additional stripping step was performed and each membrane was incubated with an antibody for the reference protein $\beta$-actin (Sigma-Aldrich, Cat\# A5441). All antibodies for phosphorylated and unphosphorylated Smad proteins were added to washing buffer containing $5 \% \mathrm{w} / \mathrm{v}$ BSA or $5 \% \mathrm{w} / \mathrm{v}$ milk powder, respectively. Antibody concentrations were optimised by titration experiments and final optimised antibody concentrations are listed in Table 2.8.6. The antibody solution was added to the membrane and incubated overnight at $4{ }^{\circ} \mathrm{C}$ with gentle agitation. 
Table 2.8.6: Optimised antibody concentrations.

\begin{tabular}{ll}
\hline Antibody & Concentration \\
\hline Phosphorylated Smad 2/3 & $1: 500$ \\
Phosphorylated Smad $1 / 5 / 8$ & $1: 500$ \\
Smad $2 / 3$ & $1: 250$ \\
Smad $1 / 5 / 8$ & $1: 250$ \\
$\beta$-actin & $1: 1,000$
\end{tabular}

\subsubsection{Secondary antibody incubation}

Upon removal of the primary antibody, membranes were washed with agitation three times for ten minutes in membrane washing buffer. Thereafter, the appropriate secondary antibody was added to membrane washing buffer containing $5 \% \mathrm{w} / \mathrm{v}$ BSA or $5 \% \mathrm{w} / \mathrm{v}$ milk powder for antibodies for phosphorylated and unphosphorylated proteins, respectively. Whilst a Horse Radish Peroxidase AffiniPure Rabbit anti-Goat IgG secondary antibody (Jackson Immunoresearch, Lot\# 117560), was used to probe for the primary unphosphorylated Smad2/3 antibody, a Horse Radish Peroxidase Goat antiRabbit IgG secondary antibody (Abcam, Ab97051), was used to probe all other Smad primary antibodies. A Horse Radish Peroxidase AffiniPure Rabbit anti-Mouse secondary antibody (Jackson Immunoresearch, Lot\# 119936) was utilised to probe the $\beta$-actin primary antibody at a 1:2,000 concentration. The optimised concentration for all other secondary antibodies used was 1:3000. Membranes were incubated with gentle agitation in the secondary antibody solution for two hours at room temperature.

\subsubsection{Western blot development}

After the antibody incubation steps, membranes were washed three times for 10 minutes in washing buffer. A Luminal: $\mathrm{H}_{2} \mathrm{O}_{2}$ solution (Western Bright ${ }^{\mathrm{TM}}$ ECL-Spray; Advantsa, K-12049-D50) was sprayed onto the membrane surface and left for three minutes. The membrane was then blotted dry and placed into an Omega Lum G Imaging 
System (Aplegen) for image capture. Membranes probed with Smad antibodies were exposed for 15 minutes, whilst those probed with $\beta$ actin were exposed for 10 minutes.

\subsubsection{Antibody stripping}

In order to strip the membranes of antibodies to allow for protein detection with another antibody, $100 \mathrm{~mL}$ of stripping buffer was prepared immediately prior to use (Appendix 1.3), and heated for 5 minutes in a plastic container placed in a water bath at $55^{\circ} \mathrm{C}$. Thereafter membranes were added to the stripping buffer and incubated for 30 minutes at $55^{\circ} \mathrm{C}$ and the container was agitated every five minutes to evenly disperse the stripping buffer over the membrane. The membranes were then washed three times for 10 minutes in washing buffer, and the blocking, primary and secondary antibody incubation steps were performed, as described previously.

\subsubsection{Antibody preabsorption}

To validate the specificity of the antibodies used in these experiments, antibodies were preabsorbed with their specific blocking peptides (Appendix 3). The same primary and secondary antibody concentrations described in sections 2.6.5 and 2.6.6 were used. The membrane was probed with its appropriate antibody, which was subject to the same conditions as the antibodies utilised for the preabsorption steps. After membrane development, the membrane was stripped for preabsorption. For preabsorption, primary antibodies were incubated with blocking peptide at a 5:1 (blocking peptide: antibody) ratio, based on molecular weight, in a total volume of $200 \mu \mathrm{L}$ of membrane washing buffer for 24 hours at $4^{\circ} \mathrm{C}$ with gentle agitation. Thereafter, the blocking peptide: antibody mixture was centrifuged for 5 minutes at $600 \mathrm{~g}$, to remove any precipitate, and the supernatant was added to the appropriate blocking buffer and developed as described previously.

\subsubsection{Western Blot Analysis}

Densitometric analysis was performed using ImageJ software (version 1.50i with Java 1.6.0_41 (64-bit), National Inustitutes of Health (NIH), USA). Images were obtained from the Omega Lum G Imaging System (Aplegen), saved as .tif files and transferred onto a PC. 
Semi-quantitative densitometric analysis was performed on each specific band using ImageJ. The mean grey value of each band was measured using a rectangle of uniform size. A total of 2-5 mean grey values of the background were measured across the blot, and the average of these values were subtracted from the value for each band to standardise the data. Thus, each band value is represented as a fold-change relative to $\beta$ actin.

\subsection{Smad Homology Comparison}

A Smad homology comparison was performed between the four test species (rat, sheep, pig and deer), in order to compare the similarity between these proteins for Western blotting. Accession numbers were obtained from National Center for Biotechnology (NCBI), apart from deer sequences, which were obtained from Brauning et al, 2015. The homology comparison was completed using NCBI BLAST.

\subsection{Statistical Analysis}

All statistical analysis was completed using the IBM software package SPSS statistics (version 22). $P$ values of $<0.05$ were considered statistically significant. Graphs were created using GraphPad Prism (Version 7.02). Prior to analyses, all data were tested for normal distribution, as determined by p-p plotting. Any data that was not normally distributed underwent either a natural log or square root transformation to ensure the data exhibited a normal distribution. All graphs show mean values \pm SEM.

Analyses of raw CPM values and fold-changes indicating GC proliferation was performed using a two-way ANOVA. If significant differences were observed, a Bonferroni post-hoc analysis test was performed.

Analyses of the qPCR $\left(2^{\wedge}(-\mathrm{ddCt})\right.$ values) and Western blotting (densiometry values) data were analysed using a one-way ANOVA. If significance was observed, either a Bonferroni post-hoc analysis test or a least significant difference (LSD) post-hoc analysis test was performed respectively. 
Table 2.9.1: Homology of Smad proteins between species.

\begin{tabular}{|c|c|c|c|c|c|}
\hline Accession number & Smad1 & Rat & Sheep & Pig & Deer \\
\hline NP_037262 & Rat & 100 & 98 & 88 & 98 \\
\hline XP_011952811.1 & Sheep & & 100 & 88 & 100 \\
\hline XP_013842259 & Pig & & & 100 & 98 \\
\hline \multirow[t]{2}{*}{$\mathrm{N} / \mathrm{A}$} & Deer & & & & 100 \\
\hline & Smad2 & & & & \\
\hline XP_006255007 & Rat & 100 & 99 & 93 & 93 \\
\hline XP_011976298 & Sheep & & 100 & 94 & 94 \\
\hline XP_005659505 & Pig & & & 100 & 94 \\
\hline \multirow[t]{2}{*}{$\mathrm{N} / \mathrm{A}$} & Deer & & & & 100 \\
\hline & Smad3 & & & & \\
\hline NP_037227 & Rat & 100 & 89 & 100 & ND \\
\hline XP_014959209 & Sheep & & 100 & 90 & ND \\
\hline NP_999302 & Pig & & & 100 & ND \\
\hline \multirow[t]{2}{*}{$\mathrm{N} / \mathrm{A}$} & Deer & & & & 100 \\
\hline & Smad5 & & & & \\
\hline NP_067724 & Rat & 100 & 99 & 99 & ND \\
\hline XP_012033923 & Sheep & & 100 & 99 & ND \\
\hline XP_013842259 & Pig & & & 100 & ND \\
\hline \multirow[t]{2}{*}{$\mathrm{N} / \mathrm{A}$} & Deer & & & & 100 \\
\hline & Smad8 & & & & \\
\hline XP_017446635 & Rat & 100 & 95 & 96 & ND \\
\hline XP_014953594 & Sheep & & 100 & 98 & ND \\
\hline NP_001182439 & Pig & & & 100 & ND \\
\hline $\mathrm{N} / \mathrm{A}$ & Deer & & & & 100 \\
\hline
\end{tabular}

ND - not determined. 


\subsection{Results}

\subsection{Effects of incubation time on GC proliferation rate}

The proliferation rate of rat, sheep, pig and deer GC following the co-incubation with the same species oocytes or with activin A (control) is illustrated in Figure 3.1.1 as a foldchange relative to baseline GC proliferation rate (normalised values), and is illustrated in Figure 3.1.2 as tritiated-thymidine uptake values of counts per minute (CPM; nonnormalised values).

The proliferation rate of rat GC after $0,4,8,12$ and 16 hours incubation with denuded oocytes of rats, or with activin A (control) is illustrated as a fold change relative to baseline GC proliferation rate in Figure 3.1.1A. The proliferation rate of sheep, pig, and deer GC after 8, 12 and 16 hours incubation with denuded oocytes of the corresponding species, or with activin A is illustrated as a fold change relative to baseline GC proliferation in Figures 3.1.1B, C and D, respectively.

Overall, the addition of oocytes of the same-species increased rat, sheep, pig, and deer GC proliferation $(\mathrm{P}<0.0001, \mathrm{P}<0.0001, \mathrm{P}<0.001$ and $\mathrm{P}<0.0001$, respectively; Figure 3.1.1). The addition of activin A only increased rat $(\mathrm{P}<0.0001)$, and sheep $(\mathrm{P}<0.009) \mathrm{GC}$ proliferation levels, but not pig and deer GC proliferation (Figure 3.1.1).

The fold change in proliferation rate of rat GC co-incubated with rat denuded oocytes was higher at 12 hours $(\mathrm{P}<0.00, \mathrm{P}<0.001$ and $\mathrm{P}<0.028$, respectively) and 16 hours $(\mathrm{P}$ $<0.0001, \mathrm{P}<0.0001$ and $\mathrm{P}<0.0001$, respectively), compared to that at 0,4 , and 8 hours (Figure 3.1.1A). Rat GC cultured with Activin A had a higher proliferation rate at 16 hours compared to 0,4 , and 8 hours $(\mathrm{P}<0.001, \mathrm{P}<0.004$ and $\mathrm{P}<0.002$, respectively). The proliferation rate of sheep GC upon sheep oocytes co-incubation was higher $(\mathrm{P}<0.019)$ after 16, compared to 8, hours of incubation. Incubation time did not influence Activin A stimulated sheep GC proliferation rate. Incubation time also did not influence the 
proliferation rate of pig or deer GC upon incubation with the same-species oocyte or with Activin A.

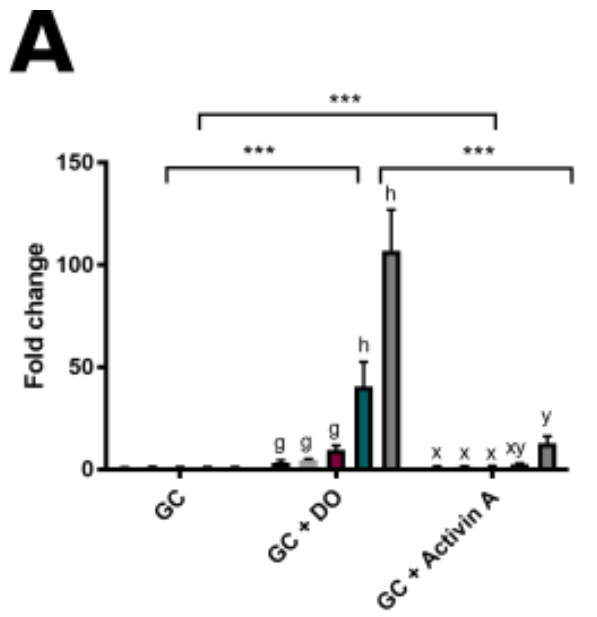

GC Co-incubation
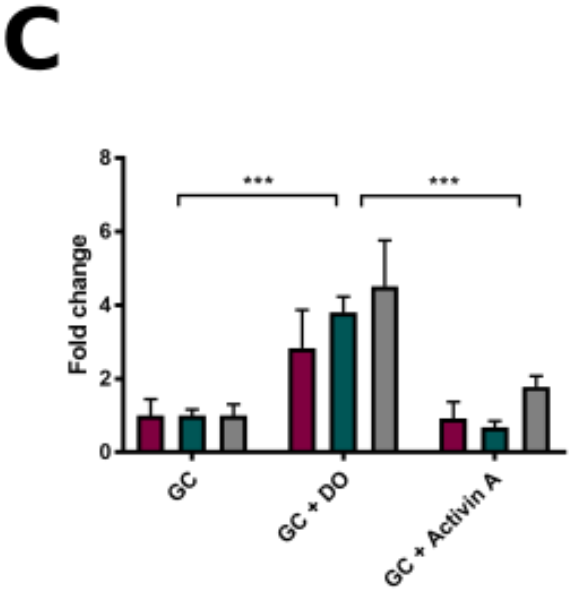

GC Co-incubation
B

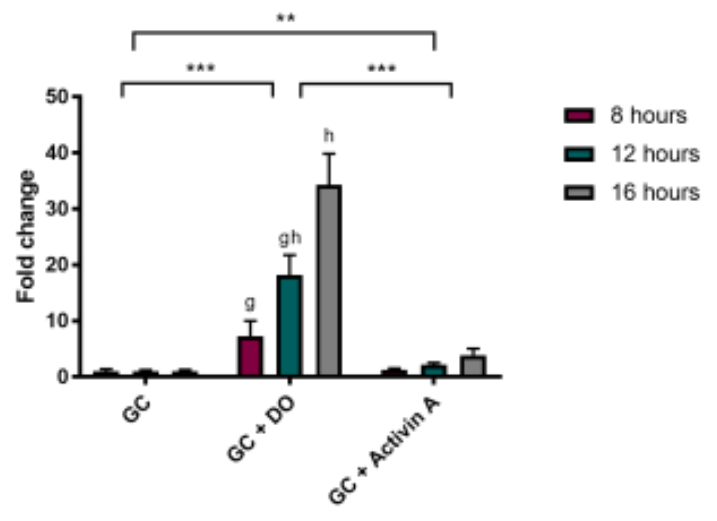

GC Co-incubation
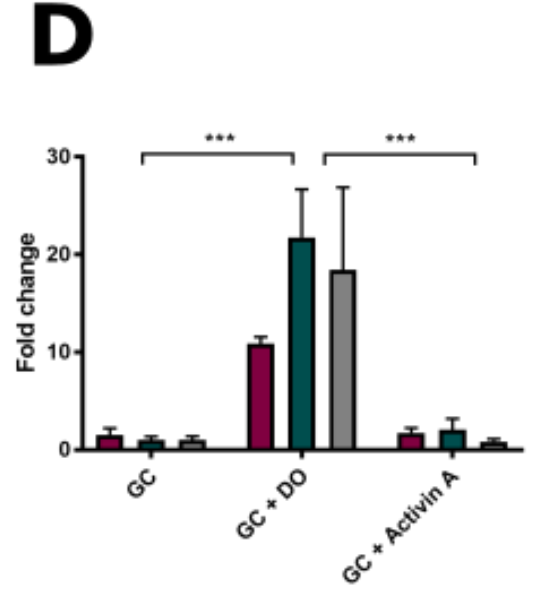

GC Co-incubation
ש 8 hours

口 12 hours

口 16 hours

Figure 3.1.1: Fold change in proliferation rate of rat, sheep, pig and deer GC with time in culture.

Mean \pm SEM fold change in the proliferation rate of rat (A) or sheep (B) or pig (C) or deer (D) GC co-incubated alone, with denuded oocytes of the corresponding species, or Activin A (10 $\mathrm{ng} / \mathrm{mL})$. Values are relative to that of GC in media alone. Mean and SEM of three to five replicates for each treatment group are shown. Different alphabetical superscripts on histograms denote significant difference $(\mathrm{P}<0.05)$, whilst asterixes $\left({ }^{*}\right)$ denote significant differences between treatment groups $(* \mathrm{P}<0.05, * * \mathrm{P}<0.01, * \mathrm{P}<0.001)$. 
When comparing raw CPM data, the addition of denuded oocytes of the same species increased proliferation of rat, sheep, pig, and deer GC $(\mathrm{P}<0.0001, \mathrm{P}<0.0001, \mathrm{P}<0.001$ and $\mathrm{P}<0.0001$, respectively). The addition of activin A only increased rat GC $(\mathrm{P}<0.0001)$ and sheep GC $(\mathrm{P}<0.009)$ proliferation, but not sheep, pig and deer GC.

Tritiated thymidine incorporation of rat GC incubated alone decreased after 12 hours $(\mathrm{P}<0.001, \mathrm{P}<0.007$ and $\mathrm{P}<0.035$, respectively) and 16 hours $(\mathrm{P}<0.0001, \mathrm{P}<0.001$ and $\mathrm{P}<0.004$ respectively) of incubation, compared to that at 0,4 , or 8 hours (Figure 3.1.2A). Tritiated thymidine incorporation was higher $(\mathrm{P}<0.0001)$ following the addition of rat oocytes but was not affected with incubation time (Figure 3.1.2A). Overall, the addition of Activin A increased tritiated thymidine incorporation however, this decreased after 12 hours incubation $(\mathrm{P}<0.047)$ (Figure 3.1.2A).

Tritiated thymidine incorporation in sheep GC cultured alone decreased after 12 and 16, compared to 8, hours incubation time $(\mathrm{P}<0.01$ and $\mathrm{P}<0.002$, respectively) (Figure 3.1.2B). Overall, tritiated thymidine incorporation in sheep GC was increased following the addition sheep denuded oocytes $(\mathrm{P}<0.0001)$ but was not effected by incubation time (Figure 3.1.2B). Similar to sheep GC cultured alone, the addition of Activin A decreased tritiated thymidine incorporation after 12 and 16 hours, compared to 8 hours, of incubation $(\mathrm{P}<0.02$ and $\mathrm{P}<0.014$, respectively) (Figure 3.1.2B).

Tritiated thymidine incorporation in pig GC cultured alone decreased at 16 hours, compared to 8 and 12 hours, of incubation ( $\mathrm{P}<0.009$ and $\mathrm{P}<0.035$, respectively) (Figure 3.1.2C). Overall, tritiated thymidine incorporation was higher in pig GC following the addition of pig oocytes, compared to GC alone or with Activin A, however this decreased after 16 hours in culture, compared to that at 8 and 12 hours $(\mathrm{P}<0.004$ and $\mathrm{P}<0.015$, respectively) (Figure 3.1.2C). Similar to pig GC cultured alone, the addition of Activin A decreased tritiated thymidine incorporation after 16 hours, compared to 8 hours, of incubation $(\mathrm{P}<0.038)$ (Figure 3.1.2C). 
Overall, tritiated thymidine incorporation was higher $(\mathrm{P}<0.0001)$ in deer GC cultured with deer oocytes, compared to media alone or Activin A (Figure 3.1.2D). However, incubation time did not affect tritiated thymidine incorporation levels in any treatment group (Figure 3.1.2D).

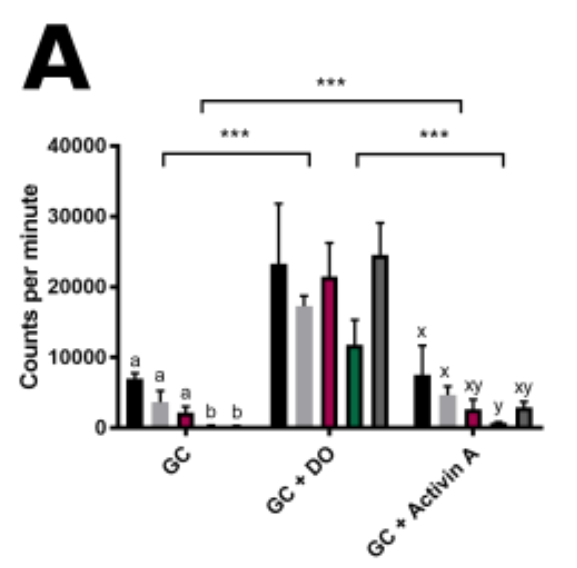

GC Co-incubation
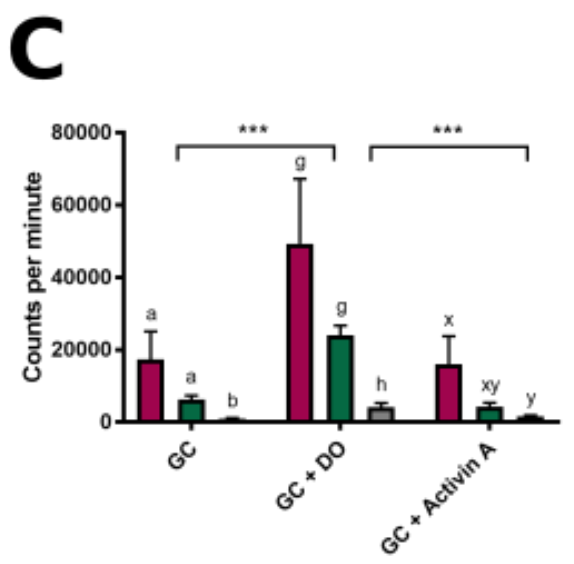

GC Co-incubation

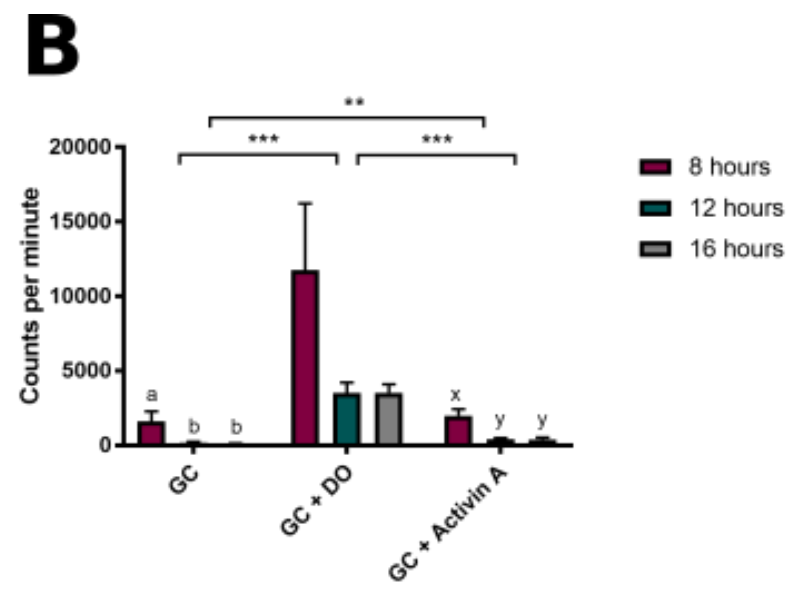

GC Co-incubation
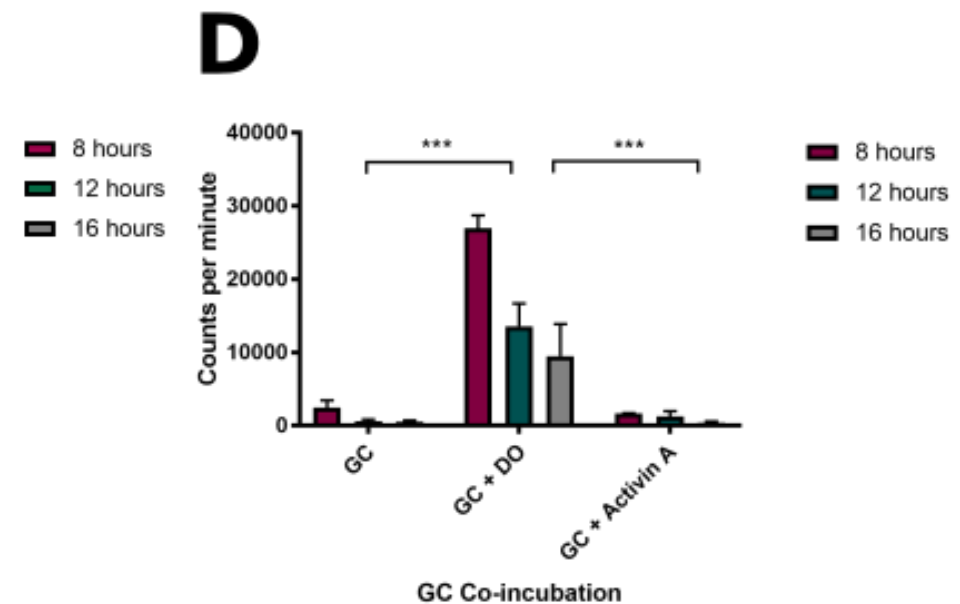

Figure 3.1.2: Tritiated thymidine incorporation of rat, sheep, pig and deer GC with time in culture.

Mean \pm SEM tritiated thymidine incorporation (counts per minute; CPM) of rat (A) or sheep (B) or pig (C) or deer (D) GC co-incubated alone, with denuded oocytes of the corresponding species, or Activin A (10 ng/mL). Mean and SEM of three to five replicates for each treatment group are shown. Different alphabetical superscripts on histograms denote significant difference $(P<0.05)$ in treatment groups between times, whilst asterixes $\left(^{*}\right)$ denote significant differences between treatment groups $\left(* \mathrm{P}<0.05,{ }^{* *} \mathrm{P}<0.01,{ }^{*} \mathrm{P}<0.001\right)$. 


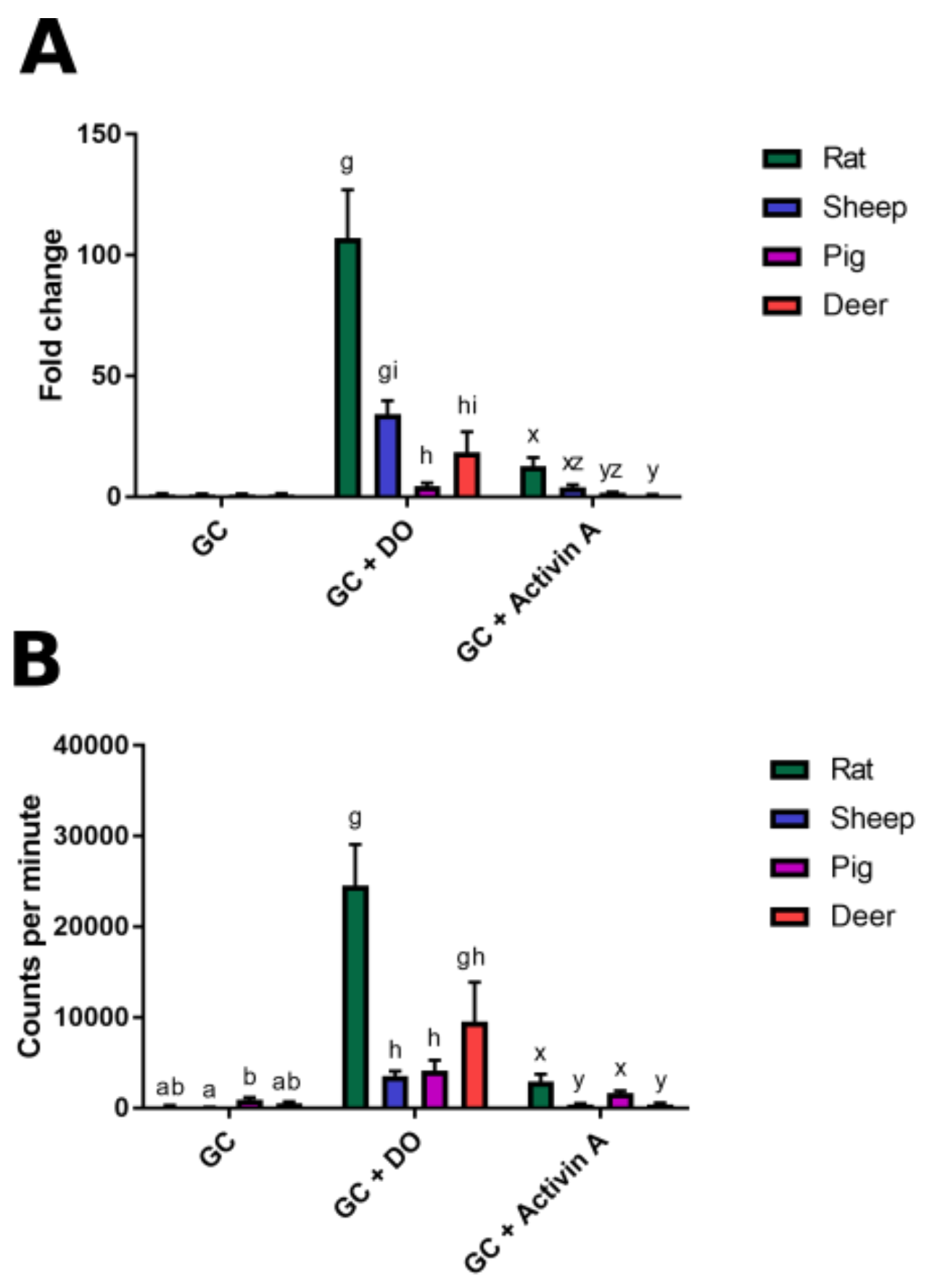

Figure 3.1.3: Proliferation rate of rat, sheep, pig and deer GC after 16 hours in culture

Mean \pm SEM fold change (A) or CPM (B) in the proliferation of all species GCs coincubated alone, with denuded oocytes, or Activin A (10 $\mathrm{ng} / \mathrm{mL})$. Mean and SEM of three to five replicates for each treatment group are shown. Different alphabetical superscripts on histograms denote significant difference $(P<0.05)$.

Upon consideration of the proliferation results after the addition of oocytes of GC of all species with time in culture, the optimal incubation time was determined to be 16 hours, as illustrated in Figure 3.1.3. Similar to the graphs shown above, results are illustrated 
as a fold change relative to baseline GC proliferation (Figure3.1.3A) or as nonnormalised tritiated-thymidine uptake values of counts per minute (CPM) (Figure 3.1.3B).

In regards to proliferation rate relative to that of GC cultured alone (fold-change), proliferation rate of GC co-incubated with denuded oocytes of the same species was highest in rats, compared to that of pigs $(\mathrm{P}<0.004)$ and deer $(\mathrm{P}<0.004)$, but similar to that of sheep (Figure 3.1.3A). Furthermore, the co-incubation of sheep GC with sheep oocytes resulted in a higher proliferation rate in comparison to that of the pigs $(\mathrm{P}<0.004)$ (Figure 3.1.3A). Activin A exhibited a higher fold change in proliferation of rat, compared to, pig $(\mathrm{P}<0.004)$ and deer $(\mathrm{P}<0.001)$ GC. Furthermore, Activin A exhibited a higher proliferation in sheep compared to deer, GC $(\mathrm{P}<0.029)$.

In regards to tritiated thymidine incorporation (CPM), pig GC cultured alone displayed a higher CPM compared to that of sheep GC (Figure 3.1.3A). The co-incubation of GC with oocytes resulted in a higher $\mathrm{CPM}$ in rats compared to that in sheep $(\mathrm{P}<0.0001)$ and pigs $(\mathrm{P}<0.005)$. The addition of Activin A resulted in a higher tritiated thymidine incorporation of rat and pig GC than to sheep ( $\mathrm{P}<0.003$ and $\mathrm{P}<0.037$, respectively) and $\operatorname{deer}(\mathrm{P}<0.003$ and $\mathrm{P}<0.048$, respectively) $\mathrm{GC}$.

\subsection{Effects of oocyte co-incubations on GC proliferation rate}

The effects of co-incubating oocytes of the same or different (cross) species on proliferation rate were examined in GC of each species.

\subsubsection{Co-incubations of rat GCs with oocytes}

The effects of co-incubating rat GC with rat, sheep, pig and deer denuded oocytes on GC proliferation rate are illustrated in Figure 3.2.1. The co-incubation of rat GC with $\operatorname{rat}(\mathrm{P}<$ 0.001), sheep $(\mathrm{P}<0.001)$, pig $(\mathrm{P}<0.001)$ and deer $(\mathrm{P}<0.001)$ oocytes markedly increased GC proliferation rate compared to rat GC cultured alone. Furthermore, the co- 
incubation with rat $(\mathrm{P}<0.001)$, sheep $(\mathrm{P}<0.001)$ and pig $(\mathrm{P}<0.003)$ oocytes stimulated rat GC to proliferate at a greater rate than when co-incubated with deer oocytes.

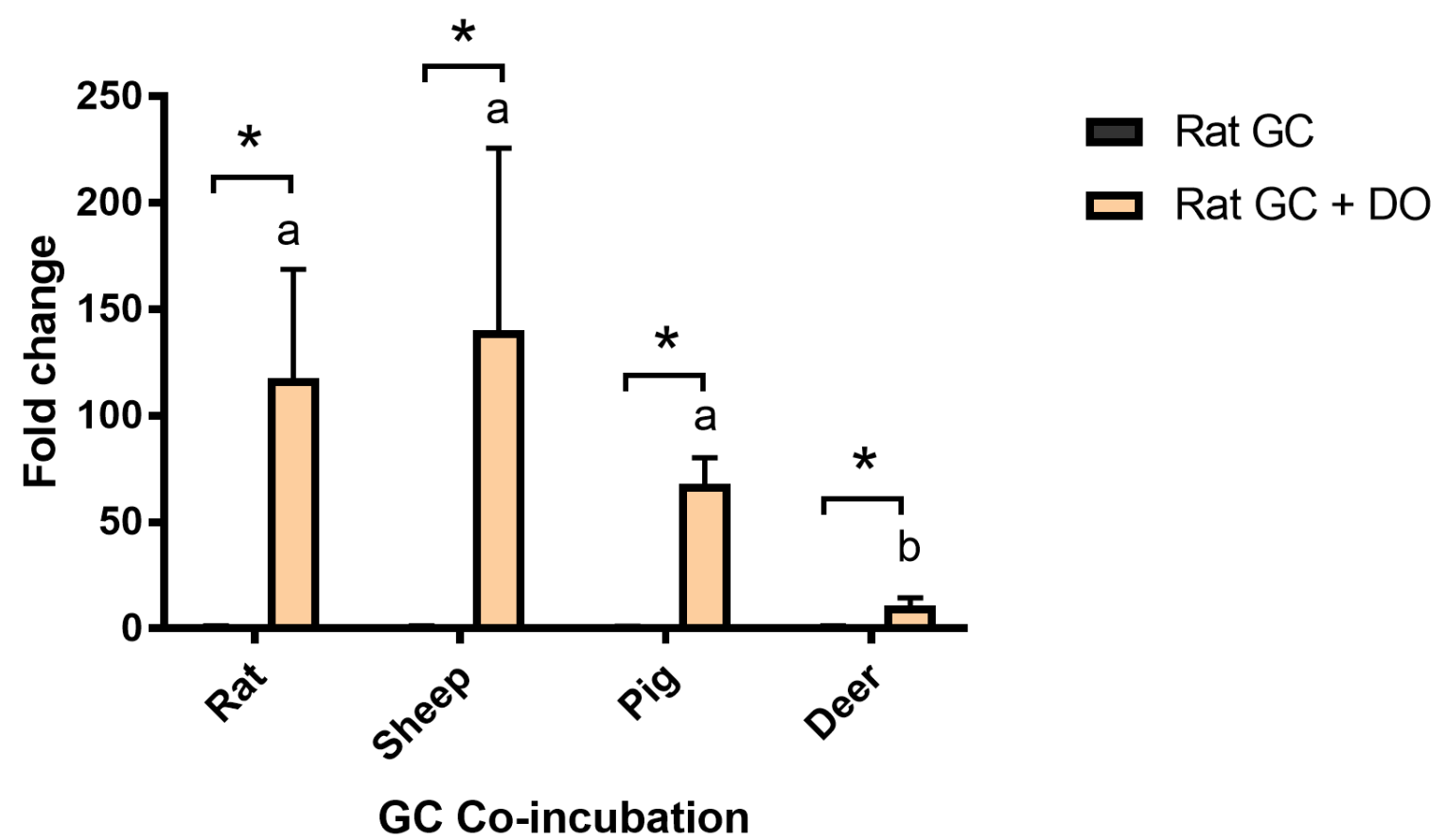

Figure 3.2.1: Proliferation rate of rat GC co-incubated with oocytes.

Mean \pm SEM fold change in the proliferation of rat GCs co-incubated with rat, sheep, pig or deer denuded oocytes. Values are relative to rat GCs in media alone. Mean values represent data from five to seven replicates for each treatment group. Different alphabetical superscripts on histograms denote significant differences $(P<0.003)$ between GCs co-incubated with denuded oocytes of different species. Asterisks denote significant differences $(\mathrm{P}<0.001)$ between GC incubated alone or with denuded oocytes within each species.

\subsubsection{Co-incubations of sheep GCs with oocytes}

The effects of co-incubating sheep GC with rat, sheep, pig and deer denuded oocytes on GC proliferation rate are illustrated in Figure 3.2.2. The co-incubation of sheep GC with rat $(\mathrm{P}<0.001)$, sheep $(\mathrm{P}<0.001)$, pig $(\mathrm{P}<0.001)$ and deer $(\mathrm{P}<0.001)$ oocytes markedly increased GC proliferation rate compared to sheep GC cultured alone. However, there were no differences in oocyte-induced GC proliferation between the different species tested. 


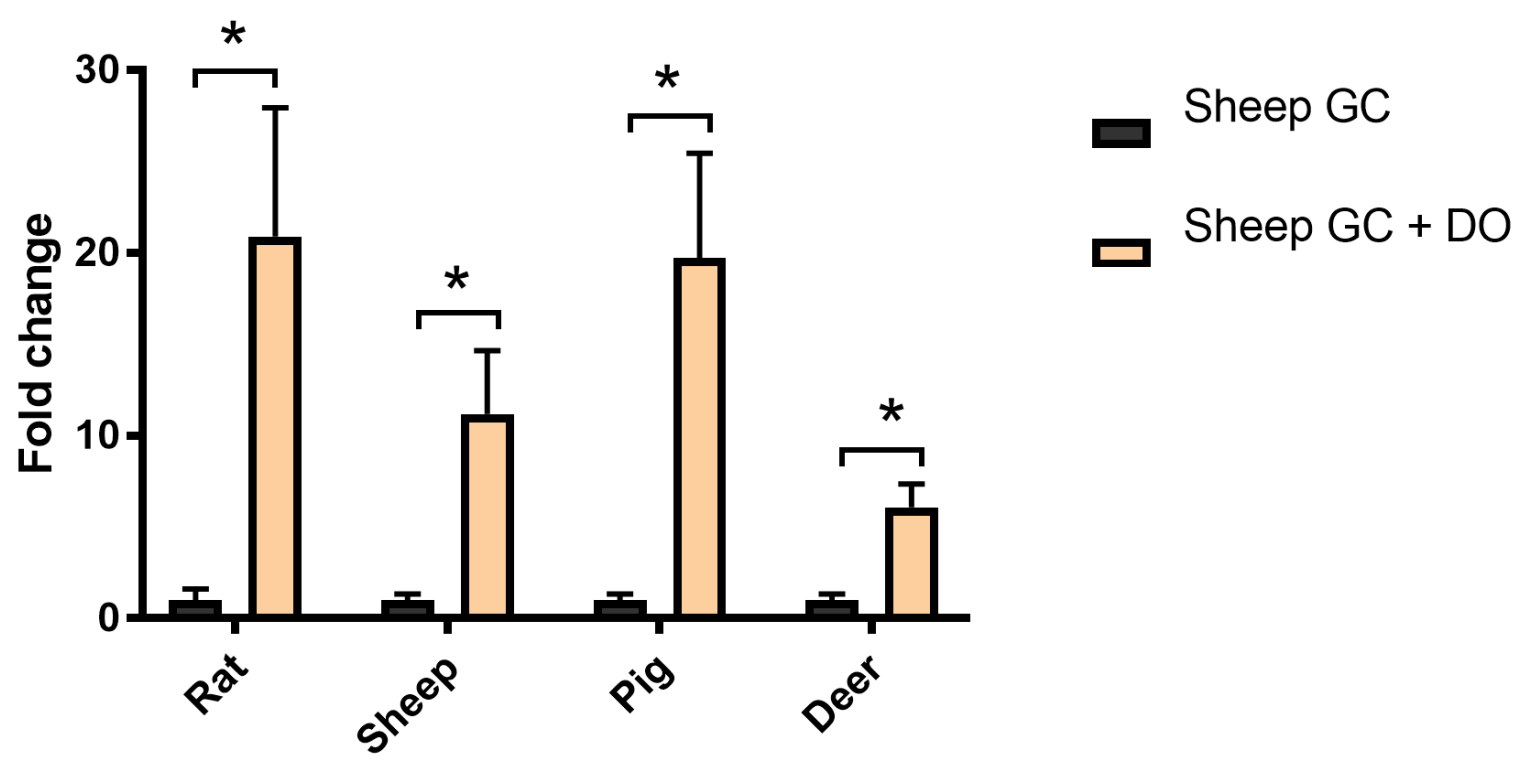

GC Co-incubation

Figure 3.2.2: Proliferation rate of sheep GC co-incubated with oocytes.

Mean \pm SEM fold change in the proliferation of sheep GCs co-incubated with rat, sheep, pig, or deer denuded oocytes. Values are relative to sheep GCs in media alone. Mean values represent data from five to seven replicates for each treatment group. Asterisks denote significant differences $(\mathrm{P}<0.001)$ between $\mathrm{GC}$ incubated alone or with denuded oocytes within each species.

\subsubsection{Co-incubations of pig GCs with oocytes}

The effects of co-incubating pig GC with rat, sheep, pig and deer denuded oocytes on GC proliferation rate are illustrated in Figure 3.2.3. The co-incubation of pig GC with rat $(\mathrm{P}<$ 0.001), sheep $(\mathrm{P}<0.001)$, pig $(\mathrm{P}<0.001)$ and deer $(\mathrm{P}<0.001)$ oocytes markedly increased GC proliferation rate compared to pig GC cultured alone. 


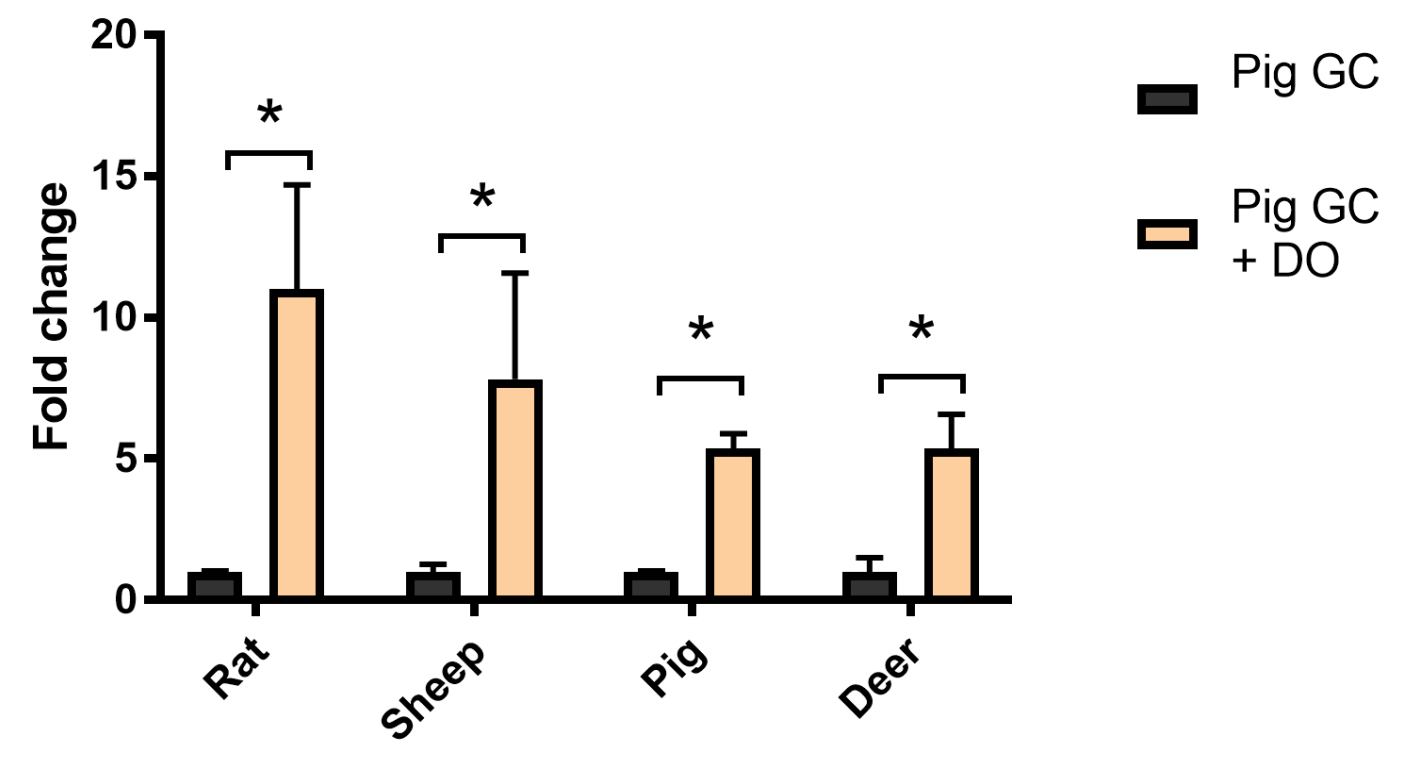

GC Co-incubation

Figure 3.2.3: Proliferation rate of pig GC co-incubated with oocytes.

Mean \pm SEM fold change in the proliferation of pig GCs co-incubated with rat, sheep, pig or deer denuded oocytes. Values are relative to pig GCs in media alone. Mean values represent data from five to seven replicates for each treatment group. Asterisks denote significant differences $(P<0.001)$ between $G C$ incubated alone or with denuded oocytes within each species.

\subsubsection{Co-incubations of deer GCs with oocytes}

The effects of co-incubating deer GC with rat, sheep, pig and deer oocytes on GC proliferation rate are illustrated in Figure 3.2.4. The co-incubation of deer GC with rat $(\mathrm{P}<0.001)$, sheep $(\mathrm{P}<0.007)$, pig $(\mathrm{P}<0.001)$ and $\operatorname{deer}(\mathrm{P}<0.001)$ oocytes markedly increased GC proliferation rate compared to deer GC cultured alone. However, there were no differences in oocyte-induced GC proliferation between the different species tested. 


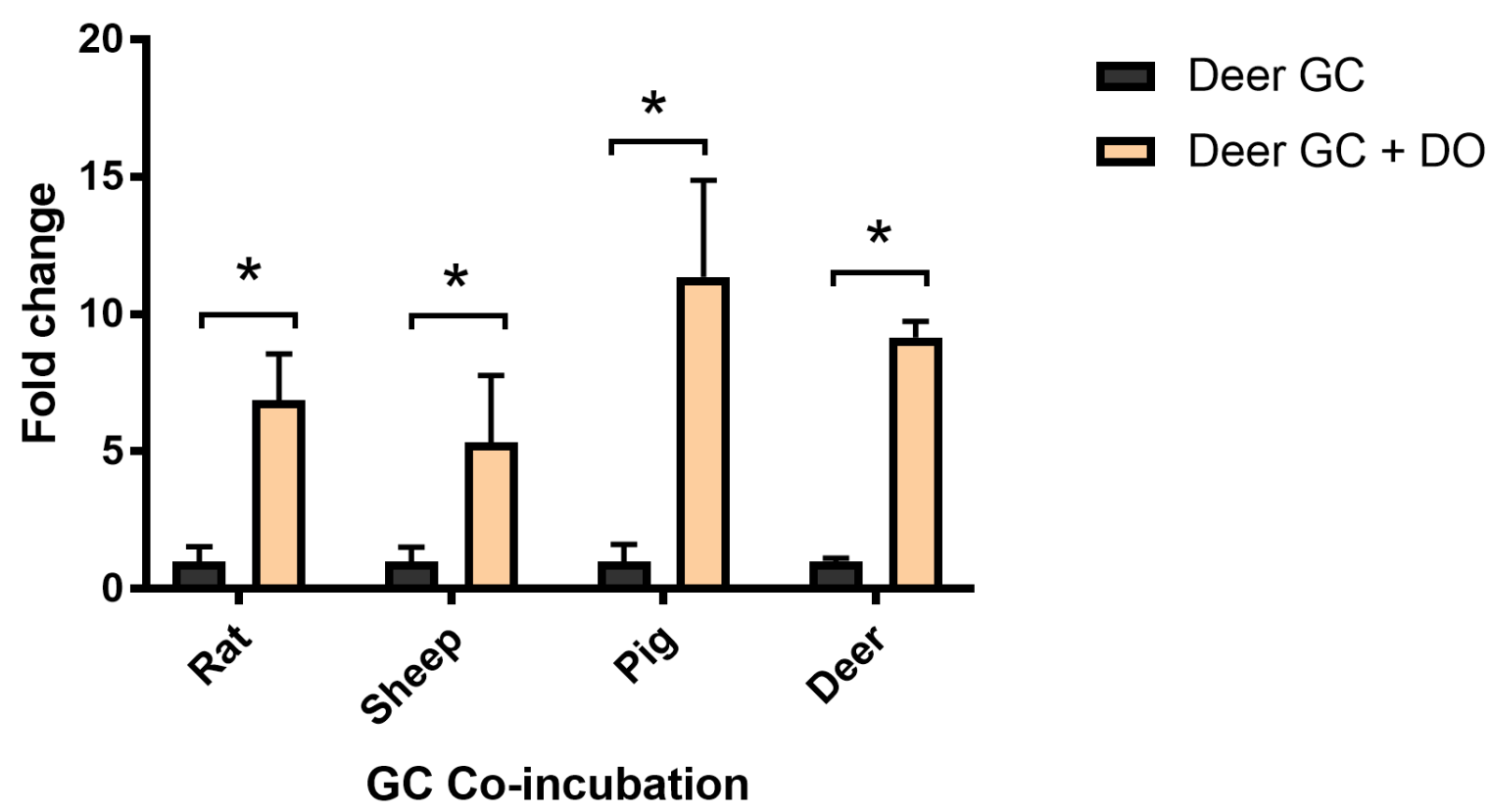

Figure 3.2.4: Proliferation rate of deer GC co-incubated with of deer oocytes.

Mean \pm SEM fold change in the proliferation of deer GCs co-incubated with rat, or sheep, or pig, or deer denuded oocytes. Values are relative to deer GCs in media alone. Mean values represent data from five to seven replicates for each treatment group. Asterisks denote significant differences $(P<0.007)$ between $\mathrm{GC}$ incubated alone or with denuded oocytes within each species.

\subsection{Effects of cell viability and species on GC proliferation rate}

The effects of differences in GC viability, and basal GC proliferation rate between species were tested.

\subsubsection{Differences in GC viability between species}

The proportion (\%) of live GC present within the GC sample at the time of collection (GC viability) for each species is illustrated in Figure 3.5.1. Whilst the GC viability of rat, sheep and pig were similar (17- 25\%), the viability of deer GC was lower (11\%; $\mathrm{P}<0.002$ ) than that of sheep and pig. 


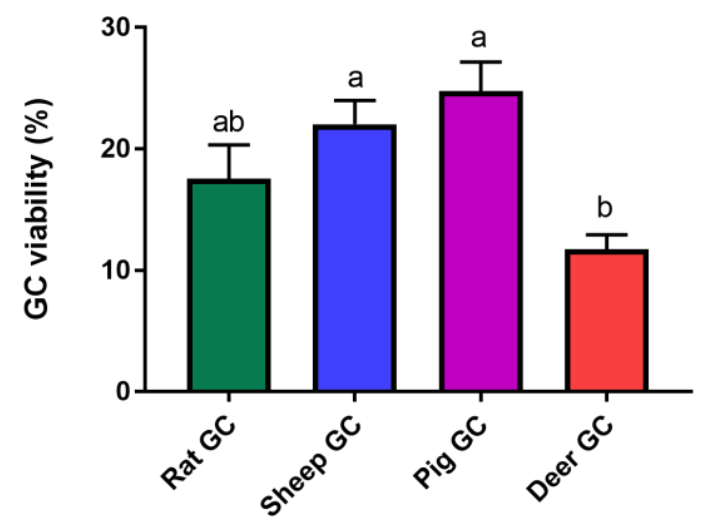

Figure 3.5.1: Cell viability of rat, sheep, pig and deer GC at time of collection.

Mean \pm SEM (\%) values represent 15 to 21 replicate samples for each species. Different alphabetical superscripts on histograms denote significant differences $(P<0.05)$ between species.

\subsubsection{Differences in basal GC proliferation rate between species} Comparisons in tritiated thymidine incorporation rate of rat, sheep, pig and deer GC incubated alone for 16 hours are illustrated in Figure 3.5.2. Whilst basal proliferation rates of GC were similar in rat, sheep and deer (623- 888 CPM), pig GC had a higher proliferation rate than that of rats $(\mathrm{P}<0.009)$ and deer $(\mathrm{P}<0.03)$.

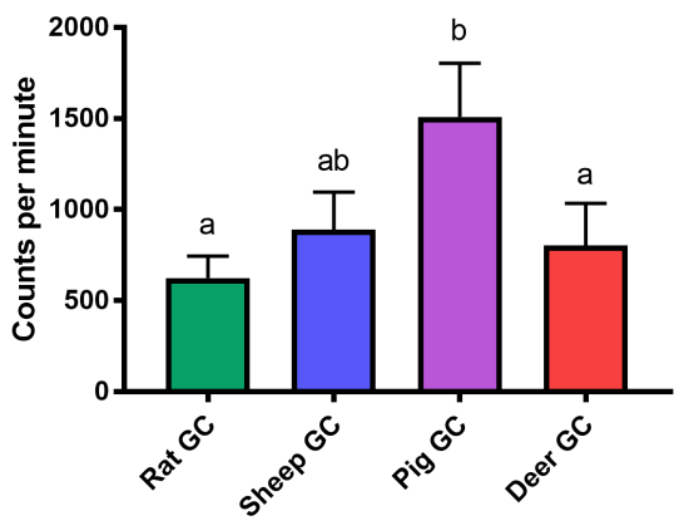

Figure 3.5.2: Basal proliferation rate of rat, sheep, pig and deer GC.

Mean \pm SEM counts per minute (CPM; proliferation rate) of rat, sheep, pig or deer GCs incubated for 16 hours in media alone. Mean values represent data from three to five replicate experiments for each treatment group. Different alphabetical superscripts on histograms denote significant differences $(P<0.03)$ between species. 


\subsubsection{Effects of GC viability on basal proliferation rate}

The correlations between cell viability (\%) and proliferation rate (CPM) in rat, sheep, pig and deer GC are illustrated in Figure 3.5.3. Due to the low $\mathrm{r}^{2}$ value calculated, it was deemed that there was no linear relationship between GC viability and basal proliferation rate in any of the species tested.
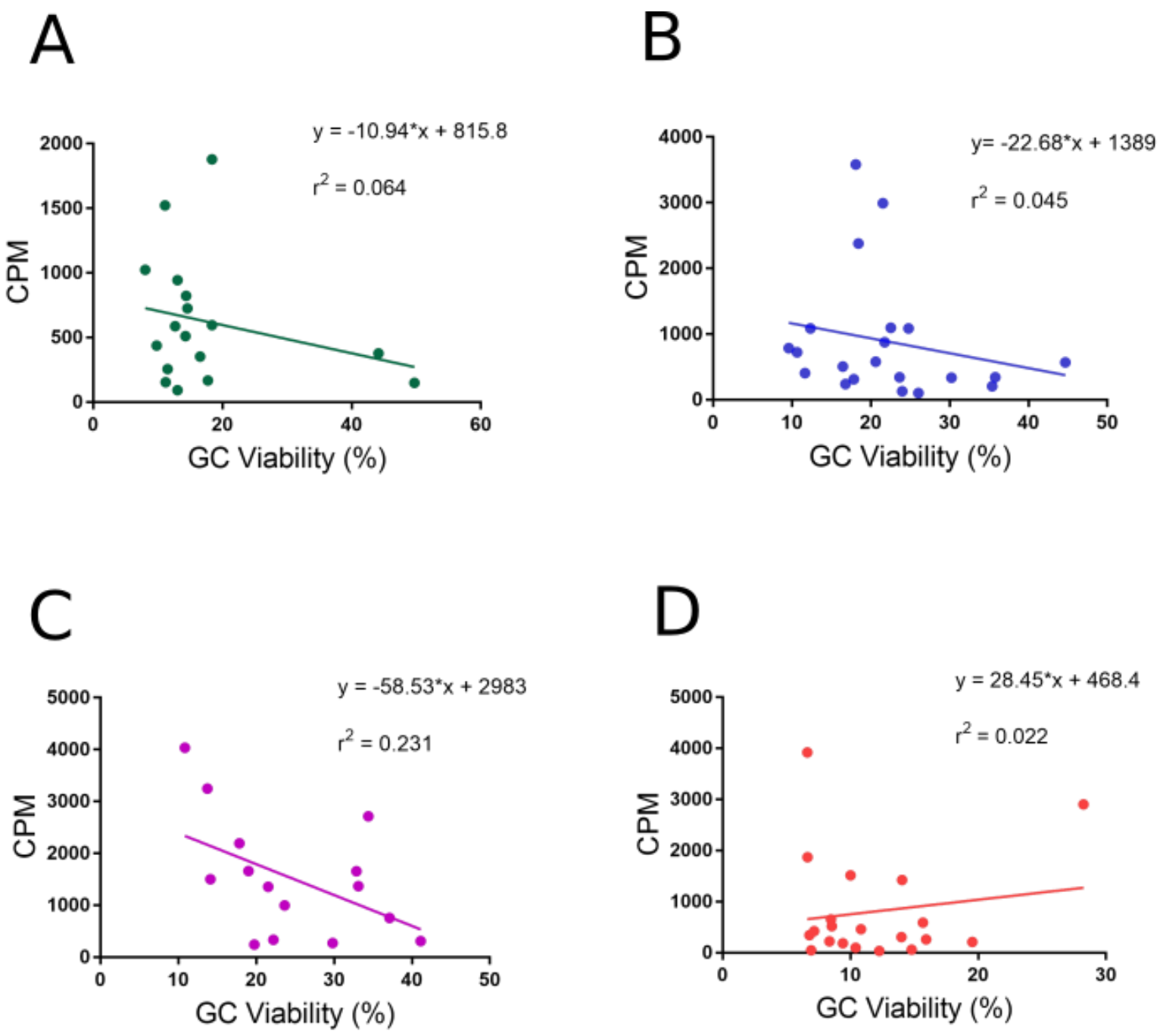

Figure 3.5.3: Correlation between GC viability and basal proliferation rate.

The correlation between the proportion of viable cells (\%) and basal proliferation rate (counts per minute; $C P M$ ) in rat (A), sheep (B), pig (C) and deer (D) GC. Each dot (circle) within each plot represents an individual replicate. $R^{2}$ values depict the coefficient of determination and measure the closeness of the data to the fitted regression line. 


\subsection{Effects of oocyte co-incubation on GC-derived gene expression}

The effects of co-incubating oocytes of the same or different (cross) species on expression levels of key genes in GC of each species were examined and are each presented below. The key genes tested were those that are responsible for the transcription of the Type I (TGFBR1, BMPRIB) and Type II (BMPR2) receptors for GDF9 and BMP15. The suitability of the chosen reference genes (RPL19, PPIA) was also examined for each species.

\subsubsection{Validation of reference genes}

Rat, sheep, pig and deer GC were co-incubated either alone or with denuded oocytes of rat, sheep, pig or deer. Comparisons between gene expression values (cycle threshold; Ct) for RPL19 and PPIA mRNA in rat, sheep, pig and deer GC samples are illustrated in Figure 3.6.1A, B, C and D, respectively.

A

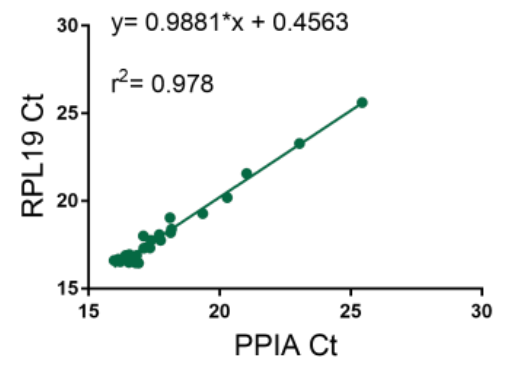

C

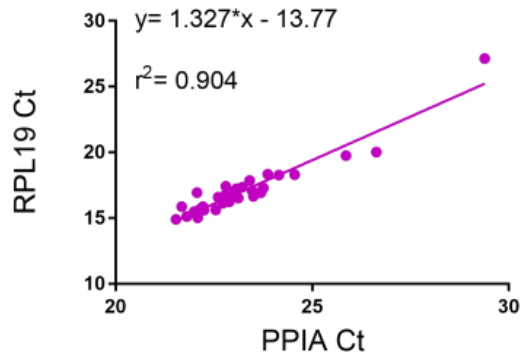

B

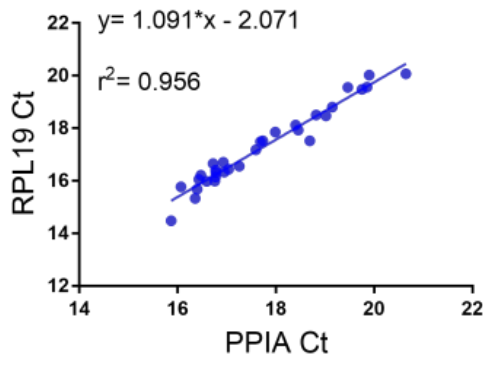

D

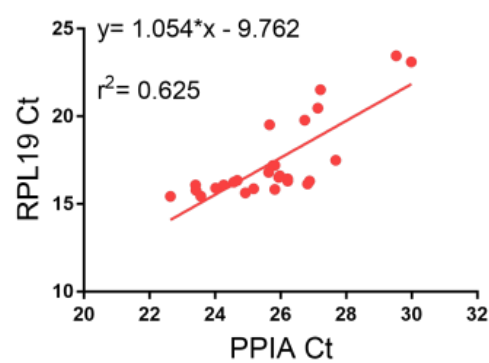

Figure 3.6.1: PPIA and RPL19 expression in rat, sheep, pig and deer GC samples.

The correlation between RPL19 and PPIA mRNA levels, expressed as a $C_{t}$ values, in rat (A), sheep (B), pig (C), or deer (D) GC samples, that have been incubated alone, or with rat, or sheep, or pig or deer denuded oocyte. Each point represents a single sample consisting of two technical replicates. $R^{2}$ values depict the coefficient of determination and measure the closeness of the data to the fitted regression line. 


\subsubsection{Relative expression of key genes in rat GCs}

The effects of co-incubating rat GC with denuded ooytes of rat, sheep, pig and deer on relative expression levels of Tgfbr1, Bmpr1b and Bmpr2 mRNA are illustrated in Figure 3.6.2. The relative expression levels of Tgfbr1 mRNA in rat GC were elevated $(\mathrm{P}<0.05)$ after co-incubation with sheep ooytes, in comparison to co-incubation with media alone or with rat, pig or deer oocytes (Figure 3.6.2A). The relative expression level of Bmpr1b mRNA in rat GC was reduced $(\mathrm{P}<0.03)$ following co-incubation with oocytes of deer, compared to that of all other species and the controls (Figure 3.6.2B). Furthermore, Bmpr1b mRNA levels of rat GC co-cultured with rat oocytes were higher $(\mathrm{P}<0.021)$ than with pig oocytes (Figure 3.6.2B), although neither differed from controls. Similarly in comparison to controls (media alone), the relative expression level of Bmpr2 mRNA in rat GC was higher $(\mathrm{P}<0.001)$ following co-incubation with rat oocytes and lower $(\mathrm{P}<0.001)$ following co-incubation with deer oocytes (Figure 3.6.2C). The co-incubation of rat GC with sheep or pig oocytes did not alter Bmpr2 mRNA levels from control values (Figure 3.6.2C).

\subsubsection{Relative expression of key genes in sheep GCs}

The effects of co-incubating sheep GC with rat, sheep, pig and deer denuded oocytes on relative expression levels of Tgfbr1, Bmpr1b and Bmpr2 mRNA are illustrated in Figure 3.6.3. The relative expression levels of Tgfbr1 mRNA in sheep GC were elevated $(\mathrm{P}<0.02)$ after co-incubation with pig oocytes, in comparison to co-incubation with media alone, or sheep or deer oocytes, but not rat oocytes (Figure 3.6.3A). The addition of oocytes of any species did not alter relative expression level of Bmpr1b mRNA in sheep GC (Figure 3.6.3B). The relative expression level of Bmpr2 mRNA in sheep GC was lower $(\mathrm{P}<0.001)$ following co-incubation with deer oocytes $(\mathrm{P}<0.05)$, compared to co-incubation with rat and sheep oocytes (Figure 3.6.3C). 

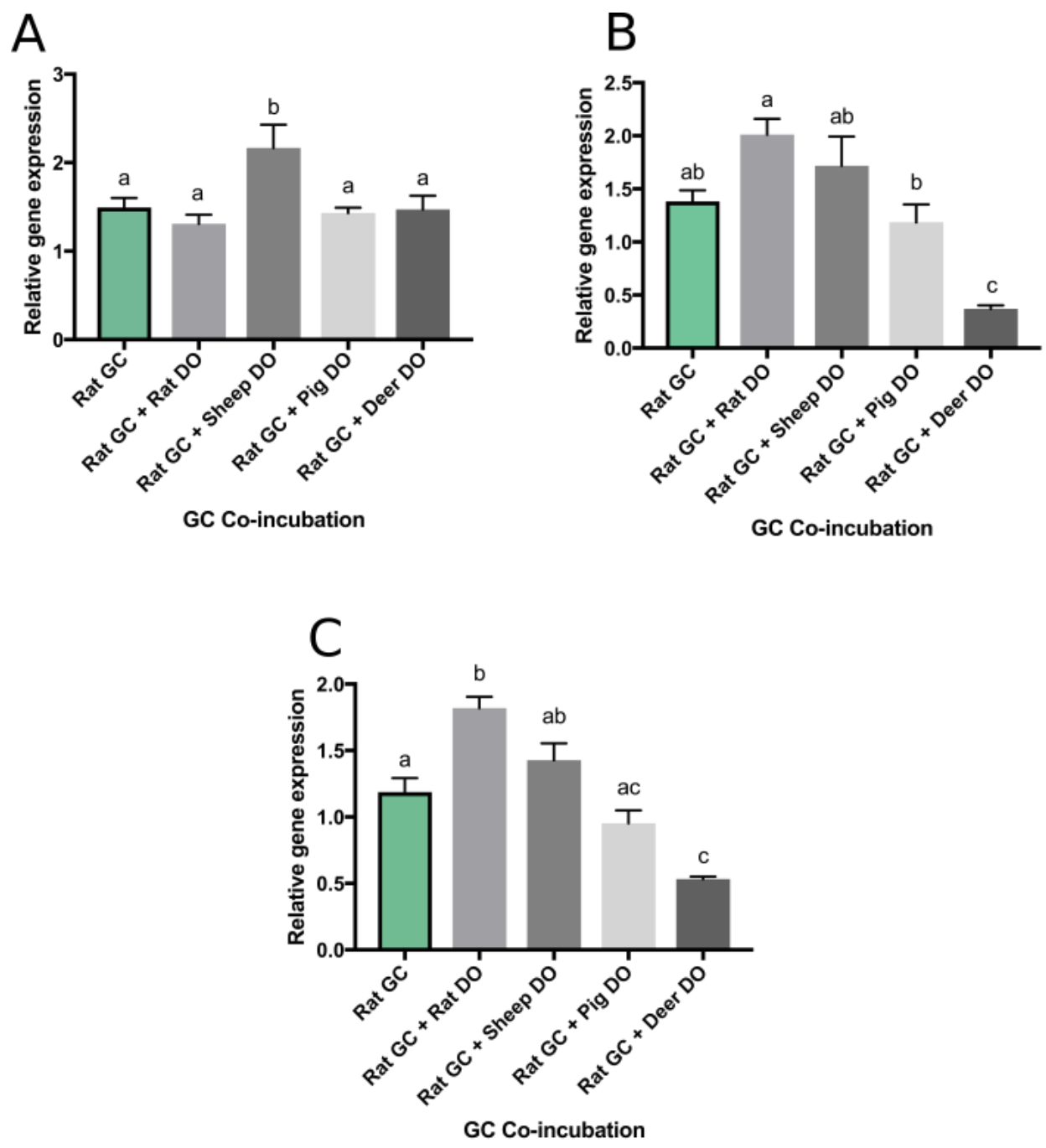

Figure 3.6.2: Gene expression levels in rat GC co-incubated with oocytes.

Mean \pm SEM values of relative expression levels of Tgfbr1 (A), Bmpr1b (B) and Bmpr2 (C) mRNA in rat GCs incubated in media alone (controls), or with rat, sheep, pig or deer denuded oocyte. Mean values represent data from five to seven replicate experiments for each GC co-incubation group. Different alphabetical superscripts on histograms denote significant differences $(\mathrm{P}<0.05)$ between rat GC incubated alone or with denuded oocyte of different species. 


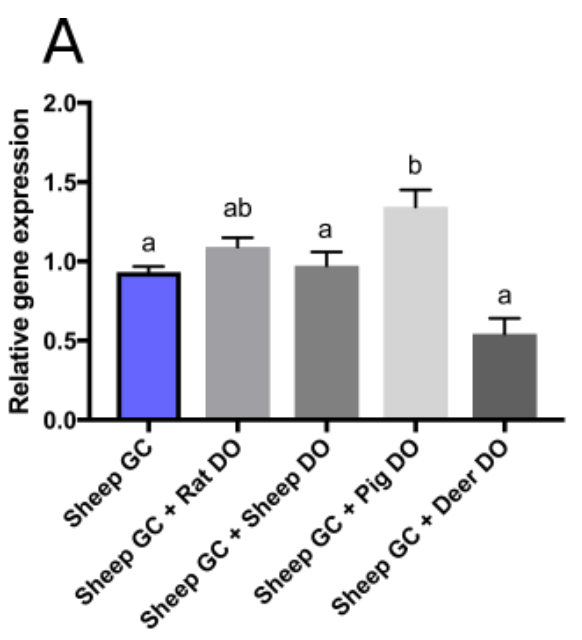

GC Co-incubation

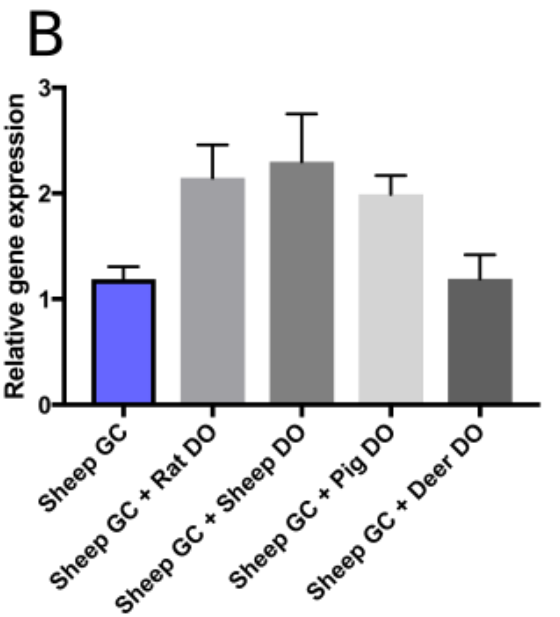

GC Co-incubation

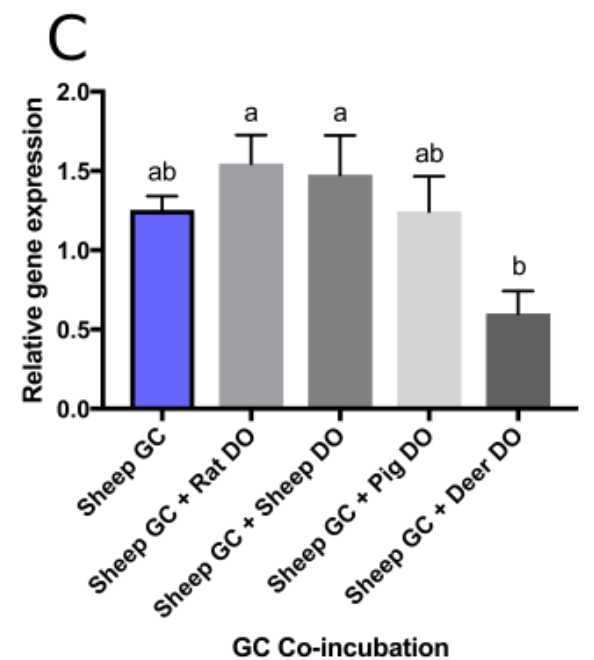

Figure 3.6.3: Gene expression levels in sheep GC co-incubated with oocytes.

Mean \pm SEM values of relative expression levels of TGFBR1 (A), BMPR1B (B) and BMPR2 (C) mRNA in sheep GC incubated in media alone (controls), or with rat, sheep, pig or deer denuded oocyte. Mean values represent data from five to seven replicate experiments for each GC co-incubation group. Different alphabetical superscripts on histograms denote significant difference $(P<0.05)$ between sheep GC incubated alone or with denuded oocyte of different species.

\subsubsection{Relative expression of key genes in pig GCs}

The effects of co-incubating pig GC with rat, sheep, pig and deer denuded oocytes on relative expression levels of TGFBR1, BMPR1B and BMPR2 mRNA are illustrated in Figure 3.6.4. The relative expression levels of TGFBR1mRNA in pig GC were higher $(\mathrm{P}<0.05)$ after co-incubation with deer oocytes, in comparison to co-incubation with media alone, or sheep oocytes, but not rat or pig oocytes (Figure 3.6.4A). The relative expression level of $B M P R 1 B$ mRNA in pig GC was higher $(\mathrm{P}<0.001)$ following co- 
incubation with pig oocytes, compared to control GC (Figure 3.6.4B). Additionally, expression levels of $B M P R 1 B$ mRNA in pig GC was markedly higher $(\mathrm{P}<0.001)$ following co-incubation with deer oocytes, compared to control GC, or pig GC co-incubated with oocytes from all other species (Figure 3.6.4B). The addition of oocytes of any species did not alter relative expression levels of BMPR2 mRNA in pig GC (Figure 3.6.4C).
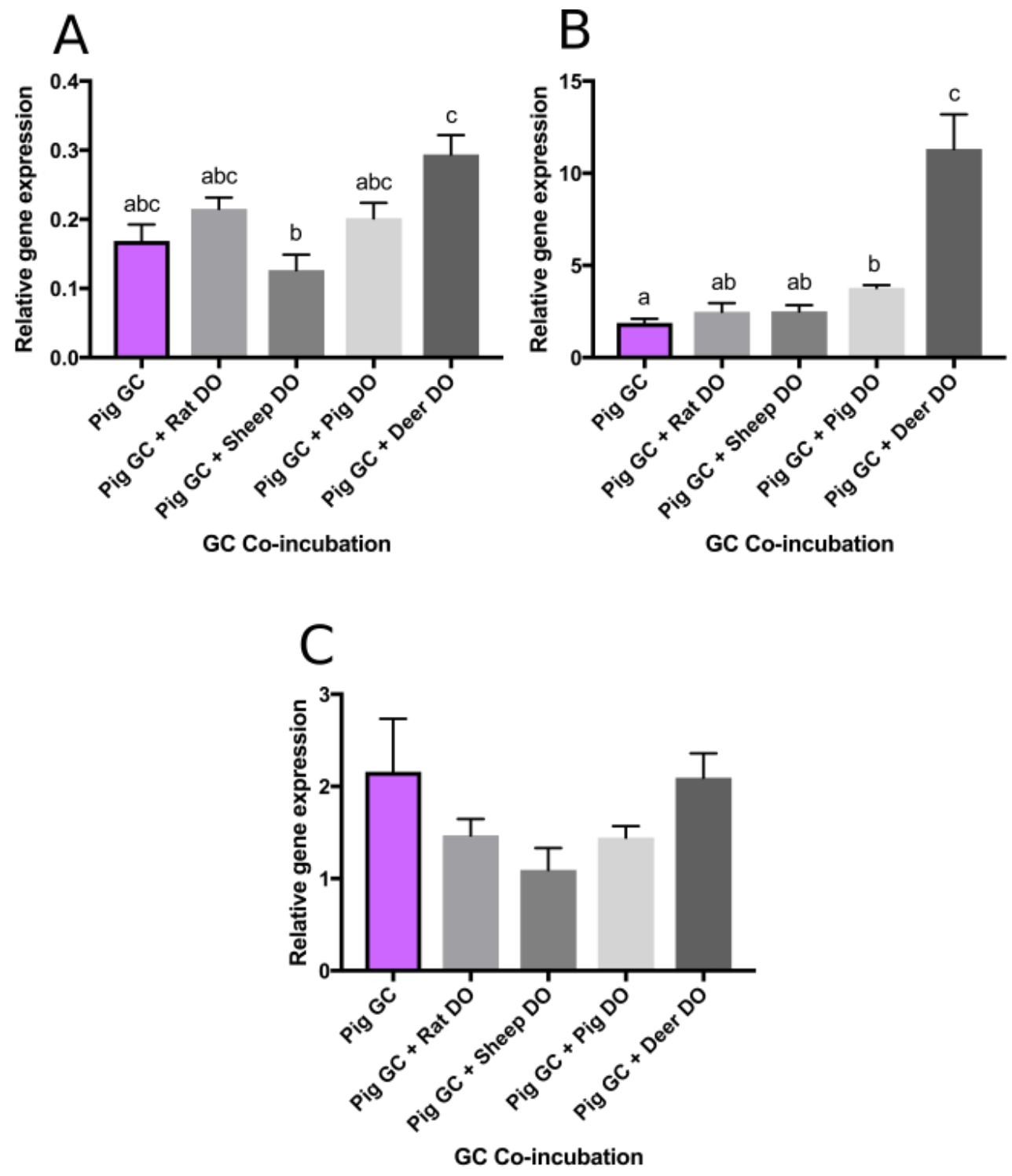

Figure 3.6.4: Gene expression levels in pig GC co-incubated with oocytes.

Mean \pm SEM values of relative expression levels of TGFBR1 (A), BMPR1B (B) and BMPR2 (C) mRNA levels in pig GC incubated in media alone (controls), or with rat, sheep, pig or deer denuded oocyte. Mean values represent data from five to seven replicate experiments for each GC co-incubation group. Different alphabetical superscripts on histograms denote significant differences $(P<0.05)$ between pig GC incubated alone or with denuded oocyte of different species. 


\subsubsection{Relative expression of key genes in deer GCs}

The effects of co-incubating deer GC with rat, sheep, pig and deer denuded oocytes on relative expression levels of TGFBR1, BMPR1B and BMPR2 mRNA are illustrated in Figure 3.6.5. The addition of rat, sheep, pig or deer oocytes to cultured deer GC did not effect expression levels of TGFBR1 or BMPR1B mRNA (Figures 3.6.5A and B, respectively). Conversely compared to control GC, the relative expression level of BMPR2 mRNA in deer GC was lower $(\mathrm{P}<0.001)$ following co-incubation with sheep or pig oocytes, but not rat or deer oocytes (Figure 3.6.5C).
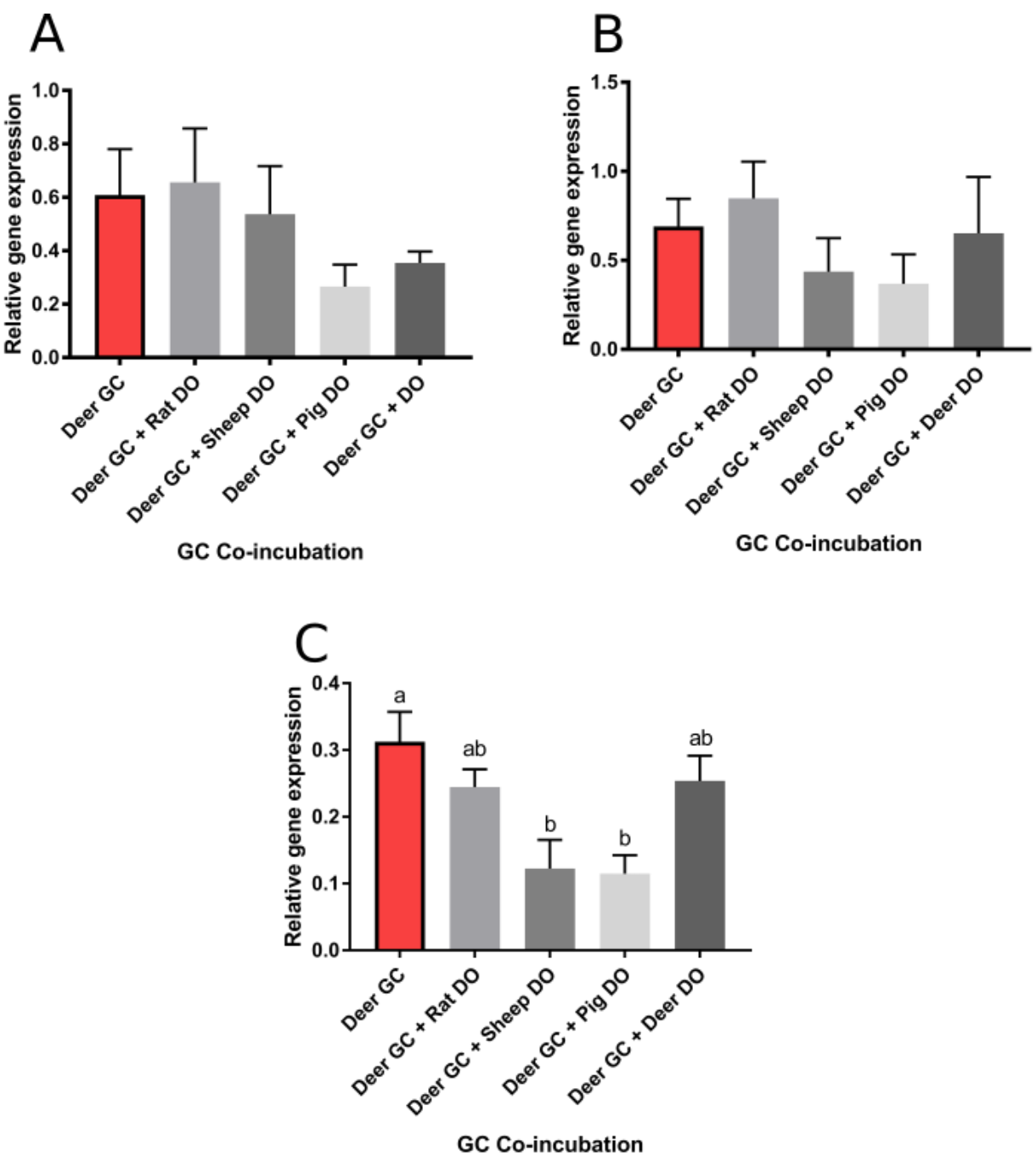

Figure 3.6.5: Gene expression levels in deer GC co-incubated with oocytes.

Mean \pm SEM values of relative expression levels of TGFBR1 (A), BMPR1B (B) and BMPR2 (C) mRNA levels in deer GC incubated in media alone (controls), or with rat, sheep, pig or deer denuded oocyte. Mean values represent data from five to seven replicate experiments for each GC co-incubation group. Different alphabetical superscripts on histograms denote significant differences $(\mathrm{P}<0.05)$ between deer GC incubated alone or with denuded oocyte of different species. 


\subsection{Effects of oocyte co-incubation on Smad protein levels in GCs}

The effects of co-incubating oocytes of the same or different (cross) species on relative Smad protein amounts in GC of each species were examined and are each presented in sub-sections below. The key Smads tested were the phosphorylated and unphosphorylated forms of Smads 2/3 and 1/5/8. The Smad protein levels presented in the graphs below are relative to the amount of the reference protein $\beta$-actin (ACTB) present. All figures presented herein (Figures 3.7.1- 3.7.4) show a representative Western blot of phosphorylated (A1) and unphosphorylated (B1) proteins, and the mean amount of phosphorylated (A2) and unphosphorylated (B2) proteins relative to ACTB protein levels from three replicate Western blots. The positions of the bands depicting the proteins of interest that were visible on the Western blots are denoted by a black box to the right side of each blot.

The negative control added to each blot consisted of secreted media from H293 cells transfected with recombinant deer GDF9. Only very faint or no bands depicting the specific proteins of interest were present on any Western blot and no corresponding densitometry results were collated.

The positive controls added to each blot were sheep GC co-incubated with H293produced recombinant deer GDF9 and deer BMP15. Previous experiments revealed that the addition of recombinant deer GDF9 and BMP15 to sheep GC cultures modestly stimulated GC proliferation rate (Bibby and Pitman, data unpublished), and were assumed to be facilitated predominantly via stimulation of the Smad2/3 and 1/5/8 pathways, respectively. In these studies, the addition of recombinant deer GDF9 and BMP15 proteins to GC of every species tested resulted in moderate to heavy bands of Smad $2 / 3$ and $1 / 5 / 8$ protein forms. Thus the prospective positive controls in these experiments were used to ensure success of the Western blotting procedure and were eliminated from the analyses. 
Several non-specific bands ( $\sim 150 \mathrm{kDa}$, and 10- $40 \mathrm{kDa})$ were observed. These bands represent unknown proteins and were denoted by a black circle to the right side of each blot.

\subsubsection{Relative Smad 2/3 protein levels in rat GCs}

Representative Western blots and mean relative densiometry results depicting the levels of phosphorylated and unphosphorylated Smad 2/3 proteins in rat GC incubated with media alone, or with rat, sheep, pig or deer oocytes are illustrated in Figure 3.7.1. The addition of oocytes, regardless of species, to rat GC cultures did not affect relative phosphorylated Smad 2/3 protein levels in rat GC (Figure 3.7.1A). The co-culture of sheep, but not rat or deer or pig, oocytes elicited an increase $(\mathrm{P}<0.05)$ in relative unphosphorylated Smad 2/3 levels in rat GC above that of rat GC cultured alone. (Figure 3.7.1B).

\subsubsection{Relative Smad 1/5/8 protein levels in rat GCs}

Representative Western blots and mean relative densiometry results depicting the levels of phosphorylated and unphosphorylated Smad1/5/8 proteins in rat GC incubated with media alone, or with rat, sheep, pig or deer oocytes are illustrated in Figure 3.7.2. The addition of oocytes, regardless of species, to rat GC cultures did not influence the relative levels of phosphorylated Smad 1/5/8 in rat GC (Figure 3.7.2A). The addition of deer oocytes to cultured rat GC increased unphosphorylated Smad $1 / 5 / 8$ levels compared to rat GC incubated with media alone $(\mathrm{P}<0.04)$, but not rat or sheep or pig oocytes (Figure 3.7.2B). 


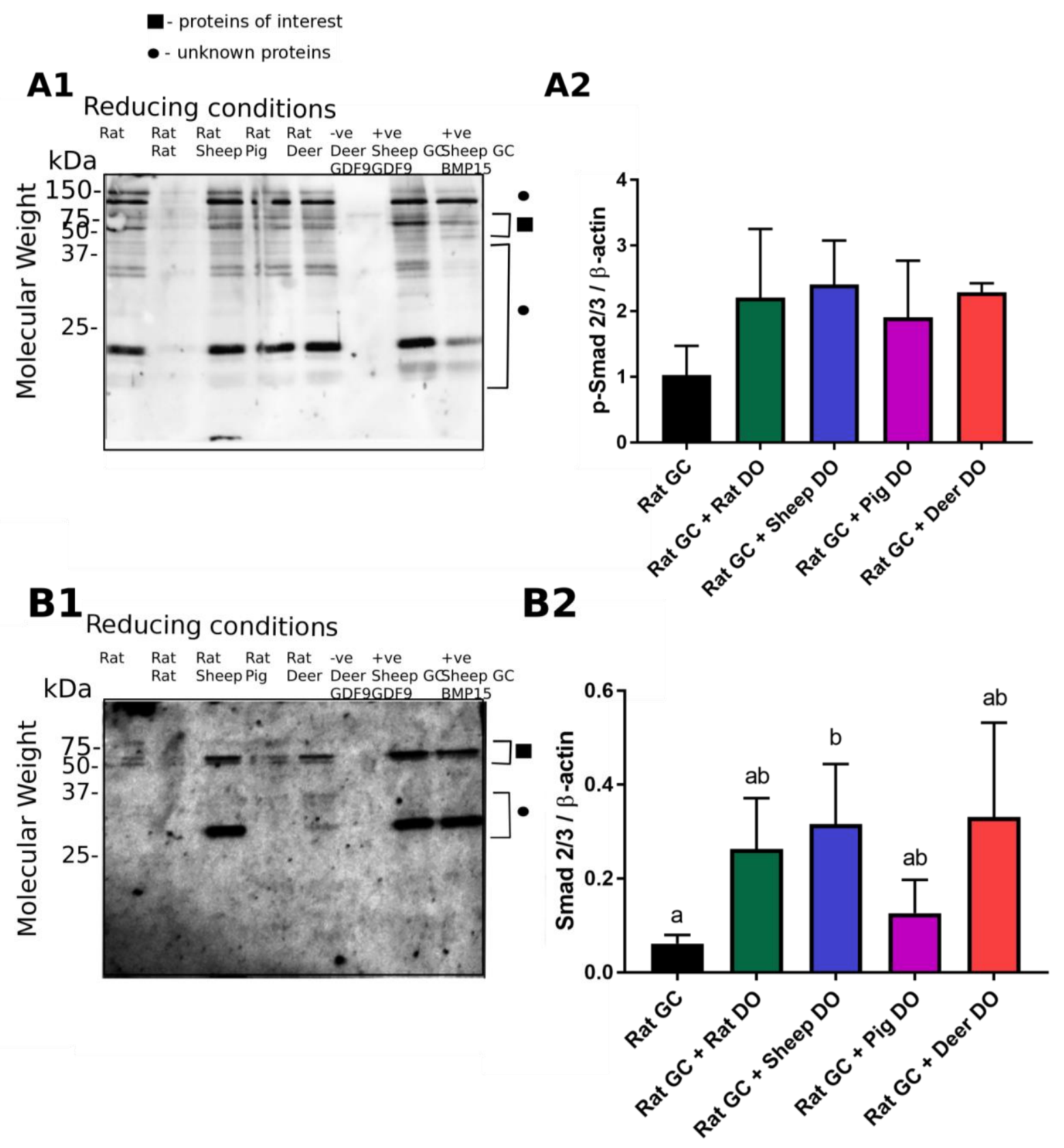

Figure 3.7.1: Smad 2/3 levels in rat GC co-incubated with oocytes.

Representative Western blots (1), and resultant plots of densiometry readings from specific proteins bands relative to ACTB bands (2) for phosphorylated (A) and unphosphorylated (B) Smad2/3 in rat GC incubated in media alone (controls), or with rat, sheep, pig or deer denuded oocyte (Lanes 1-5, respectively). Recombinant deer GDF9 was used as a negative control (Lane 6), and sheep GC treated with either recombinant deer GDF9 (Lane 7) or BMP15 (Lane 8) were used as positive controls. Blots were probed with phosphorylated (p)-Smad 2/3 antibody (A1, A2), and thereafter stripped and reprobed for Smad 2/3 antibody (B1, B2). All blots were performed under reducing conditions. A2 and B2 represent mean $\pm S E M$ values from three replicate Western blot experiments. Histograms that do not share at least one similar alphabetical superscript are significantly different $(P<0.05)$ to each other. 


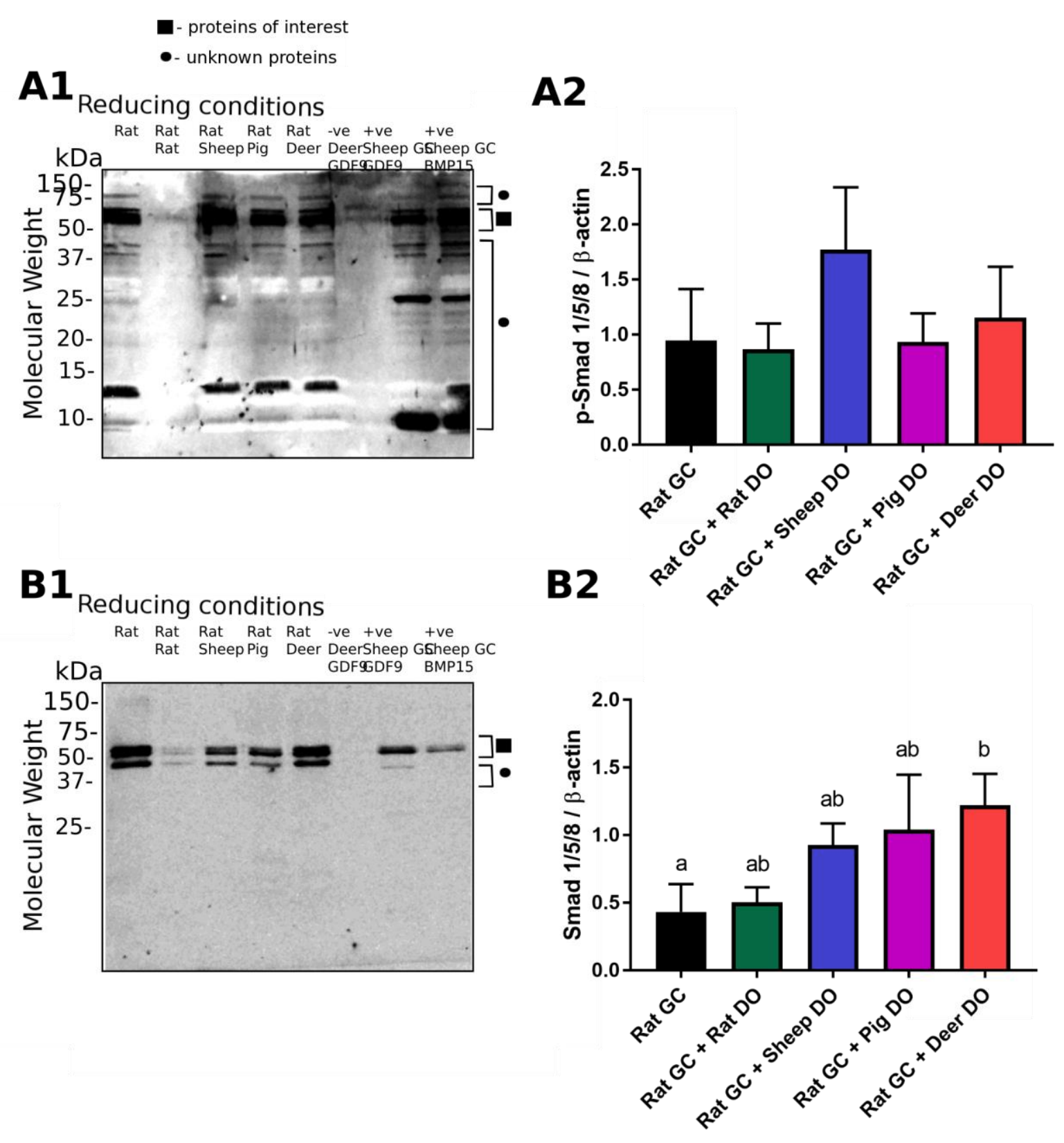

Figure 3.7.2: Smad 1/5/8 levels in rat GC co-incubated with oocytes.

Representative Western blots (1), and resultant plots of densiometry readings from specific proteins bands relative to ACTB bands (2) for phosphorylated (A) and unphosphorylated (B) Smad1/5/8 in rat GC incubated in media alone (controls), or with rat, sheep, pig or deer denuded oocyte (Lanes 1-5, respectively). Recombinant deer GDF9 was used as a negative control (Lane 6), and sheep GC treated with either recombinant deer GDF9 (Lane 7) or BMP15 (Lane 8) were used as positive controls. Blots were probed with phosphorylated (p)-Smad1/5/8 antibody (A1, A2), and thereafter stripped and reprobed for Smad1/5/8 antibody (B1, B2). All blots were performed under reducing conditions. $A 2$ and $B 2$ represent mean $\pm S E M$ values from three replicate Western blot experiments.. Histograms that do not share at least one similar alphabetical superscripts are significantly different $(P<0.05)$ to each other. 


\subsubsection{Relative Smad 2/3 protein levels in deer GCs}

Representative Western blots and mean relative densiometry results depicting the levels of phosphorylated and unphosphorylated Smad2/3 proteins in deer GC incubated with media alone, or with rat, sheep, pig or deer oocytes are illustrated in Figure 3.7.3. The addition of deer oocytes to cultured deer GC increased phosphorylated Smad2/3 protein levels above that of deer GC cultured alone ( $\mathrm{P}<0.018$ (Figure 3.7.3A). In contrast, there were no effects of oocytes, regardless of species (rat, sheep, pig, deer), on unphosphorylated Smad2/3 levels in deer GC (Figure 3.7.3B).

\subsubsection{Relative Smad 1/5/8 in deer GCs}

Representative Western blots and mean relative densiometry results depicting the levels of phosphorylated and unphosphorylated Smad1/5/8 proteins in deer GC incubated with media alone, or with rat, sheep, pig or deer oocytes are illustrated in Figure 3.7.4. The addition of oocytes, regardless of species (rat, sheep, pig or deer) to deer GC cultures did not alter phosphorylated Smad1/5/8 levels in these GC (Figure 3.7.4A). In contrast, the addition of deer, but not rat, sheep or pig, oocytes to cultured deer GC increased $(\mathrm{P}<0.012)$ unphosphorylated Smad 1/5/8 protein levels compared to deer GC cultured alone (Figure 3.7.4B). 


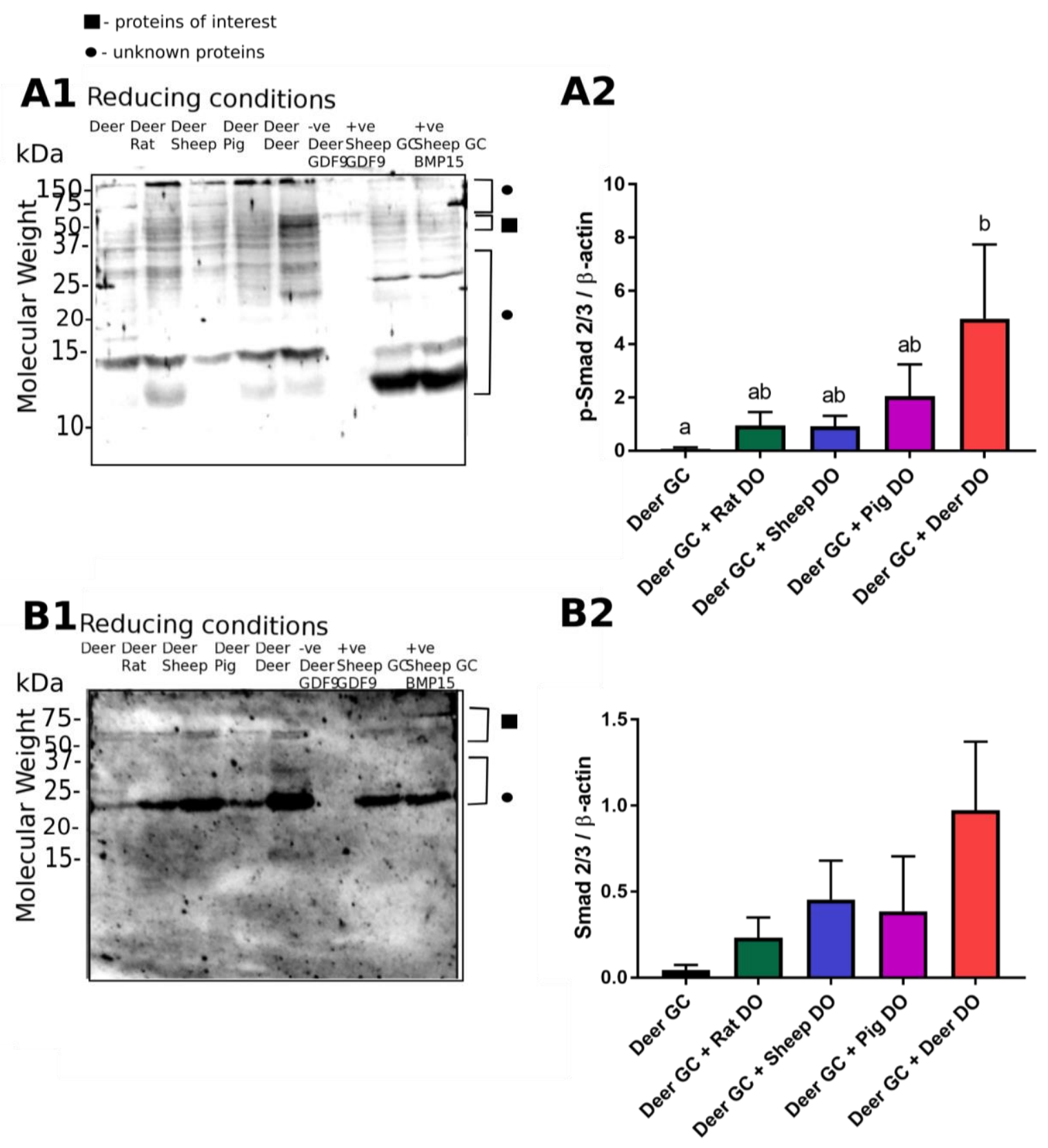

Figure 3.7.3: Smad 2/3 levels in deer GC co-incubated with oocytes.

Representative Western blots (1), and resultant plots of densiometry readings from specific proteins bands relative to ACTB bands (2) for phosphorylated (A) and unphosphorylated (B) Smad2/3 in deer GC incubated in media alone (controls), or with rat, sheep, pig or deer denuded oocyte (Lanes 1-5, respectively). Recombinant deer GDF9 was used as a negative control (Lane 6), and sheep GC treated with either recombinant deer GDF9 (Lane 7) or BMP15 (Lane 8) were used as positive controls. Blots were probed with phosphorylated (p)-Smad 2/3 antibody (A1, A2), and thereafter stripped and reprobed for Smad 2/3 antibody (B1, B2). All blots were performed under reducing conditions. A2 and $B 2$ represent mean $\pm S E M$ values from three replicate Western blot experiments. Histograms that do not share at least one similar alphabetical superscripts are significantly different $(P<0.05)$ to each other. 


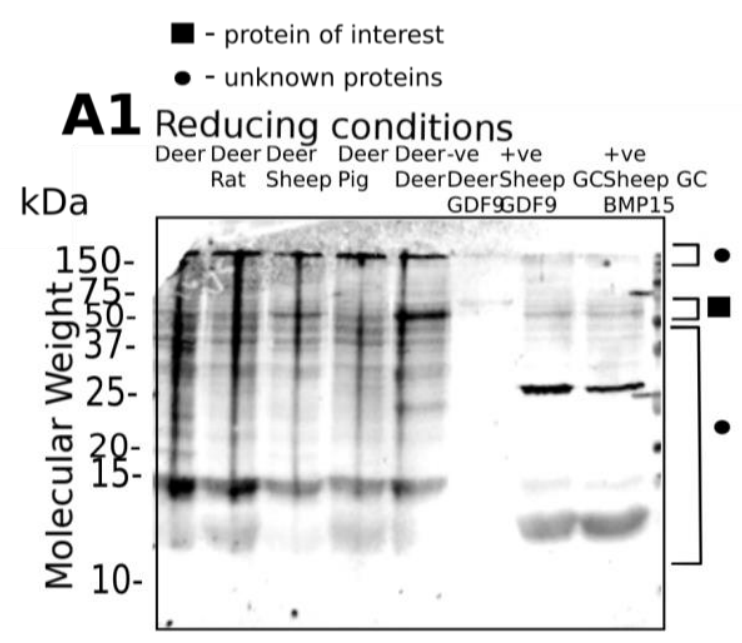

A2
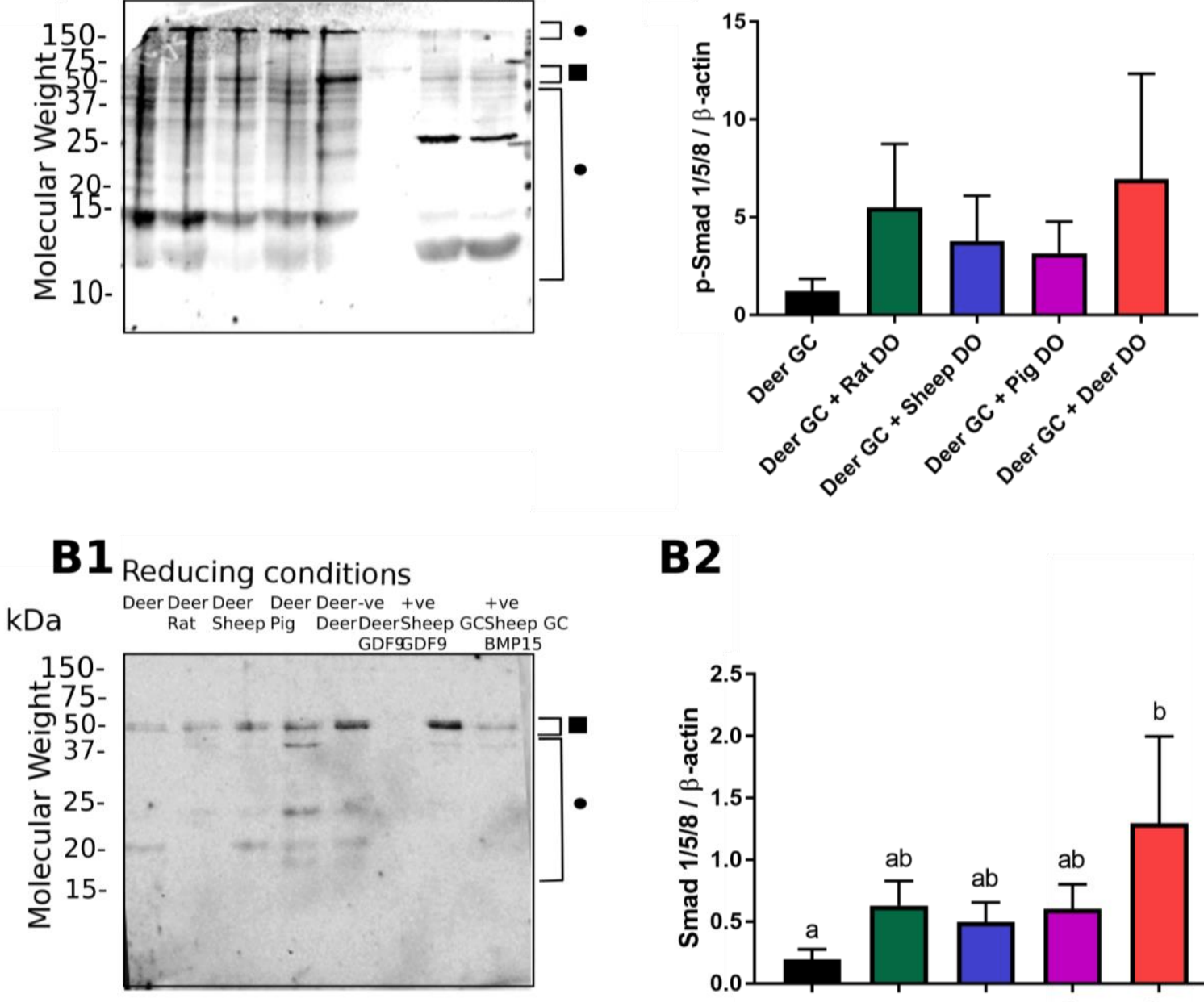

B2

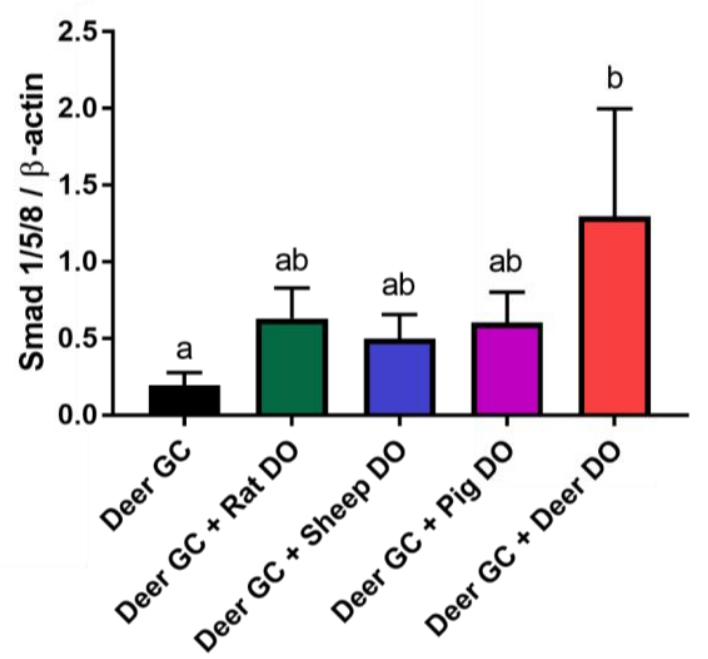

Figure 3.7.4: Smad 1/5/8 levels in deer GC co-incubated with oocytes

Representative Western blots (1), and resultant plots of densiometry readings from specific proteins bands relative to ACTB bands (2) for phosphorylated (A) and unphosphorylated (B) Smad1/5/8 in deer GC incubated in media alone (controls), or with rat, sheep, pig or deer denuded oocyte (Lanes 1-5, respectively). Recombinant deer GDF9 was used as a negative control (Lane 6), and sheep GC treated with either recombinant deer GDF9 (Lane 7) or BMP15 (Lane 8) were used as positive controls. Blots were probed with phosphorylated (p)-Smad1/5/8 antibody (A1, A2), and thereafter stripped and reprobed for Smad1/5/8 antibody (B1, B2). All blots were performed under reducing conditions. $A 2$ and $B 2$ represent mean \pm SEM values from three replicate Western blot experiments.. Histograms that do not share at least one similar alphabetical superscripts are significantly different $(P<0.05)$ to each other. 


\subsection{Validation of Smad 2/3 and Smad 1/5/8 antibodies}

Western blots containing preparations of sheep GC treated with a mixture of recombinant GDF9 and BMP15 proteins were probed with phosphorylated and unphosphorylated Smad 2/3 antibodies, resulting in the presence of specific and nonspecific bands, as illustrated in Figure 3.8A1 and B1). These bands were $\sim 78, \sim 32$ and $\sim 16 \mathrm{kDa}$ in size (Figure 3.8A1) for phosphorylated Smad 2/3, and $\sim 23 \mathrm{kDa}$ in size (Figure 3.6B1), for unphosphorylated Smad 2/3. In comparison, non-specific bands were not observed for unphosphorylated Smad 1/5/8, as illustrated in Figure 3.8C1.

All blots were stripped and reprobed with the same antibody that had been preabsorbed with its corresponding blocking peptide, as illustrated in Figures 3.8A2, B2 and C2. Upon preabsorption, the band representing phosphorylated Smad2/3 ( $\sim 52 \mathrm{kDa})$ was only very faint, whilst the bands at $\sim 16$ and $\sim 32 \mathrm{kDa}$ are still present, indicating that these bands are non-specific bands, as illustrated in Figure 3.8A2. Similarly, the $\sim 51 \mathrm{kDa}$ band, representing unphosphorylated Smad2/3 disappeared upon preabsorption, indicating the specificity of this antibody. Interestingly, the non-specific band at $\sim 23$ $\mathrm{kDa}$ also faded significantly, although it was still visible (Figure 3.8B2). As illustrated in Figure 3.8C2, the band representing unphosphorylated Smad 1/5/8 disappeared, illustrating the specificity of this antibody. 

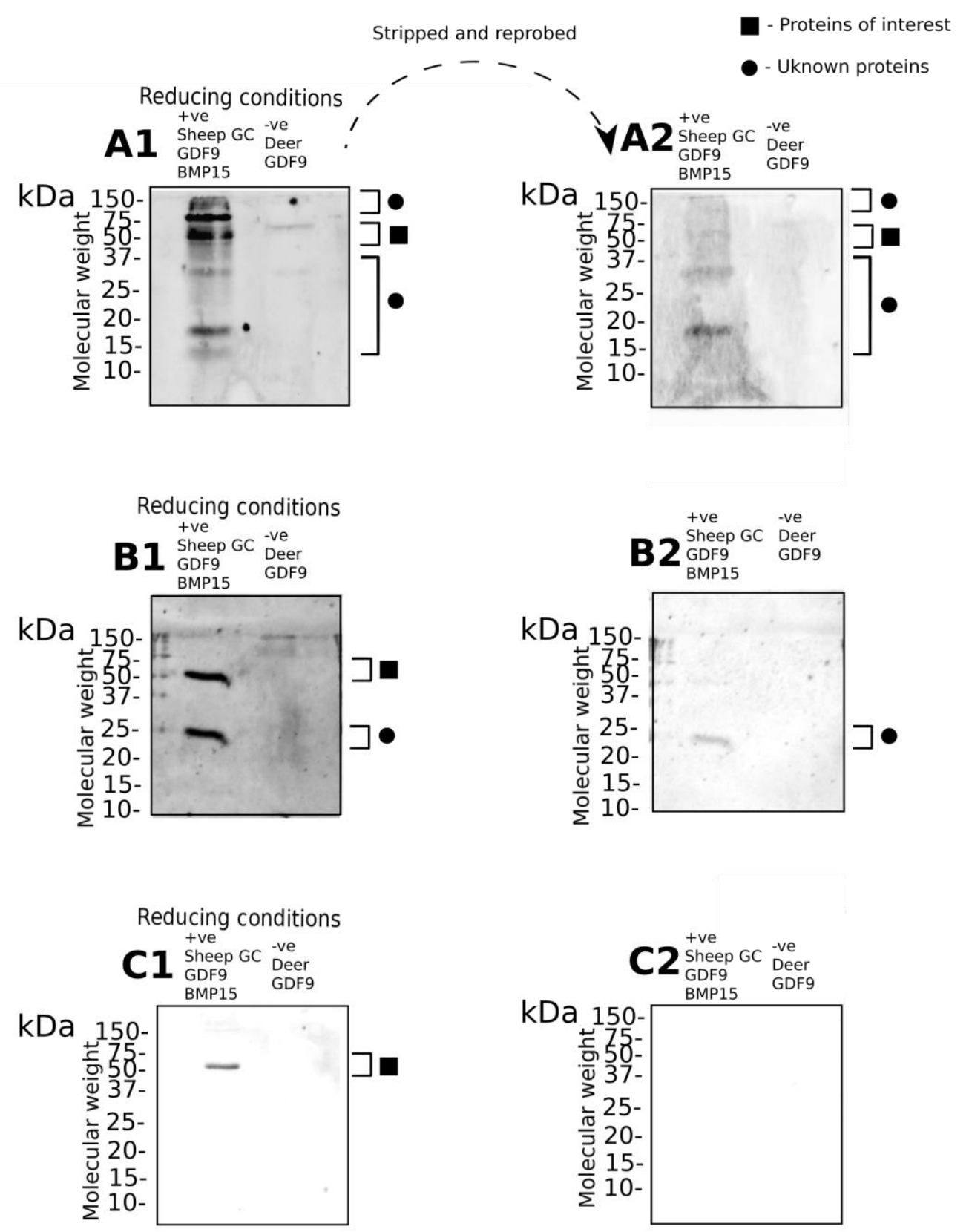

Figure 3.8: Western blots testing Smad2/3 and 1/5/8 antibody specificity.

Sheep GC cultured with recombinant deer GDF9 and BMP15 were probed with antibodies for either phosphorylated Smad2/3 (A1), Smad2/3 (B1) or Smad 1/5/8 (C1). Thereafter, membranes were stripped and reprobed with their appropriate antibodies (phosphorylated Smad 2/3 (A2), Smad 2/3 (B2) and Smad 1/5/8 (C2)) preabsorbed with their specific blocking peptides. Recombinant deer GDF9 was used as a negative control for all blots. 


\subsection{Discussion}

This is the first reported study that compares differences in the ability of OSFs from mono-ovulatory and non-rodent poly-ovulatory species to stimulate GC proliferation. This study evaluated these species differences through the cross-incubation of oocytes and GCs from rats, sheep, pigs and deer. The results described herein revealed that OSFs influenced the capacity of GC to proliferate in a species-specific manner. Additionally, the innate ability of GC to proliferate in the absence of OSF also differed between species. The downstream effects of OSF binding onto GC were also species-specific with differences observed in both the upregulation of target receptors, and activation of downstream Smad signaling pathways

The use of oocytes in this study, rather than specific recombinant proteins, allows only for speculation as to which OSFs are eliciting the proliferation of GC. Several previous studies have illustrated the multitude of factors secreted from oocytes, and the different target receptors that are expressed in GCs of different species (see Table 4.1.1 for a summary). These studies utilised various methods to quantify the protein and gene levels reported and thus, it is difficult to draw comparisons between this data and that presented herein. Furthermore, it is important to note that only a proportion of the OSFs listed in Table 4.1.1. are capable of stimulating GC proliferation. These proliferative factors include TGF $\beta$, GDF9 (Gilchrist et al, 2006, Mottershead et al, 2008, Sasseville et al, 2010), BMP15 (Gilchrist et al, 2006, Mottershead et al, 2008, Sasseville et al, 2010), BMP1 (Lei et al, 2016), BMP7 (Lee et al, 2001), and Activin A (Reader et al, 2011). However, BMP6 (Otsuka et al, 2001, Gilchrist et al, 2006) and BMP2 (Juengel et al, 2006) are not capable of eliciting a proliferative response in GC and other OSF are only proliferative in some species, for example BMP4, 6 and 7 are able to stimulate GC proliferation in rats, but not sheep (Juengel et al, 2006).

The following discussion focusses on GDF9 and BMP15 as the main OSF contributors to the GC proliferation reported herein. The rationale for this is that both recombinant 
GDF9 and BMP15 have been reported to elicit GC proliferation (Otsuka and Shimasaki, 2002, McNatty et al, 2005b, Gilchrist et al, 2006) and the immunoneutralisation of either GDF9 or BMP15 in oocyte-GC co-culture experiments revealed that GDF9 and BMP15 are responsible for a significant proportion, if not all, of GC proliferation observed upon cross-incubation of oocytes with GCs (Lin et al., 2012). For example, immunoneutralisation of GDF9 decreased the proliferation of both sheep and rat GC coincubated with rat or sheep oocytes by $50 \%$ and $100 \%$, respectively. Furthermore, the immunoneutralisation of BMP15 reduced the proliferation of sheep GCs co-incubated with sheep oocytes by over $50 \%$ (Lin et al, 2012). Thus, the immunoneutralisation of both OSFs in sheep GC co-incubated with sheep oocytes would likely completely inhibit sheep GC proliferation. 
GDF9

BMP15

BMP1

BMP2

BMP3

BMP4

BMP5
Rat: (Crawford and McNatty, 2012),

(Lin et al, 2012), (Jaatinen et al, 1999), (Hung et al, 2012)

Sheep: (Bodensteiner et al, 1999), (Crawford and McNatty, 2012), (Hung et al, 2012), (Kyasari et al, 2012), (Lin et al, 2012)

Pig: (Prochazka et al, 2004), (Zhu et al, 2008), (Paradis et al, 2009), (Sun et al, 2010), (Crawford and McNatty, 2012), (Jackowska et al, 2013)

Deer: (Crawford and McNatty, 2012)

Rat: (Erickson and Shimasaki, 2003), (Crawford and McNatty et al, 2012) Sheep: (Galloway et al, 2000), (Kyasari et al, 2012), (Lin et al, 2012)

Pig: (Zhu et al, 2008), (Paradis et al, 2009), (Sun et al, 2010), (Crawford and McNatty, 2012)

Deer: (Crawford and McNatty, 2012)

\section{Rat: unknown}

Sheep: uknown

Pig: (Lei et al, 2017)

Deer: unknown

Rat: Not expressed (Erickson and Shimasaki, 2003)

Sheep: Not expressed (Juengel et al, 2006)

Pig: (Brankin et al, 2005), (Paradis et al, 2009)

Deer: unknown

Rat: not expressed (Erickson and Shimasaki, 2003)

Sheep: unknown

Pig: unknown

Deer: unknown

Rat: not expressed (Erickson and Shimasaki, 2003)

Sheep: not expressed (Juengel et al, 2006)

Pig: expressed in ovaries (Shimizu et al, 2004)

Deer: unknown

Rat: (Pierre et al, 2005)

Sheep: unknown

Pig: expressed in ovaries (Shimizu et al, 2004)

Deer: unknown
Rat: not expressed (Jaatinen et al, 1999)

Sheep: not expressed (Bodensteiner et al, 1999)

Pig:(Prochazka et al, 2004), (Paradis et al, 2009), (Sun et al, 2010)

\section{Deer: Unknown}

Rat: not expressed (Erickson and Shimasaki, 2003)

Sheep: not expressed (Galloway et al, 2000)

Pig: (Paradis et al, 2009), (Sun et al, 2010)

\section{Deer: unknown}

\section{Rat: unknown}

Sheep: (Canty-Laird et al, 2010)

Pig: (Lei et al, 2017)

Deer: unknown

Rat: (Hung et al, 2012), (Erickson and Shimasaki, 2003)

Sheep: (Juengel et al, 2006), (Hung et al, 2012)

Pig: (Brankin et al, 2005), (Paradis et al, 2009)

Deer: unknown

Rat: not expressed (Erickson and Shimasaki, 2003)

Sheep: unknown

Pig: unknown

Deer: unknown

Rat: not expressed (Erickson and Shimasaki, 2003)

Sheep: not expressed (Juengel et al, 2006)

Pig: expressed in ovaries (Shimizu et al, 2004)

Deer: unknown

Rat: (Pierre et al, 2005)

Sheep: unknown

Pig: expressed in ovaries (Shimizu et al, 2004)

Deer: unknown 


\begin{tabular}{|c|c|c|}
\hline & Oocyte & Granulosa cells \\
\hline BMP6 & $\begin{array}{l}\text { Rat: (Erickson and Shimasaki, 2003) } \\
\text { Sheep: (McNatty et al, 2005a), } \\
\text { (Campbell et al, 2006), (Juengel et al, } \\
\text { 2006), (Kayasari et al, 2012) } \\
\text { Pig: (Brankin et al, 2005), (Zhu et al, } \\
\text { 2008), (Paradis et al, 2009) } \\
\text { Deer: unknown }\end{array}$ & $\begin{array}{l}\text { Rat: (Erickson and Shimasaki, 2003) } \\
\text { Sheep: Conflicting evidence; } \\
\text { expressed (Campbell et al, 2006), } \\
\text { not expressed (Juengel et al, 2006) } \\
\text { Pig: (Branklin et al, 2005) } \\
\text { Deer: unknown }\end{array}$ \\
\hline BMP7 & $\begin{array}{l}\text { Rat: not expressed (Erickson and } \\
\text { Shimasaki, 2003) } \\
\text { Sheep: not expressed (Juengel et al, } \\
\text { 2006) } \\
\text { Pig: unknown } \\
\text { Deer: unknown }\end{array}$ & $\begin{array}{l}\text { Rat: not expressed (Erickson and } \\
\text { Shimasaki, 2003) } \\
\text { Sheep: (Juengel et al, 2006) } \\
\text { Pig: unknown } \\
\text { Deer: unknown }\end{array}$ \\
\hline BMP9 (GDF2) & $\begin{array}{l}\text { Rat: not expressed (Hosoya et al, } \\
\text { 2015) } \\
\text { Sheep: unknown } \\
\text { Pig: unknown } \\
\text { Deer: unknown }\end{array}$ & $\begin{array}{l}\text { Rat: (Hosoya et al, 2015) } \\
\text { Sheep: unknown } \\
\text { Pig: unknown } \\
\text { Deer: unknown }\end{array}$ \\
\hline Inhibin $\alpha$ & $\begin{array}{l}\text { Rat: (Ogawa et al, 1991) } \\
\text { Sheep: not expressed (Tisdall et al, } \\
\text { 1994) } \\
\text { Pig: unknown } \\
\text { Deer: unknown }\end{array}$ & $\begin{array}{l}\text { Rat: (Woodruff et al, 1987), (Meunier et } \\
\text { al, 1988), (Ogawa et al, 1991), } \\
\text { (Drummond et al, 1996) } \\
\text { Sheep: (Tisdall et al, 1994) } \\
\text { Pig: (Wang et al, 2015) } \\
\text { Deer: unknown }\end{array}$ \\
\hline Inhibin $\beta$ A & $\begin{array}{l}\text { Rat: (Ogawa et al, 1991), (Drummond } \\
\text { et al, 1996) } \\
\text { Sheep: expressed in antral follicles } \\
\text { (Tisdall et al, 1994) } \\
\text { Pig: (Kempisty et al, 2015) } \\
\text { Deer: unknown }\end{array}$ & $\begin{array}{l}\text { Rat: (Woodruff et al, 1987), (Meunier et } \\
\text { al, 1988), (Ogawa et al, 1991), } \\
\text { (Drummond et al, 1996) } \\
\text { Sheep: expressed in antral follicles } \\
\text { (Tisdall et al, 1994) } \\
\text { Pig: (van den Hurk and van de Pavert, } \\
\text { 2001) } \\
\text { Deer: unknown }\end{array}$ \\
\hline Inhibin $\beta$ B & $\begin{array}{l}\text { Rat: (Ogawa et al, 1991), (Agca et al, } \\
\text { 2013) } \\
\text { Sheep: unknown }\end{array}$ & $\begin{array}{l}\text { Rat: (Ogawa et al, 1991), (Meunier et al, } \\
\text { 1988), (Drummond et al, 1996), } \\
\text { Sheep: unknown }\end{array}$ \\
\hline & $\begin{array}{l}\text { Pig: (Kempisty et al, 2015) } \\
\text { Deer: unknown }\end{array}$ & $\begin{array}{l}\text { Pig: (van den Hurk and van de Pavert, } \\
\text { 2001) } \\
\text { Deer: unknown }\end{array}$ \\
\hline TGF $\beta 1$ & $\begin{array}{l}\text { Rat: (Teerds and Dorrington, 1992) } \\
\text { Sheep: not expressed (Juengel et al, } \\
\text { 2004a) } \\
\text { Pig: (Jackowska et al, 2013) } \\
\text { Deer: unknown }\end{array}$ & $\begin{array}{l}\text { Rat: (Teerds and Dorrington, 1992) } \\
\text { Sheep: not expressed (Juengel et al, } \\
\text { 2004a) } \\
\text { Pig: (May et al, 1996), (Sriperumbudur et } \\
\text { al, 2010) } \\
\text { Deer: unknown }\end{array}$ \\
\hline
\end{tabular}




\begin{tabular}{|c|c|c|}
\hline & Oocyte & Granulosa cells \\
\hline TGF $\beta 2$ & $\begin{array}{l}\text { Rat: (Teerds and Dorrington, 1992), } \\
\text { (Ergin et al, 2008), (Agca et al, 2013) } \\
\text { Sheep: not expressed (Juengel et al, } \\
\text { 2004a) } \\
\text { Pig: (Jackowska et al, 2013) } \\
\text { Deer: unknown }\end{array}$ & $\begin{array}{l}\text { Rat: (Mulheron and Schomberg, 1990), } \\
\text { (Teerds and Dorrington, 1992) } \\
\text { Sheep: not expressed (Juengel et al, } \\
\text { 2004a) } \\
\text { Pig: not expressed (Sriperumbudur et } \\
\text { al, 2010) } \\
\text { Deer: unknown }\end{array}$ \\
\hline TGF $\beta 3$ & $\begin{array}{l}\text { Rat: expressed in ovaries (Rosairo et } \\
\text { al, 2008) } \\
\text { Sheep: not expressed (Juengel et al, } \\
\text { 2004a) } \\
\text { Pig: (Steffl et al, 2008), (Jackowska et } \\
\text { al, 2013) } \\
\text { Deer: unknown }\end{array}$ & $\begin{array}{l}\text { Rat: expressed in ovaries (Rosairo et al, } \\
2008 \text { ) } \\
\text { Sheep: not expressed (Juengel et al, } \\
\text { 2004a) } \\
\text { Pig: not expressed (Steffl et al, 2008) }\end{array}$ \\
\hline AMH & $\begin{array}{l}\text { Rat: not expressed (Baarends et al, } \\
\text { 1995) } \\
\text { Sheep: not expressed (Bézard et al, } \\
\text { 1988), (Campbell et al, 2012) } \\
\text { Pig: (Almeida et al, 2012) } \\
\text { Deer: unknown }\end{array}$ & $\begin{array}{l}\text { Rat: (Ueno et al, 1989), (Baarends et al, } \\
\text { 1995), (Ortega et al, 2012) } \\
\text { Sheep: (Bézard et al, 1988), (Campbell et } \\
\text { al, 2012) } \\
\text { Pig: (Almeida et al, 2012) } \\
\text { Deer: unknown }\end{array}$ \\
\hline Nodal & $\begin{array}{l}\text { Rat: not expressed (Wang et al, 2006) } \\
\text { Sheep: unknown } \\
\text { Pig: unknown } \\
\text { Deer: unknown }\end{array}$ & $\begin{array}{l}\text { Rat: (Wang et al, 2006) } \\
\text { Sheep: unknown } \\
\text { Pig: unknown } \\
\text { Deer: unknown }\end{array}$ \\
\hline $\begin{array}{l}\text { BMPR2 } \\
\text { (BRK3/T-Alk) }\end{array}$ & $\begin{array}{l}\text { Rat: (Shimasaki et al, 1999) } \\
\text { Sheep: (Wilson et al, 2001), (Bertoldo } \\
\text { et al, 2014), (Kyasari et al, 2012) } \\
\text { Pig: (Quinn et al, 2004), (Zhu et al, } \\
\text { 2008), (Paradis et al, 2009), (Quinn et } \\
\text { al, 2004), (Sun et al, 2010) } \\
\text { Deer: unknown }\end{array}$ & $\begin{array}{l}\text { Rat: (Shimasaki et al, 1999), (Erickson } \\
\text { and Shimasaki, 2003) } \\
\text { Sheep: (Chen et al, 2009), (Wilson et al, } \\
\text { 2001), (Souza et al, 2002), (Bertoldo et } \\
\text { al, 2014) } \\
\text { Pig: (Quinn et al, 2004), (Paradis et al, } \\
\text { 2009), (Quinn et al, 2004), (Sun et al, } \\
\text { 2010) } \\
\text { Deer: unknown }\end{array}$ \\
\hline $\begin{array}{l}\text { ALK1 } \\
\text { (TSR1/SKR3/A } \\
\text { CVRL1) }\end{array}$ & $\begin{array}{l}\text { Rat: unknown } \\
\text { Sheep: unknown } \\
\text { Pig: unknown } \\
\text { Deer: unknown }\end{array}$ & $\begin{array}{l}\text { Rat: (Hosoya et al, 2015) } \\
\text { Sheep: unknown } \\
\text { Pig: unknown } \\
\text { Deer: unknown }\end{array}$ \\
\hline $\begin{array}{l}\text { ALK2 } \\
\text { (TSK7L/ActRIA } \\
\text { /SKR1) }\end{array}$ & $\begin{array}{l}\text { Rat: (Drummond et al, 2002) } \\
\text { Sheep: unknown } \\
\text { Pig: unknown } \\
\text { Deer: unknown }\end{array}$ & $\begin{array}{l}\text { Rat: (Drummond et al, 2002) } \\
\text { Sheep: unknown } \\
\text { Pig: unknown } \\
\text { Deer: unknown }\end{array}$ \\
\hline $\begin{array}{l}\text { ALK3 } \\
\text { (BMPRI/BMPRI } \\
\text { A/BRK1/Tfr11/ } \\
\text { ACVRLK3) }\end{array}$ & $\begin{array}{l}\text { Rat: (Shimasaki et al, 1999), (Erickson } \\
\text { and Shimasaki, 2003) } \\
\text { Sheep: (Kyasari et al, 2012), (Bertoldo } \\
\text { et al, 2014) } \\
\text { Pig: (Zhu et al, 2008) } \\
\text { Deer: unknown }\end{array}$ & $\begin{array}{l}\text { Rat: (Shimasaki et al, 1999), (Erickson } \\
\text { and Shimasaki, 2003) } \\
\text { Sheep: (Bertoldo et al, 2014) } \\
\text { Pig: unknown } \\
\text { Deer: unknown }\end{array}$ \\
\hline $\begin{array}{l}\text { ALK4 } \\
\text { (ActRIB/ACVR1 } \\
\text { B) }\end{array}$ & $\begin{array}{l}\text { Rat: (Drummond et al, 2002) } \\
\text { Sheep: unknown } \\
\text { Pig: unknown } \\
\text { Deer: unknown }\end{array}$ & $\begin{array}{l}\text { Rat: (Drummond et al, 2002) } \\
\text { Sheep: unknown } \\
\text { Pig: unknown } \\
\text { Deer: unknown }\end{array}$ \\
\hline
\end{tabular}




\begin{tabular}{|c|c|c|}
\hline & Oocyte & Granulosa cells \\
\hline $\begin{array}{l}\text { ALK5 (TGF } \beta \\
\text { R1) }\end{array}$ & $\begin{array}{l}\text { Rat: unknown } \\
\text { Sheep: (Juengel et al, 2004a), (Kyasari } \\
\text { et al, 2012) } \\
\text { Pig: (Paradis et al, 2009) } \\
\text { Deer: unknown }\end{array}$ & $\begin{array}{l}\text { Rat: (Mazerbourg et al, 2004) } \\
\text { Sheep: (Juengel et al, 2004a), (Chen et al, } \\
\text { 2009) } \\
\text { Pig: (Paradis et al, 2009), (Sun et al, } \\
\text { 2010), (Sriperumbudur et al, 2010) } \\
\text { Deer: unknown }\end{array}$ \\
\hline $\begin{array}{l}\text { ALK6 } \\
\text { (BMPR1B) }\end{array}$ & $\begin{array}{l}\text { Rat: (Shimasaki et al, 1999), (Erickson } \\
\text { and Shimasaki, 2003) } \\
\text { Sheep: (Wilson et al, 2001), (Kyasari et } \\
\text { al, 2012), (Bertoldo et al, 2014) } \\
\text { Pig: (Quinn et al, 2004), (Zhu et al, } \\
\text { 2008), (Paradis et al, 2009), (Quinn et } \\
\text { al, 2004), (Sun et al, 2010) } \\
\text { Deer: unknown }\end{array}$ & $\begin{array}{l}\text { Rat: (Shimasaki et al, 1999), (Erickson } \\
\text { and Shimasaki, 2003) } \\
\text { Sheep: (Chen et al, 2009), (Souza et al, } \\
\text { 2002), (Bertoldo et al, 2014) } \\
\text { Pig: (Quinn et al, 2004), (Paradis et al, } \\
\text { 2009), (Quinn et al, 2004), (Sun et al, } \\
\text { 2010) } \\
\text { Deer: unknown }\end{array}$ \\
\hline ALK7 (ACVR1C) & $\begin{array}{l}\text { Rat: unknown } \\
\text { Sheep: unknown } \\
\text { Pig: unknown } \\
\text { Deer: unknown }\end{array}$ & $\begin{array}{l}\text { Rat: (Wang et al, 2006) } \\
\text { Sheep: unknown } \\
\text { Pig: unknown } \\
\text { Deer: unknown }\end{array}$ \\
\hline ActRII (ACVR2) & $\begin{array}{l}\text { Rat: unknown } \\
\text { Sheep: unknown } \\
\text { Pig: (van den Hurk and van de Pavert, } \\
\text { 2001) conflicting evidence } \\
\text { Deer: unknown }\end{array}$ & $\begin{array}{l}\text { Rat: unknown } \\
\text { Sheep: unknown } \\
\text { Pig: (van den Hurk and van de Pavert, } \\
\text { 2001) } \\
\text { Deer: unknown }\end{array}$ \\
\hline $\begin{array}{l}\text { ActRIIA } \\
\text { (ACVR2A) }\end{array}$ & $\begin{array}{l}\text { Rat: (Sadatsuki et al, 1993), } \\
\text { (Drummond et al, 2002) } \\
\text { Sheep: unknown } \\
\text { Pig: unknown } \\
\text { Deer unknown }\end{array}$ & $\begin{array}{l}\text { Rat: (Drummond et al, 2002) } \\
\text { Sheep: unknown } \\
\text { Pig: unknown } \\
\text { Deer: unknown }\end{array}$ \\
\hline $\begin{array}{l}\text { ActRIIB } \\
\text { (ACVR2B) }\end{array}$ & $\begin{array}{l}\text { Rat: (Cameron et al, 1994), } \\
\text { (Drummond et al, 2002) } \\
\text { Sheep: (Kyasari et al, 2012) } \\
\text { Pig: unknown } \\
\text { Deer: unknown }\end{array}$ & $\begin{array}{l}\text { Rat: (Cameron et al, 1994), (Drummond } \\
\text { et al, 2002) } \\
\text { Sheep: unknown } \\
\text { Pig: unknown } \\
\text { Deer: unknown }\end{array}$ \\
\hline TGF $\beta$ RII & $\begin{array}{l}\text { Rat: (MacConnell et al, 2002) } \\
\text { Sheep: not expressed (Juengel et al, } \\
\text { 2004a) } \\
\text { Pig: unknown } \\
\text { Deer: unknown }\end{array}$ & $\begin{array}{l}\text { Rat: (MacConnell et al, 2002) } \\
\text { Sheep: not expressed (Juengel et al, } \\
\text { 2004a) } \\
\text { Pig: (Sriperumbudur et al, 2010) } \\
\text { Deer: unknown }\end{array}$ \\
\hline TGF $\beta$ RIII & $\begin{array}{l}\text { Rat: (Drummond et al, 2002), (Agca et } \\
\text { al, 2013) } \\
\text { Sheep: unknown } \\
\text { Pig: unknown } \\
\text { Deer: unknown }\end{array}$ & $\begin{array}{l}\text { Rat: (Drummond et al, 2002), (Omori et } \\
\text { al, 2005) } \\
\text { Sheep: unknown } \\
\text { Pig: (Wang et al, 2015) } \\
\text { Deer: unknown }\end{array}$ \\
\hline $\begin{array}{l}\text { MIS RII } \\
\text { (AMHR2) }\end{array}$ & $\begin{array}{l}\text { Rat: not expressed (Baarends et al, } \\
\text { 1995) } \\
\text { Sheep: unknown } \\
\text { Pig: (Knapczyk-Stwora et al, 2014) } \\
\text { Deer: unknown }\end{array}$ & $\begin{array}{l}\text { Rat: (Baarends et al, 1995) } \\
\text { Sheep: (Pierre et al, 2016) } \\
\text { Pig: not expressed (Knapczyk-Stwora et } \\
\text { al, 2014) } \\
\text { Deer: unknown }\end{array}$ \\
\hline
\end{tabular}




\subsection{Proliferation assay time series}

Prior to initiation of the co-culturing experiments, it was critical to determine the timing of maximum GC proliferation after incubation with oocytes or activin A in each of the species studied. This information indicates the time taken for appreciable amounts of stimulatory factors to be secreted from the oocyte into the media to cause GC proliferation. The downside of an extended incubation time is the increasing chance that the GC will lose their GC characteristics as discussed below.

The timing of maximum GC proliferation rate following co-incubation with oocytes or activin A, relative to GCs cultured alone, occurred at 16 hours for the rat and sheep. In contrast, incubation time did not affect GC proliferation rate in pig or deer, which is likely due to high variation between replicates and in the case of the pig, a much lower fold change GC proliferation. Thus, 16 hours was selected as the optimum incubation time for all four species to allow for species comparisons.

As stated above, the increase in GC proliferation rate in the rat and sheep after 16 hours of co-culturing with oocytes is most likely due to increasing OSF concentrations, but an upregulation of their concomitant receptors in GC over time also can't be discounted. Interestingly, a previous study illustrated that sheep COCs cultured in vitro had higher BMPR1B and BMPRII mRNA expression after 27 hours, compared to 3 hours, in culture (Kyasari et al, 2012). Furthermore, mRNA levels of GDF9 and BMP15 in rat and sheep oocytes decreased after $24 \mathrm{~h}$ incubation (Lin et al, 2012). It is possible that whilst the rat and sheep cultures may exhibit changing levels of OSFs and/or receptor numbers, they remain relatively constant in pigs and deer.

Overall, an increase in GC proliferation was observed amongst all species upon oocyte co-incubation. This is presumably due to stimulation by OSF, as members of the TGF $\beta$ superfamily have been previously shown to elicit GC proliferation (Otsuka and Shimasaki, 2002, McNatty et al, 2005b, McNatty et al, 2005c, Gilchrist et al, 2006, Spicer et al, 2006). Moreover, the addition of BMP15, GDF9 or denuded oocytes to cumulus cell cultures prevented cumulus cell apoptosis (Hussein et al, 2005; Orisaka et al, 2006). Due 
to the culture of rat, sheep or pig GCs alone over time displaying a decrease in CPM, GCs may require OSFs to prevent apoptosis and elicit proliferation under the current culture conditions. Conversely, a decrease in CPM was not observed upon the culture of deer GCs alone over time. The presence of growth factors in GCs themselves has also been illustrated (see Table 4.1.1; Drummond et al, 2000, Erickson an Shimasaki, 2003, Juengel et al, 2006, Hung et al, 2012). Therefore, as deer was the only species whereby a decrease in CPM of GC was not observed with time in culture, it is possible that deer GCs secrete a factor preventing apoptosis

The high CPM values observed in unstimulated (cultured alone) GCs of pigs, compared to the other species, suggests that pig GCs secrete proliferative growth factors or have a higher mitotic rate. Interestingly, the ability of rat OSFs to stimulate rat GCs (CPM values) did not dissipate with time in culture. In contrast, the CPM values of pig GCs cocultured with oocytes markedly declined with time in culture, and those of sheep and deer showed an apparent decline although this was not significant. This may indicate that rat OSFs may either reduce luteinisation or apoptosis in rat GC.

The in vitro culture system used in this study resulted in GCs being adhered to the bottom of a plastic well in a monolayer. This does not provide an adequate 3D-scaffold and enable GC luteinisation to occur (Vigo et al, 2005), as illustrated by increased progesterone, and decreased oestradiol production (Picton et al, 1999). Moreover, the culture of GCs on plastic has been reported to decrease gap junction communication (Ben-Ze'ev and Amsterdam, 1985), with GCs dislaying a 25\% survival rate after 48 hours of culture on uncoated wells (Huet et al, 2001). The decrease with time in proliferation rate of cultured GC in this study suggests that the GCs of all species were undergoing at least a degree of luteinisation and/or apoptosis. The addition of components from the ECM, such as laminin or collagen, together with utilising 3D culture systems has been shown to promote survival in cultured GCs (Huet et al, 2001, Bellego et al, 2002, Joo et al, 2016), and may be used in the future to mimic follicular integrity and potentially decrease cell death. Additionally, a decline in GC proliferation rate with time in culture may also be attributed to the inadequate components present in the culture media. To create a media that accurately replicates follicular fluid, proteomic analysis of this 
follicular fluid could be undertaken. However, studies utilising mass spectrometry to identify follicular fluid proteins (Zamah et al, 2015), demonstrate how difficult it is to replicate the in vivo follicular environment due to the presence of hundreds of proteins in various quantities.

It is unlikely that the decrease in proliferation rate with time in culture is due to tritiated thymidine exposure. Several studies have illustrated that tritiated thymidine in cell proliferation assays causes cell cycle perturbations (Hoy et al, 1990, Solary et al, 1992, $\mathrm{Hu}$ et al, 2002), which is largely dependent on the amount of radiation and the length of exposure (Hu et al, 2002). However, in this experiment the amount and time of exposure to tritiated thymidine was kept constant at $\sim 0.4 \mu \mathrm{Ci}$ and six hours respectively. However to adequately discount this, alternative methods for measuring cell proliferation may be utilised, including adenosine triphosphate bioluminescence (Crouch et al, 1993), and fluorometric assays (Rak et al, 2015). This would also enable the comparison of intra-assay sensitivity in determining GC proliferation rate. As tritiated thymidine incorporation occurs at the $S$ phase of the cell cycle (Naito et al, 1987), the recorded CPM is likely influenced by the cell cycle stage the GCs are at, although in the current in vitro environment, it is unknown how long one GC cycle would take. To verify whether at each time point, the proportion of GCs incorporating tritiated thymidine into their DNA correlates with the number of GCs present, the expression of Ccnd2, a cell cycle transcript, could be monitored at each time point.

Activin A is a member of the TGF $\beta$ superfamily of granulosa cell origin (Knight and Glister, 2006), which activates the Smad2/3 pathway (Baker and Harland, 1996, Dennler et al, 1998). This growth factor was included as a positive control as it has been previously shown to increase proliferation of rat GC (Reader et al, 2011). In addition to eliciting GC proliferation, activin A is also involved in GC steroidogenesis (Chang et al, 2014, Chang et al, 2015) and embryo development (Kannampuzha-Francis et al, 2016). In this study, rats and sheep were the only species to show an increase in GC proliferation upon activin $\mathrm{A}$ addition, with rat GCs being more sensitive $(\sim 13$-fold versus $\sim 4$-fold increase in GC proliferation, respectively). In contrast, neither pig nor deer GC responded to activin A, and it appeared that deer GC proliferation was partially 
inhibited ( $\sim 0.8$ fold change) by activin A at 16 hours. This anti-mitogenic effect may be due to the activin A concentration used $(10 \mathrm{ng} / \mathrm{mL})$ being much higher than that observed in the deer's in vivo follicular environment, eliciting a toxic effect. The results of this in vitro culture may indicate species differences in the importance of activin $A$ in follicular development in vivo. It is important to note that in this study, human recombinant activin A was used from a Chinese hamster ovary cell line (R \& D systems), rather than the native proteins for each species. Therefore, species' differences in activin A stimulation of GC proliferation may be partially attributed to differences in homology in the ActRII/IIB receptor, whereby the recombinant activin A used had a different affinity to the receptor in each of the species.

Thus, species differences in GC proliferation were observed in GC cultured alone and with oocytes. The co-incubation of rat oocytes with rat GC caused a markedly higher proliferation ( $\sim 107$-fold), compared to deer and pig GC co-incubated with their respective oocytes. This is likely due to differences in amounts and bioactivity of the OSFs of each species' in combination with receptivity differences of GCs. Through the addition of recombinant OSFs to GC culture, it has been illustrated that different OSFs increase the uptake of tritiated thymidine to varying degrees, with activin A promoting higher murine GC proliferation compared to BMP4, FCS and a combination of GDF9 and BMP15 (Reader et al, 2011). As summarised in Table 4.1.1, oocytes from all the species tested secrete a multitude of OSFs, although little is known about the secretions of deer oocytes. These OSFs are likely to be secreted in differing amounts with differing bioactivities which are dependent on the species, and thus have varying capacities of inducing proliferation. Furthermore, the types and levels of target receptors are also likely to differ in the GCs of different species'. These species' differences in OSFs and receptors can be further studied through same and different species cross-incubations, as is discussed in Chapter 4.2 below.

\subsection{Effects of oocyte co-incubations on GC proliferation rate}

To compare the biological activity of OSFs, together with the receptivity of GC across four species that differed in ovulation rate, cross-species incubations of oocytes with GC 
were employed. The study hypothesis that differences in the types, bioactivity and/or amounts of OSFs between species would result in differences in proliferation levels was validated by comparing effects of OSFs from all species on proliferation of GC from each species. Additionally, the study hypothesis that differences in GC receptivity between species would result in differences in proliferation levels was also validated by comparing effects of OSF from each species on proliferation of GC from all species. Thus the species-specific differeneces in proliferation rate are due to both differences in bioactivity of OSFs and the receptivity of GC between species.

The proliferation rate of rat GCs after a $16 \mathrm{~h}$ incubation with OSFs (excluding deer OSFs) was higher than that of GCs of the other species tested. As discussed in the previous section, this may indicate that OSFs may either reduce luteinisation or apoptosis in rat GC. The higher mitogenicity of rat GC in response to OSF has been previously reported. A four fold increase in DNA synthesis was observed of rat GC following co-culture with GDF9 and BMP15 (McNatty et al, 2005c, Reader et al, 2011), compared to a 1.5 fold increase in sheep GC (McNatty et al, 2005b). The reason that rat GCs were more proliferative is likely due to differences in receptor expression, with rat GCs potentially expressing higher levels of target receptors in response to OSF. These results may also be indicative of what occurs in vivo. Follicular growth in rats is much faster compared to sheep (Peters and McNatty, 1980). Rapid follicular growth may be necessary in this species due to a shorter oestrous cycle ( $\sim$ days; Westwood, 2008) compared to sheep ( $\sim 16$ days; Woody et al, 1967), pigs ( $\sim 21$ days; Henricks et al, 1972$)$ and red deer $(\sim 18$ days; Guiness et al, 1971).

Another interesting observation from this study is that deer oocytes are less stimulatory, compared to other species, on rat GC proliferation rate. Deer oocytes express much lower mRNA levels of GDF9 compared to rat, sheep and pig oocytes (Crawford and McNatty, 2012). Moreover, the ratio of GDF9:BMP15 mRNA expression in deer oocytes is very low compared to that in the other species tested (rat > sheep > pig > deer). Thus, the reduced ability of deer oocytes to stimulate GC proliferation may be due to this lower abundance of the GDF9 gene. It is important to note however that the higher levels of GDF9 expression in rat and sheep oocytes in this study are unlikely to be 
solely responsible for the mitogenic effects on murine GC, as has been previously illustrated through immuno-neutralisation of this OSF (Gilchrist et al, 2004, Lin et al, 2012). Previous studies illustrate that recombinant GDF9 stimulates murine GC proliferation to a greater extent than recombinant BMP15 (Mottershead et al, 2012), and immunoneutralisation studies show that rat GC do not require BMP15 for proliferation (Lin et al, 2012). However the addition of a GDF9 antibody to a rat oocyteGC culture revealed that immunoneutralisation of GDF9 ablated oocyte-stimulated GC proliferation (Lin et al, 2012). This present study validates the mitogenic responsiveness of rat GC to high GDF9 levels compared to BMP15, as rat oocytes elicit high proliferation, and express higher Gdf9 mRNA levels, and lower Bmp15 mRNA levels compared to deer oocytes. It has been further hypothesised that BMP15 may in fact have an inhibitory effect on murine folliculogenesis, due to a reduction in mouse preantral follicle proliferation upon BMP15 culture being observed over time (Fenwick et al, 2013), whilst mutations of BMPR1B or Smads 1 and 5, increase mouse GC proliferation, ultimately leading to tumorigenesis (Middlebrook et al, 2009, Edson et al, 2010). Deer oocytes are unique in that they express negligible GDF9 mRNA levels but moderate BMP15 expression levels. Thus, murine GCs, which are known to only require GDF9 for proliferation, would be exposed to mostly BMP15 upon deer oocyte co-incubation, concomitantly stimulating murine GC proliferation to a lesser extent than oocytes from the other species.

It is well acknowledged that the addition of a combination of both GDF9 and BMP15 results in a synergistic effect on GC proliferation, in comparison to the addition of GDF9 and BMP15 separately (McNatty, 2005bc, Mottershead et al, 2012). Thus, it might be expected that any species's oocytes, that secretes appreciable amounts of both GDF9 and BMP15 would stimulate high GC proliferation The sheep and pig both express significant amounts of both Gdf9 and Bmp15 mRNA (GDF9:BMP15 ratio of 1.26 and 0.56, respectively), whilst as stated above, the rat expresses mainly Gdf9 mRNA (Gdf9:Bmp15 ratio of 3.65) and the deer expresses relatively more BMP15 mRNA (GDF9:BMP15 ratio of 0.10) (Crawford \& McNatty, 2012). Thus, it is likely that both the sheep and pig elicit the highest synergistic effect of these two growth factors. It is important to note that whilst the culture of mouse preantral follicles with BMP15 decreases follicle growth 
over time, this does not occur with the addition of GDF9 and BMP15 together, or GDF9 alone (Fenwick et al, 2013). This is in accordance with this study, which illustrated increased rat GC proliferation upon incubation with pig and sheep oocytes, which express significant amounts of both GDF9 and BMP15, and incubation with rat oocytes, which express high Gdf9 mRNA levels. In addition, this raises the possibility that activation of the Smad 2/3 pathway has highly proliferative effects on murine GC, as the synergistic actions of GDF9 and BMP15, secreted from sheep and pig oocytes, would be expected to act through the Smad 2/3 pathway (Mottershead et al, 2012), in addition to the high levels of Gdf9 in rat oocytes, which would also utilise this pathway (Mazerbourg et al, 2004). In contrast, as deer oocytes express negligible GDF9 mRNA, the relatively high BMP15 mRNA levels in deer oocytes would stimulate the Smad 1/5/8 pathway (Moore et al, 2003), which is potentially less proliferative.

In comparison, no species-specific effects were observed on proliferation of sheep, pig, or deer GC following co-culture of oocytes from any of the species tested. This may be due to the proliferation of GC being too low or variable to denote a significant species' differences in cross-species oocyte co-culture. However, given that the proliferation rate of GCs of sheep, pig and deer in response to co-incubation with deer oocytes was similar to that after co-incuation with rat, sheep and pig oocytes, this supports the notion that whilst the addition of BMP15 alone may have an inhibitory effect on GC proliferation in murine species (Fenwick et al, 2013), it has a stimulatory effect in other species. This is strongly supported by studies in sheep, whereby natural mutations in BMP15 (Davis et al, 1992, Galloway et al, 2000) or BMPR1B (Wilson et al, 2001) increased ovulation rate. In mice however, overexpression of BMP15 increases atresia in antral follicles with mice exhibiting early acyclicity. Interestingly however, litter size is not impacted in these transgenic mice (McMahon et al, 2008a).

\subsection{Baseline CPM of GC proliferation}

Examination of species differences in the baseline (i.e. unstimulated) proliferation rate of GCs after 16 hours in cultures lends an insight into differences in GC function. However several factors must be taken into consideration. 
Firstly, deer GCs had a lower viability compared to that of rat, sheep and pigs. The time taken to transport deer ovaries back to the laboratory was longer than for rat and sheep ovaries, but similar to that for the pig. Despite this, differing cell viability between species was unlikely to influence this study's results as only viable GC were counted for inclusion in the proliferation assays. This resulted in the total number of cells utilised in qPCR and western blots to differ between samples, therefore each sample was corrected against RPL19 and $\beta$-actin respectively, to correct for these differences.

Furthermore, basal GC proliferation varied across species also. Unstimulated pig GC had a higher tritiated thymidine incorporation compared to sheep GC, but similar to that of rat and deer GC. There was no correlation between GC viability and basal proliferation rate. Thus, elevated innate proliferation levels in pig GC may be due to the presence of growth factors within the cell culture system, that affect pig, but not sheep, GCs. This may be due to differences in secreted growth factors from pig GC or a factor in the media in which pig GC are more receptive to. The expression of GDF9 and BMP15 mRNA is confined to the oocyte in sheep and rats (Bodensteiner et al, 1999, Galloway et al, 2000, Crawford et al, 2012, Laitinen et al, 1998, Mester et al, 2014) but numerous reports indicate that pig GC also expression of GDF9 and BMP15 mRNA (Prochazka et al, 2004, Paradis et al, 2009). It is currently not known whether deer GCs express GDF9 and BMP15 mRNA, however deer cumulus cells do not (Crawford et al., 2012). Therefore, if GDF9 and BMP15 are expressed in pig GC, these growth factors will stimulate proliferation in the absence of oocytes. Alternatively, growth factors such as IGF1 and $E G F$ are also expressed in pig GC (Silva et al, 2011), and have been shown to stimulate GC proliferation (Baranao and Hammond, 1984, Buck and Schomberg, 1988, Gospodarowicz et al, 1977, Mao et al, 2004). As GC proliferation was deduced as a fold change relative to baseline GC proliferation, high basal proliferation levels in GC of pigs influences the calculated fold change such that the pig GCs have a low proliferation rate following oocyte co-culture, in comparison to other species. Therefore, this low fold change may not be only due to pig oocyte secreted factors being unable to elicit proliferation as effectively as other species' oocyte secreted factors, but rather due to growth factors secreted by pig GCs raising the baseline levels. 


\subsection{Relative expression of key genes in GCs}

Species-specific effects of OSF on the transcriptional regulation of target receptors in GCs was also investigated in this study. Cross-species co-cultures of oocytes and GC showed that OSF from different species, elicited species-specific affects on the expression levels of GC-derived type I and type II receptors for GDF9 and BMP15. Despite this, the three receptors investigated in this study, TGF $\beta R 1$, BMPR1B and BMPR2, are bound and activated by a number of ligands. In addition to GDF9, the ligands for TGF $\beta R 1$ include GDF8, GDF11, TGF $\beta 1$ and TGF $\beta 2$ (Goumans et al, 2003, Rebbapragada et al, 2003, Mazerbourg et al, 2004, Kaivo-Oja et al, 2005, Andersson et al, 2006, Townsend et al, 2011). Conversely, in addition to BMP15, the ligands for BMPR1B include GDF5, GDF6, GDF7, BMP4, BMP10 and AMH (ten Dijke et al, 1994, Nishitoh et al, 1996, Gouedard et al, 2000, Wilson et al, 2001, Mazerbourg et al, 2005). Furthermore, BMPR2 binds several ligands including GDF9, BMP15, inhibins, BMP2, BMP4, BMP6, BMP10, GDF2, GDF5, GDF6 and GDF7 also display an affinity for BMPR2 (Nohno et al, 1995, Ebisawa et al, 1999, Vitt et al, 2002, Moore et al, 2003, Wiater et al, 2003, Mazerbourg et al, 2005, Scharpfenecker et al, 2007, Kirkbride et al, 2008). For ease of species comparisons in this study, the gene expression results for the target receptors are summarised in Table 4.4.1, 4.4.2 and 4.4.3.

Table 4.4.1: The effect of oocytes on TGF $\beta R 1$ mRNA levels in GCs in monoovulatory and poly-ovulatory species. Values are relative to GC cultured alone.

\begin{tabular}{|c|c|ccccc|}
\hline \multirow{4}{*}{ GCs } & \multicolumn{5}{c|}{ Oocytes } \\
\cline { 2 - 6 } & \multirow{4}{*}{ Rat } & Rat & Sheep & Pig & Deer \\
\cline { 3 - 6 } & Sheep & - & $\uparrow$ & - & - \\
& Pig & - & - & $\uparrow$ & - \\
& Deer & - & - & - & $\uparrow$ \\
& & - & - & - & - \\
\hline
\end{tabular}


Table 4.4.2: The effect of oocytes on BMPR1B mRNA levels in GCs in monoovulatory and poly-ovulatory species. Values are relative to GC cultured alone.

\begin{tabular}{|c|c|cccc|}
\hline \multirow{4}{*}{ GCs } & \multicolumn{5}{c|}{ Oocytes } \\
\cline { 2 - 6 } & & Rat & Sheep & Pig & Deer \\
\cline { 2 - 6 } & Rat & - & - & - & $\downarrow$ \\
& Sheep & - & - & - & - \\
& Pig & - & - & $\uparrow$ & $\uparrow \uparrow$ \\
& Deer & - & - & - & - \\
\hline
\end{tabular}

Table 4.4.3: The effect of oocytes on BMPR2 mRNA levels in GCs in mono-ovulatory and poly-ovulatory species. Values are relative to GC cultured alone.

\begin{tabular}{|c|cccccc|}
\hline \multirow{4}{*}{ GCs } & \multicolumn{5}{c|}{ Oocytes } \\
\cline { 2 - 6 } & & Rat & Sheep & Pig & Deer \\
\cline { 2 - 6 } & Rat & $\uparrow$ & - & - & $\downarrow$ \\
& Sheep & - & - & - & - \\
& Pig & - & - & - & - \\
& Deer & - & $\downarrow$ & $\downarrow$ & - \\
\hline
\end{tabular}

In rat GCs, $T g f \beta r 1$ mRNA levels increased upon the co-incubation of sheep oocytes, whilst in sheep GCs, TGF $\beta R 1$ mRNA levels increased upon the co-incubation of pig oocytes. As previously mentioned, the synergistic effects of GDF9 and BMP15, in addition to the biological effects of GDF9 alone, both utilise TGF $\beta R 1$ as their receptor (Mazerbourg et al, 2004, Kaivo-Oja et al, 2005, Mottershead et al, 2012). Thus rat and sheep GCs, in response to sheep and pig oocytes, which are both known to express appreciable levels of both GDF9 and BMP15 (Crawford and McNatty, 2012), may be responding to the synergistic action of these two OSFs by increasing TGF $\beta R 1$ expression. It is interesting to note however, that mouse preantral follicles treated with both GDF9 and BMP15 displayed a decrease in $T g f \beta r 1$ expression (Fenwick et al, 2013), which is not in accordance with this study's results in murine GCs. As this study utilised oocytes, rather than recombinant proteins, affinity differences in the binding of recombinant and native proteins, or interactions between GDF9, BMP15 and other expressed OSFs in sheep oocytes may cause these result disparities. The increase in TGF $\beta R 1$ mRNA levels in rat and sheep GCs, upon the respective co-incubation of sheep and pig oocytes may 
potentially lead to a concomitant increase in the Smad 2/3 signaling pathway, which has been previously suggested to be highly proliferative.

Interestingly, TGF $\beta R 1$ expression in pig GCs increased upon deer oocyte co-incubation. As deer oocytes have a low abundance of GDF9 mRNA, several other OSFs secreted by deer oocytes, and known to signal through this receptor may be eliciting increased TGF $\beta R 1$ mRNA levels. In contrast to other species, pig GCs express GDF9 (Paradis et al, 2009), which may be acting synergistically with BMP15 secreted from deer oocytes via TGF $\beta$ R1, thus eliciting an increase in mRNA levels. Although pig and sheep oocytes express relatively higher $B M P 15$ mRNA levels than deer oocytes, this may implicate an increased bioactivity of deer BMP15, or an increased ability of this species' OSF to synergistically interact with pig GDF9.

A reduction in Bmpr1b mRNA levels was observed in rat GCs upon the co-incubation with deer oocytes. Conversely, whilst rat oocytes appeared to increase Bmpr1b mRNA levels, this did not reach significance. Whilst rat oocytes express $G d f 9$, and negligible Bmp15, deer oocytes express BMP15 and negligible GDF9 (Crawford and McNatty, 2012). In vivo, rat GCs would not usually be exposed to BMP15 alone. Thus, rat GCs may respond to treatment with $B M P 15$ alone, from deer oocytes, by reducing $B m p r 1 \mathrm{~b}$ expression, which is in accordance with a study whereby treatment of mouse preantral follicles with BMP15 elicited a trend in decreased Tgfßr1 expression (Fenwick et al, 2013). Murine GCs may respond in such a manner to concomitantly decrease downstream Smad 1/5/8 signaling. Whilst the sheep and pig express higher BMP15 levels than the deer, there is a disparity between these species, as sheep and pig oocytes also express significant amounts of GDF9. Thus GDF9 and BMP15 levels from pig and sheep oocytes would activate the Tgf $\beta r 1$ receptor, rather than Bmpr1b.

In contrast to both rat and pig GCs, sheep and deer GCs did not display altered BMPR1B mRNA levels in response to oocyte co-cultures. In pig GCs, co-cultures with pig oocytes increased $B M P R 1 B$ mRNA levels above baseline, whilst deer oocytes dramatically increased $B M P R 1 B$ expression. In particular, this may be an indication of pig GCs 
responding to $B M P 15$ secreted by deer and pig oocytes, through increased $B M P R 1 B$ mRNA levels, and potentially a concomitant increase in Smad 1/5/8 signaling. Low proliferation levels were observed throughout this study when utilising pig GCs, which may be due to this species' innate response to increase BMP15 signaling.

Bmpr2 expression increased in rat GC upon rat oocyte co-incubation, and conversely decreased upon deer oocyte co-incubation. As rat oocytes express Gdf9, whilst deer oocytes express BMP15, this may be indicative of $B m p r 2$ expression to decrease in murine GC upon exposure to BMP15 alone and conversely increase Bmpr2 expression upon exposure to Gdf9 alone. Furthermore, sheep GCs co-incubated with rat oocytes displayed higher BMPR2 mRNA levels compared to those co-incubated with deer oocytes. These results are in accordance with a previous study, which illustrated that GDF9 increases Bmpr2 mRNA levels in murine and ovine GC to a greater extent than BMP15. However, due to large replicate variation, differences in receptor expression with these two different oocyte secreted factors did not reach significance (J Hutchison, personal communication). As deer oocytes elicited less proliferation in murine GC compared to other species, this may be indicative of a correlation between $\mathrm{Bmpr} 2$ expression, and the murine GCs capacity of proliferation.

In contrast to this, $B M P R 2$ expression was not affected in pig GC upon co-incubation with oocytes from any species. Furthermore, the co-incubation of sheep and pig oocytes with deer GC decreased BMPR2 expression below that of deer GC incubated alone. In its natural follicular environment in vivo, deer oocytes express negligible GDF9, and lower BMP15 mRNA levels than sheep and pig oocytes and thus BMPR2 may not have copious amounts of OSFs activating this receptor. Therefore, in this in vitro culture system, deer GCs may respond to these high levels of both GDF9 and BMP15 from sheep and pig oocytes by decreasing receptor availability. This is supported by the fact that deer oocytes did not decrease BMPR2 expression in deer GC, as was observed in rat and sheep GCs. 


\subsection{Effects of oocyte co-incubation on Smad protein levels in GCs}

To determine the signaling pathways involved in the species-specific actions of OSF on GC proliferation, Smad protein levels were investigated. The same- and cross-species coculture of oocytes with rat or deer GC resulted in the differential upregulation of phosphorylated and unphosphorylated Smad protein levels. This is in accordance with the hypothesis that the cross-species co-incubation of oocytes with GC would differentially stimulate the Smad $2 / 3$ and Smad $1 / 5 / 8$ pathways in GC, due to the secretion of varying levels, forms and bioactivities of factors secreted by monoovulatory and poly-ovulatory species' oocytes. Whilst GDF9 is known to stimulate the phosphorylation of Smad 2/3 (Mazerbourg et al, 2004), conversely BMP15 is reported to stimulate the phosphorylation of the Smad 1/5/8 pathway (Moore et al, 2003). Furthermore, as previously stated, different species' oocytes secrete several other oocyte-secreted factors (as summarised in Table 4.1.1), which are known to differentially stimulate either the Smad 2/3 or Smad 1/5/8 pathway.

Unfortunately due to time constraints, the GCs from every species could be not tested. Rat GCs were utilised for these experiments as they exhibited the highest between species variation in proliferation elicited by OSF and are known to only require GDF9 for this proliferative effect. Conversely, deer GCs were also selected due to the fact that deer oocytes express predominantly BMP15 mRNA and thus, it is hypothesised that deer GCs may only require BMP15 to proliferate.

Interestingly in this study, the addition of oocytes (regardless of species) did not affect the levels of either phosphorylated Smad proteins (either p-Smad 2/3 or p-Smad1/5/8) in rat GC. However, the addition of sheep oocytes increased the unphosphorylated Smad 2/3 levels compared to rat GC cultured alone. This observation supports the previous finding that sheep oocytes up-regulated Tgfbr1 mRNA expression, which is the type 1 receptor for GDF9. Thus, this receptor up-regulation occurs concomitantly with an upregulation of the Smad signaling pathway for GDF9 (i.e. Smad 2/3). Moreover, as mentioned previously sheep oocytes express significant amounts of both GDF9 and BMP15 (Crawford and McNatty, 2012), which cooperatively act through the Smad 2/3 
pathway (Reader et al, 2011). Upon comparison of the relative GDF9 mRNA levels between the studied species, pig oocytes display the highest expression, followed by sheep, rat and deer. Thus, although pig oocytes display higher GDF9 mRNA levels, known to utilise the Smad 2/3 pathway, compared to sheep oocytes, the latter species increased Smad 2/3 levels whilst pig oocytes did not. This however does not take into account the potential variation in bioactivity of GDF9 and BMP15 across species, which would also influence their ability to activate the Smad 2/3 pathway. Whilst GDF9 and BMP15 are known to be responsible for a high proportion of mitogenicity in sheep and rat GCs (Lin et al, 2012), several other OSFs may be increasing Smad 2/3 signaling, such as the activins, TGF $\beta$ s, GDF1, GDF8, GDF9, GDF11 and GDF15 (Baker and Harland, 1996, Nakao et al, 1997, Dennler et al, 1998, Oh et al, 2002, Rebbapragada et al, 2003, Xu et al, 2006). Conversely, although rat oocytes appeared to increase Smad 2/3 levels, this did not reach significance, and may be due to the relatively lower $G d f 9$ expression compared to sheep oocytes. However, GDF9 also stimulates the MAPK pathway (Su et al, 2002, Sasseville et al, 2010) in addition to the Smad 2/3 pathway. Thus, rat oocytes would potentially activate this pathway also, and perhaps to a greater extent than the Smad $2 / 3$ pathway.

Interestingly, deer oocytes stimulated the phosphorylation of Smad 2/3 proteins in deer GC cultures, despite the extremely low levels of GDF9 mRNA expressed in deer oocytes. The ability of deer oocytes to activate Smad 2/3 phosphorylation, whilst other species do not, suggests species differences in receptivity of GC, causing a species-specific affinity of deer OSFs to their native receptors, thus eliciting Smad phosphorylation. In addition to the BMP15 expressed in deer oocytes, it is plausible these oocytes also express higher levels of other OSFs that are capable of stimulating Smad 2/3 in deer GC. . It is interesting to note that of the four species studied, pig oocytes express the highest relative amount of GDF9 mRNA. Although it appears pig oocytes also slightly increased phosphorylated Smad 2/3 levels in deer GCs, this did not reach significance, further suggesting differences in the bioactivity of GDF9 between species and/or differences in OSF affinity to deer GC receptors. 
The effects of OSFs on unphosphorylated Smad 1/5/8 levels were also species-specific, with deer oocytes stimulating higher Smad 1/5/8 levels in rat GC. As mentioned previously, whilst sheep and pig oocytes express higher BMP15 mRNA levels than deer oocytes, there is a disparity between these species, as sheep and pig oocytes also express significant amounts of GDF9. In contrast, deer oocytes express almost only BMP15 (Crawford and McNatty, 2012), known to utilise the Smad 1/5/8 pathway (Moore et al, 2003), thus validating this study's findings. It is interesting to note that pig oocytes express higher relative levels of BMP15 mRNA, than sheep or rat oocytes (Crawford and McNatty, 2012), which is in agreement with this study's results, whereby there was a trend in pig oocytes stimulating higher Smad 1/5/8 levels, although this did not reach significance. Moreover, deer oocytes also stimulated unphosphorylated Smad 1/5/8 protein levels in deer GC cultures, illustrating that the BMP15 from deer oocytes, which is likely eliciting this increase in Smad 1/5/8 is not influenced by a difference in species' GCs. This may illustrate minimal variation in the protein abundance of BMPR1B between rat and deer GC, in addition to minimal differences in the affinity of deer BMP15 to this receptor. Interestingly, co-incubation of deer oocytes with rat GC increased Smad 1/5/8 levels, but decreased Bmpr1b expression in these GC. This suggests that a negative feedback mechanism may exist whereby the stimulation of the Smad 1/5/8 pathway in rat GC under stimulation with BMP15 alone (i.e.incubation with deer oocytes) may be regulated by a decrease in receptor transcription of Bmpr $1 b$ mRNA. In the future, it would be interesting to observe whether this decrease in Bmpr1b transcription in rat GCs upon deer oocyte co-incubation translates to a decrease in Smad $1 / 5 / 8$ protein levels over a longer period of time.

Sheep GC treated with deer recombinant GDF9 or BMP15 were used in this study as a positive control, with the expectation that samples treated with GDF9 would lead to increased phosphorylated Smad 2/3 levels, whilst treatment with BMP15 would stimulate phosphorylated Smad 1/5/8 levels. Sheep GC were used as their oocytes are known to express both GDF9 and BMP15 (Crawford and McNatty, 2012), therefore their GCs would be expected to respond to both of these OSFs. However, although an increase in unphosphorylated Smad 1/5/8 levels was seen in sheep GC treated with GDF9 or BMP15, no differences in phosphorylated Smad levels were observed in these positive 
controls. The concentration of recombinant deer GDF9 and BMP15 utilised may have been unable to stimulate the Smad pathways, however the concentrations of these proteins in the follicular fluid of deer are unknown. Previously, both recombinant deer and recombinant pig GDF9 and BMP15 have been used to increase proliferation rate in sheep and rat GC, with recombinant pig proteins stimulating proliferation to a higher degree (JL Pitman, unpublished results) suggesting a reduced biological activity of the recombinant deer proteins.

Differences in Smad phosphorylation levels were only observed in deer GC upon observation of the Smad 2/3 pathway. This may indicate that the timing of maximum Smad phosphorylation did not coincide with the time of GC sample collection. The time of maximum proliferation rate of GCs was determined as 16 hours. Thus, this incubation time was utilised for proliferation assays, and GC sample collection for qPCR and western blotting, with the assumption that the time of the maximum GC proliferation coincides with the maximum receptor expression and Smad phosphorylation. In addition this enables a direct comparison between all results. Previous studies however have utilised 60-90 minute incubation times, and have illustrated increased Smad phosphorylation in murine GC upon their stimulation with oocytes or recombinant OSFs. (Mazerbourg et al, 2004, Gilchrist et al, 2006). Furthermore, the dynamic and transient nature of Smad signaling has been previously illustrated (Schmierer et al, 2008, Shi et al, 2009), further indicating that in this study, Smad phosphorylation may have occurred at an earlier time point. Smad phosphorylation in GCs may also be species-specific, due to varying bioactivities of OSFs from different species' oocytes. In summary, it is likely that protein phosphorylation is more instantaneous compared to a change in $\mathrm{GC}$ receptor transcription and the instigation of GC proliferation by OSFs. In contrast, differences in total Smad protein levels were widely variable in this study upon oocyte co-incubation, despite the regulation of Smad activation being primarily through phosphorylation events. Changes in Smad translation are likely to occur over a longer period of time, explaining why changes in unphosphorylated Smad protein levels were observed. It has been previously validated that stimulation of the Smad signaling pathway may result in changes in the Smad protein levels themselves, as treatment of mice with FSH increases Smad2 protein levels (Guéripel et al, 2004). 
The antibodies utilised in this study were for a combination of phosphorylated Smad 2/3 or Smad 1/5/8, through detection of phosphorylation at their respective serine residues. In a similar manner, a combination of unphosphorylated Smad 2/3 and Smad 1/5/8 was detected. On occasion, double bands were observed and measured, although Smad 2/3 and Smad 1/5/8 are extremely homologous, and form homo-oligomers upon their phosphorylation (Kawabata et al, 1998). However, doublets have been observed previously with the same phospho-Smad 1/5/8 antibody used in this study (Zhang et al, 2016). As these antibodies detected phosphorylated Smad complexes, it is not possible to validate which Smad proteins were detected in each band.

Furthermore, rat GCs co-incubated with rat oocytes showed lower protein levels, including a lower abundance of $\beta$-actin, compared to other GC samples. This is unlikely to be due to uneven protein transfer, as both Smad 2/3 and Smad 1/5/8 displayed this lower abundance, despite being on separate blots. Therefore, this is indicative of lower cell numbers in these samples. This is plausible, due to the previously discussed variation in GC viability between replicates and species. As each sample contained 20,000 previously viable cells, the total cell number between samples would be expected to vary considerably. Thus, $\beta$-actin was utilised as a reference protein, with the assumption that total $\beta$-actin levels correspond to the total protein content within each sample. It has been illustrated however, that $\beta$-actin antibodies cannot distinguish between varying $\beta$-actin protein levels when a high abundance of protein is loaded (Dittmer and Dittmer, 2006). In future studies, varying numbers of GCs may be tested to determine $\beta$-actin sensitivity, and the optimum cell number for maximum detection of Smad levels. To determine $\beta$-actin levels, each membrane was stripped and reprobed for $\beta$-actin. The stripping procedure introduces variability, due to the possibility of uneven stripping making protein quantification variable. Due to the presence of bands near to the area where the $\beta$-actin band would be detected, it was not possible to probe for $\beta$ actin without stripping blots. 
With the exception of phosphorylated Smad 1/5/8 antibodies, which were monoclonal, polyclonal antibodies were utilised in this study. The polyclonal antibodies used are said to detect a wider range of species, which is of use to this study. However, the homology comparison of Smads between species (Table 2.9.1), illustrated high homology between species, with the lowest homology observed being $88 \%$. This suggests that the antibodies utilised in this study were likely capable of probing proteins across all the species studied.

\subsection{Validation of reference genes}

The mRNA levels of the type I and II receptors in GC samples were displayed as a fold change relative to RPL19, which was utilised as a reference gene. In order to validate the use of RPL19 as a reference gene in this study, mRNA levels of both RPL19 and PPIA were measured in each species' GC cDNA sample. A strong linear relationship between RPL19 and PPIA expression, with $\mathrm{R}^{2}$ values above 0.9 , were observed in rat, sheep, and pig GC. However, in deer GC samples, the relationship between RPL19 and PPIA expression was not as strong as the other species in this study, with an $\mathrm{R}^{2}$ value of 0.625 . This may indicate that in deer GC RPL19 and/or PPIA expression is not as stable compared to the other species GC. Due to the lower cell viability in deer GC, a higher proportion of these cells had undergone apoptosis, leading to a poor regulation of PPIA and RPL19 in these deer samples. Previous studies, have utilised both RPL19 (Eppig et al, 1997, Otsuka and Shimasaki, 2002) and PPIA as reference genes in GC samples (Sasseville et al, 2010), however not in deer GCs. In future studies, further reference genes may be utilised as a comparison to determine the stability of RPL19 and PPIA in deer GCs. Furthermore, more prompt deer GC collection to increase cell viability would verify whether the mRNA degradation in apoptotic deer GC is influencing PPIA and RPL19 mRNA levels.

\subsection{Validation of Smad 2/3 and Smad 1/5/8 antibodies}

Probing with antibodies to detect Smad proteins led to identification of several nonspecific bands, in particular upon the detection of phosphorylated Smad proteins. Whilst milk powder was utilised for blocking and antibody incubation for unphosphorylated 
Smad protein detection, BSA was used for phosphorylated Smad protein detection, due to the presence of casein in milk powder, as caseins such as casein kinase II are known to contribute to Smad phosphorylation (Chaverneff and Barett, 2009). Thus, milk powder would be assumed to increase background levels for phosphorylated protein detection. However, it is possible that BSA was not as efficient as milk powder in blocking the binding of antibodies to non-specific protein, as can be seen in the presence of non-specific bands. Acetylation and splice variants of phosphorylated Smads may influence the presence of non-specific bands also. Upon their phosphorylation, acetylation of Smads 2 and 3 has been demonstrated (Simonsson et al, 2006, Inoue et al, 2007, Tu and Luo, 2007). Furthermore, an alternatively spliced variant of Smad2 has been observed, which can be phosphorylated in a similar manner to wild type Smad2 (Yagi et al, 1999), However, this splice variant is of similar size to wild type Smad2. Phosphorylation of Smad2 drives the formation of homotrimers, with a molecular size of $170 \mathrm{kDa}$ (Wu et al, 2001b), raising the possibility that the antibodies utilised were capable of probing Smad homotrimers. Furthermore, previous published studies that utilise these antibodies do not include full blots, presenting only the specific band, thus making it difficult to deduce whether the non-specific bands in this study are due to methodology, or the presence of acetylation, splice variants or homotrimers.

In order to validate the specificity of the detected Smad proteins, the polyclonal antibodies were preabsorbed with their corresponding blocking peptide, which led to the disappearance of all specific bands. Upon preabsorption of phosphorylated Smad $2 / 3$ it appears as if a very light specific band is present. However, it is difficult to deduce band presence due to high background levels. The preabsorption of Smad 2/3 resulted in a lighter non-specific band at $\sim 25 \mathrm{kDa}$. As this band was not observed at the same affinity as the same band on the non-preabsorbed blot, this suggests that this antibody is capable of binding this non-specific protein, or that this protein may be part of the Smad 2/3 complex. However, complete disappearance of this band was not observed, and it should be noted that blots were stripped prior to preabsorption, which would likely lead to protein loss. A blocking peptide for the phosphorylated Smad 1/5/8 antibody was not available, however, this antibody's specificity has been previously illustrated, as specific 
bands were almost absent with a vehicle control and TGF $\beta$ treatment on SVOG immortalised human GCs (Zhang et al, 2016).

Preabsorption studies were performed on sheep GC, in comparison to the results obtained from rat and deer GC. Generally, preabsorption experiments showed fewer non-specific bands in comparison to previous western blot results in rat and deer GC. Therefore, it is difficult to determine whether these bands were due to the antibodies recognising non-specific proteins.

\subsection{Study limitations}

The treatment of GCs with oocytes to stimulate proliferation is advantageous, as GC are subjected to several OSFs simultaneously, and in their native forms, as would occur in vivo (Gilchrist et al, 2008). A disadvantage to this methodology includes the difficulty in determining which OSFs, or a combination of these, is causing GC proliferation. Immunoneutralisation of GDF9 and BMP15 in rat and sheep GC has previously illustrated that it is these OSFs that are responsible for a significant proportion of GC proliferation (Lin et al, 2012). Although immunoneutralisation is a useful tool in determining which OSFs induce proliferation, studies using exogenous growth factors and those using oocytes are difficult to compare, as it is unknown at what concentration the OSFs are secreted from the oocyte, and it has not been established whether GC would respond in a similar manner to recombinant, compared to native, forms of OSFs.

It is important to note that the large variation observed in GC proliferation assays is likely due to utilising GCs and oocytes from follicles that are at different developmental stages. The hierarchical nature of follicular development in the ovary of all species means that no follicles are at the same stage of development at any given time (McNatty et al, 2010). Within a replicate, GC aliquots are identical, as they are derived from a pool of cells, however between replicates, variations in GCs would be observed. In this study, each GC replicate would have a different capacity of proliferation, as shown previously through varying proliferating cell nuclear antigen (PCNA) staining varying between GCs within each follicle (Lundy et al, 1999). Furthermore, follicles at different developmental 
stages differ in the presence and abundance of GC receptors (Paradis et al, 2009), influencing the gene expression results in this study due to the varying ability of GCs to respond to OSFs. Although effort was made to use only healthy COCs as determined by morphology, each oocyte from an ovary is functionally different, due to the different follicular environment it was obtained from. This would further increase replicate variation, due to the differing capacity of these oocytes to elicit GC proliferation, and activate OSF receptors and signaling pathways. Furthermore, it is important to note the limitations involved in the culture system used, whereby the amounts of oocytes and GCs utilised are not representative of GC and oocyte distribution in the ovary, illustrating the different OSF concentrations present in this culture system compared to an in vivo environment.

The methodology utilised to retrieve GCs would have lead to the culture of other cell types, such as theca cells and follicular epithelial cells. Due to the technical difficulty in removing these non-GC from the culture system, these cells were included in the proliferation assays. Therefore it is possible that a proportion of the recorded proliferation may be attributed to the proliferation of the other cell types mentioned. Several methodologies may be utilised in the future to remove the presence of these cells such as a density gradient with Percoll or Ficoll (Beckmann et al, 1991; Kolena et al, 1983; Kwintkiewicz et al, 2010; Liu et al, 2010). Furthermore, immunocytochemistry can be used to validate the presence of GCs compared to other cells (Aghadavod et al, 2015; Chilvers et al, 2012).

Another limitation in this study is the different age and breed of animals used. As sheep, pig and deer ovaries were obtained from local abattoirs, these factors are unknown. In contrast, 3-4 week old prepubertal Sprague Dawley rats were used in this study. Several factors such as season, breed and age in sheep influence folliculogenesis (Cahill, 1981). For example, in this study, during breeding season the quality and quantity of oocytes and GCs would decrease. This, alongside the differing ages and breeds in mammals between different experimental replicates may have influenced GC proliferation, as well as gene and protein phosphorylation and levels, increasing the variation between replicates observed. 


\subsection{Conclusions}

Overall, the results of this study clearly illustrated species differences in GC proliferation, receptor upregulation and Smad activation upon same- and cross-species oocyte co-incubation. These observed differences were dependent on the species from which both the GCs and the oocytes were obtained. This illustrates species differences in OSFs, and differences in growth factors and receptor abundance in GCs in monoovulatory and poly-ovulatory species.

Rat GCs demonstrated a high mitogenic capacity compared to other species, however the co-incubation of deer oocytes, which express higher levels of $B M P 15$, in relation to GDF9, mRNA, stimulated the proliferation of rat GCs to a lesser extent than oocytes from the other species studied. Furthermore, deer oocytes also decreased both Bmpr1b and Bmpr2 expression in rat GC, which may indicate that rat GC are responding to stimulation by BMP15 alone by decreasing receptor levels, in order to decrease the signaling of this OSF. This is in accordance with previous studies whereby BMP15 has an inhibitory effect on folliculogenesis in mouse preantral follicles (Fenwick et al, 2013). Interestingly in rat GCs, phosphorylated Smad 2/3 levels, and unphosphorylated Smad $1 / 5 / 8$ levels were increased after deer oocyte co-incubations, suggesting that GCs were negatively regulating the increased activation of the BMP15 signalling pathway by down-regulating its type 1 and type 2 receptor.

A high proliferation rate together with a high expression of Bmpr2 in rat GC coincubated with rat denuded oocytes may illustrate that whichever OSFs are eliciting high proliferation in rat GC are also upregulating this receptor. Furthermore, sheep oocytes also elicited high rat GC proliferation and concomitantly increased $\mathrm{Tgf} \beta r 1$ expression, and increased Smad 2/3 in these GCs. This is indicative of the significant levels of both GDF9 and BMP15 levels in sheep oocytes, two OSFs that are known to act cooperatively in GC proliferation and utilise $T g f \beta r 1$ and Smad 2/3 signaling. 
Conversely, in pig GCs, there was no species differences in oocytes ability to elicit proliferation, and interestingly deer denuded oocyte increased BMPR1B mRNA levels. The rat and the pig are both high-ovulation rate species, however whilst rat oocytes express a high ratio of Gdf9:Bmp15, pig oocytes express a low GDF9:BMP15 mRNA ratio (Crawford and McNatty 2012). This study may indicate further differences between these two species, as BMP15 may influence folliculogenesis, and GC proliferation in particular, differently in these two species. Thus, whilst BMP15 may have an inhibitory effect on GC proliferation in the rat, this may not be the case in the pig, sheep and deer, illustrating that despite these species being poly-ovulatory and mono-ovulatory respectively, they may respond in a similar manner to the stimulation of BMP15 alone.

There were no species differences in proliferation rate of GCs from sheep, pig or deer when cultured with denuded oocytes from the same or different species. Co-incubation of deer oocytes with deer GC however also increased both phosphorylated Smad 2/3 levels and unphosphorylated Smad 1/5/8 levels. Whilst an increase in Smad 1/5/8 levels may be due to BMP15 secreted from deer oocytes, increased phosphorylation of Smad 2/3 may be indicative of deer GC requiring particular OSFs present only in their oocytes to activate this Smad signaling.

\subsection{Future directions}

As mentioned, a major limitation to using oocytes in this study is that it is unknown which OSFs are eliciting GC proliferation, receptor upregulation and Smad pathway activation. To make direct comparisons between OSFs in rat, sheep, pig and deer oocytes, an unbiased approach such as mass spectroscopy may be employed in the future. Immuno-neutralisation of OSFs upon oocyte co-incubation also offers an indirect means of determining which OSF is acting to promote proliferation, or Smad pathway activation. Due to the differing follicular functions of BMP15 between species, as shown in mutations in sheep and mice, it would be of particular interest to immuno-neutralise BMP15 in these cross-incubations, to elucidate whether this OSF impacts proliferation differently in GCs of each of the species tested. 
In the current study it is difficult to attribute the observed GC proliferaton to the activation of certain Smad signaling pathways. Thus signaling pathway inhibitors may be used to enable a direct comparison between proliferation assays and Western blotting. However, due to the redundancy observed in the Smad signaling pathway, this technique would not offer a means of elucidating which OSF is activating these signaling pathways. It would also be of interest to immuno-neutralise non-Smad signaling pathways as a means to compare the differenes in the utilisation of extra-Smad signalling pathways in the different species. Alternatively, the activation of non-Smad signaling pathways in GCs upon oocyte cross-incubation through the use of phosphoantibodies against for example, the MAPK signaling pathway may be utilised. In particular, this may indicate whether rat oocytes signal through non-Smad signaling pathways to a greater extent than sheep oocytes, as both species' oocytes were able to stimulate high levels of GC proliferation, however only sheep oocytes increased Smad 2/3 levels in these GC.

Pig GCs displayed the highest proliferation when incubated alone, which was not related to GC viability. In order to validate whether this is due to the presence of TGF $\beta$ superfamily members, or other growth factors secreted by these GCs, it would be of importance to look at the gene expression of candidate growth factors, including GDF9 and $B M P 15$, in this species', and other species' GCs. It is particularly interesting to note that it has been demonstrated that whilst in the pig oocyte, GDF9 expression is higher than BMP15 expression (Paradis et al, 2009, Crawford and McNatty, 2012), in GCs, GDF9 has a 30- fold higher abundance than BMP15 (Paradis et al, 2009).

Using qPCR methodologies, the results obtained indicate which type I and II receptors are being transcribed in GCs at that point in time (i.e. 16 hours after incubation). However, the ability of OSFs to signal through these receptors depends on the presence of these receptors at the cell surface. In order to validate this study's findings, western blot analysis may be performed in these GCs to deduce the protein levels of the type I and II receptors. In particular, in several of the cross-species incubations, the addition of oocytes decreased receptor mRNA levels compared to basal receptor levels. This may be due to the overstimulation of receptors by OSFs causing a decrease in transcription of 
these receptors, however western blot analysis may give a better indication of the dynamics of receptor availability.

In order to verify whether a shorter GC incubation time would elicit a greater Smad phosphorylation, a time series could be performed in future, whereby GCs incubation occurs at various time points, with and without oocytes or recombinant OSFs, to determine the time of maximum Smad phosphorylation compared to controls.

Due to time restrictions, only four mammalian species were included in this study. However, to expand our understanding of the differences in GC proliferation and Smad signaling in mono and poly-ovulatory species, several other species may be added in future studies. For example, the mouse is a poly-ovulatory species that expresses a high ratio of GDF9: BMP15 mRNA, whilst the cow is a mono-ovulatory species that expresses a low ratio of GDF9:BMP15 (Crawford and McNatty, 2012).

In addition to GC proliferation and SMAD signaling, OSFs affect several other pathways, including steroidogenesis and apoptosis. In the future, this could be studied through gene expression experiments, by looking at the expression of Bax and Bcl2, which are pro-apoptotic and anti-apoptotic respectively. Thereby the ratio of these genes may be used to determine the effects of OSFs from various species oocytes on the apoptosis of GCs. OSFs are also known to impact steroidogenesis in follicular development, therefore species differences in the oocyte ability to upregulate genes involved in steroidogenesis, such as StAR, AROM and FSHR.

Whilst members of the TGF $\beta$ superfamily, such as GDF9 and BMP15 are involved in follicular development, to gain a more comprehensive view of the follicular environment, the effect of other growth factors such as IGFs, FGFs, EGFs and gonadotropins may be considered in the future for their expression and impact on folliculogenesis in these cross-incubations. 


\section{References}

Abécassis L, Rogier E, Vazquez A, Atfi A, Bourgeade M-F (2004), Evidence for a Role of MSK1 in Transforming Growth Factor- $\beta$-mediated Responses through $\mathrm{p} 38 \alpha$ and Smad Signaling Pathways, Journal of Biological Chemistry, 279: 30474-30479

Aghadavod E, Zarghami N, Farzadi L, Zare M, Barzegari A, Movassaghpour A A, Nouri M (2015), Isolation of granulosa cells from follicular fluid; applications in biomedical and molecular biology experiemnts, Advanced Biomedical Research, 4: 250

Akkoyunlu G, Demir R, Ustunel I (2003), Distribution patterns of TGF- $\alpha$, laminin and fibronectin and their relationship with folliculogenesis in rat ovary, Acta Histochemica, 105(4): 295-301

Allendorph G P, Vale W W, Choe S (2006), Structure of the ternary signaling complex of a TGF- $\beta$ superfamily member, Proceedings of the National Academy of Sciences USA, 103(20): 7643-6748

Almeida F, Teerds K, Auler P, Soede N (2012), Anti-Mullerian hormone: expression and possible roles in the porcine ovary, Reproduction in Domestic Animals, 47: 496497

Andersson 0, Reissmann E, Ibanez C F (2006), Growth differentiation factor 11 signals through the transforming growth factor- $\beta$ receptor ALK5 to regionalize the anterior-posterior axis, EMBO Reports, 7(8): 831-837

Annes J P, Chen Y, Munger J S, Rifkin D B (2004), Integrin $\alpha_{v} \beta_{6}$-mediated activation of latent TGF $\beta$ requires the latent TGF $\beta$ binding protein-1, Journal of Cell Biology, 165(5): 723-734

Baarends W M, Uilenbroekt J T J, Kramer P, Hoogerbrugge J W, Vanleeuwen E C M, Themmen A P N, Grootegoed J A (1995), Anti-mullerian hormone and antimullerian hormone type II receptor messenger ribonucleic acid expression in rat ovaries during postnatal development, the estrous cycle, and gonadotropininduced follicle growth, Endocrinology, 136(11): 4951-4962

Baker J C, Harland R M (1996), A novel mesoderm inducer, Madr2, functions in the activin signal transduction pathway, Genes \& Development, 10: 1880-1889

Baranao J L S, Hammond J M (1984), Comparative effects of insulin and insulin-like growth factors on DNA synthesis and differentiation of porcine granulosa cells, Biochemical and Biophysical Research Communications, 124(2): 484-490

Barket M, Gilmore T D (1999), Control of apoptosis by Rel/NF- $\kappa B$ transcription factors, Oncogene, 18: 6910-6924

Beckmann M W, Polacek D, Seung L, Schreiber J R (1991), Human ovarian granulosa cell culture: determination of blood cell contamination and evaluation of possible culture purification steps, Fertility and Sterility, 54(5): 881-887

Bellego F L, Pisselet C, Huet C, Monget P, Monniaux D (2002), Laminin- $\alpha_{6} \beta_{1}$ integrin interaction enhances survival and proliferation and modulates steroidogenesis of ovine granulosa cells, Journal of Endocrinology, 172: 45-59 
Benjannet S, Rondeau N, Day R, Chrétien M, Seidah NG (1991) PC1 and PC2 are proprotein convertases capable of cleaving proopiomelanocortin at distinct pairs of basic residues, Proceedings of the National Academy of Sciences USA, 88: 35643568

Ben-Ze'ev A, Amsterdam A (1985), Regulation of cytoskeletal proteins involved in cell contact formation during differentiation of granulosa cells on extracellular matrix, Proceedings of the National. Academy of. Sciences USA, 83: 2894-2898

Bertoldo M J, Duffard N, Bernard J, Frapsauce C, Calais L, Rico C, Mermillod P, Locatelli Y (2014), Effects of bone morphogenetic protein 4 (BMP4) supplementation during culture of the sheep ovarian cortex, Animal Reproduction Science, 149(3-4): 124134

Bézard J, Vigier B, Tran D, Mauléon P, Josso N (1988), Anti-mullerian hormone in sheep follicles, Reproduction Nutrition Development, 28(4B): 1105-1112

Bodensteiner K J, Clay C M, Moeller C L, Sawyer H R (1999), Molecular Cloning of the Ovine Growth/Differentiation Factor Expression of Growth/Differentiation Factor-9 in Ovine and Bovine Ovaries, Biology of Reproduction, 60: 381-386

Brankin V, Quin R L, Webb R, Hunter M G (2005), Evidence for a functional bone morphogenetic protein (BMP) system in the porcine ovary, Domestic Animal Endocrinology, 28: 367-379

Brauning R, Fisher P J, McCulloch A F, Smithies R J, Ward J F, Bixley M J, Lawley C T, Rowe S J, McEwan J C (2015), Utilisation of high throughput genome sequencing technology for large scale single nucleotide polymorphism discovery in red deer Canadian elk, bioRxiv, In press http://dx.doi.org/10.1101/027318

Braw-Tal R, McNatty K P, Smith P, Heath D A, Hudson N L, Phillips D J, McLeod B J, David G H (1993), Ovaries of Ewes Homozygous for the X-Linked Inverdale Gene (FeXI) Are Devoid of Secondary and Tertiary Follicles but Contain Many Abnormal Structures, Biology of Reproduction, 49: 895-907

Braw-Tal R (1994), Expression of mRNA for follistatin and inhibin/activin subunits during follicular growth and atresia, Journal of Molecular Endocrinology, 13: 253264

Brown C B, Boyer A S, Runyan R B, Barnett J V (1999), Requirement of type III TGF- $\beta$ receptor for endocardial cell transformation in the heart, Science, 283(5410): 2080-2082

Buck P A, Schomberg D W (1988), [125I] iodo-epidermal growth factor binding and mitotic responsiveness of porcine granulosa cells are modulated by differentiation and follicle-stimulating hormone, Endocrinology, 122(1): 28-33

Burt D W (1992), Evolutionary grouping of the transforming growth factor- $\beta$ superfamily, Biochemical and Biophysical Research Communications, 184(2): 590595

Cahill L P (1981), Folliculogenesis in the sheep as influenced by breed, season and oestrous cycle, Journal of Reproduction and Fertility, 30: 135-142

Cameron V A Nishimura E, Mathews L S, Sawchenko P E, Vale W W (1994), Hybridization histochemical localization of activin receptor subtypes in rat brain, pituitary, ovary, and testis, Endocrinology, 134: 799-808 
Campbell B K, Souza C J, Skinner A J, Webb R, Baird D T (2006), Enhanced response of granulosa and theca cells from sheep carriers of the FecB mutation in vitro to gonadotropins and bone morphogenic protein-2, -4, and -6, Endocrinology, 147(4): 1608-1620

Campbell B K, Clinton M, Webb R (2012), The Role of Anti-Mullerian Hormone (AMH) During Follicle Development in a Monovulatory Species (Sheep), Endocrinology, 153(9): 4533-4543

Carabatsos M J, Elvin J, Matzuk M M, Albertini D F (1998), Characterization of Oocyte and Follicle Development in Growth Differentiation Factor-9-Deficient Mice, Developmental Biology, 204: 373-384

Carrington L M, Albon J, Anderson I, Kamma C, Boulton M (2006), Differential regulation of key stages in early corneal wound healing by TGF-beta isoforms and their inhibitors, Investigative Ophthalmology \& Visual Science, 47(5): 1886-1894

Celá P, Buchtová M, Veselá I, Fu K, Bogardi J P, Song Y, Barlow A, Buxton P, Medalová J, Francis-West P, Richman J M (2016), BMP signaling regulates the fate of chondroosteoprogenitor cells in facial mesenchyme in a stage-specific manner, Developmental Dynamics, 245(9): 947-962

Chacko B M, Qin B, Correia J J, Lam S S, de Caestecker M P, Lin K (2001), The L3 loop and C-terminal phosphorylation jointly define Smad protein trimerization, Nature, 8(3): 248-253

Chang H, Brown C W, Matzuk M M (2002), Genetic Analysis of the Mammalian Transforming Growth Factor- $\beta$ Superfamily, Endocrine Reviews, 23(6): 787-823

Chang H, Matzuk M M (2001), Smad5 is required for mouse primordial germ cell development, Mechanisms of Development, 104: 61-67

Chang H M, Cheng J C, Huang H F, Shi F T, Leung P C (2015), Activin A, B and AB decrease progesterone production by down-regulating StAR in granulosa cells, Molecular and Cellular Endocrinology, 412: 290-301

Chang H-M, Cheng J-C, Klausen C, Leung P C K (2013), BMP15 Suppresses Progesterone Production by Down-Regulating StAR via ALK3 in Human Granulosa Cells, Molecular Endocrinology, 27(12): 2093-2104

Chang H M, Cheng J C, Klausen C, Taylor E L, Leung P C (2014), Effects of recombinant activins on steroidogenesis in human granulosa-lutein cells, Journal of Clinical Endocrinology \& Metabolism, 99(10): 1922-1932

Chang L and Karin M (2001), Mammalian MAP kinase signaling cascades, Nature, 410: $37-40$

Chaverneff F, Barrett J (2009), Casein kinase II contributes to the synergistic effects of BMP7 and BDNF on Smad 1/5/8 phosphorylation in septal neurons under hypoglycemic stress, Journal of Neurochemistry, 109(3): 733- 743

Cheifetz S, Andres, J L, Massagué J (1988), The Transforming Growth Factor- $\beta$ Receptor Type III Is a Membrane Proteoglycan, Journal of Biological Chemistry, 263(32): 16984-16991

Chen A Q, Yu S D, Wang Z G, Xu R, Yang Z G (2009), Stage-specific expression of bone morphogenetic protein type I and type II receptor genes: Effects of follicle- 
stimulating hormone on ovine antral follicles, Animal Reproduction Science, 111(2-4): 391-399

Chen Y, Bhushab A, Vale W (1997), Smad8 mediates the signaling of the receptor serine kinase, Proceedings of the National Academy of Sciences USA, 94(24): 1293812943

Chilvers R A, Bodenbrg Y H, Denner L A, Urban R J (2012), Development of a novel protocol for isolation and purification of human granulosa cells, Journal of Assisted Reproduction and Genetics, 29(6): 547-556

Constam D B, Robertson E J (1999), Regulation of Bone Morphogenetic Protein Activity by Pro Domains and Proprotein Convertases, Journal of Cell Biology, 144(1): 139149

Crawford J L, McNatty K P (2012) The ratio of growth differentiation factor 9: BMP15 mRNA expression is tightly co-regulated and differs between species over a wide range of ovulation rates, Molecular and Cellular Endocrinology, 348: 339-343

Crouch S P M, Kozlowski R, Slater K J, Fletcher J (1993), The use of ATP bioluminescence as a measure of cell proliferation and cytotoxicity, Journal of Immunological Methods, 160(1): 81-88

Davis G H, McEwan J C, Fennessy P F, Dodds K G, Farquhar P A (1991), Evidence for the Presence of a Major Gene Influencing Ovulation Rate on the X Chromosome of Sheep, Biology of Reproduction, 44: 620-624

Demirhan O, Turkmen S, Schwabe G C, Soyupak S, Akgul E, Tastemir D, Karahan D, Mundlos S, Lehmann K (2005), A homozygous BMPR1B mutation causes a new subtype of acromesomelic chondrodysplasia with genital anomalies, Journal of Medical Genetics, 42(4): 314-317

Dennler S, Itoh S, Vivien D, ten Dijke P, Huet S, Gauthier J M (1998), Direct binding of Smad3 and Smad4 to critical TGF beta-inducible elements in the promoter of human plasminogen activator inhibitor-type 1 gene, The EMBO Journal, 17(11): 3091-3100

Dennler S, Huet S, Gauthier J-M (1999), A short amino-acid sequence in MH1 domain is responsible for functional differences between Smad2 and Smad3, Oncogene, 18: 163-1648

Derynck R, Gelbart W M, Harland R M, Heldin C-H, Kem S E, Massagué J, Melton D, Mlodzik M, Padgett R W, Roberts A B, Smith J, Thomsen G H, Vogelstein B, Wang $X-F$ (1996), Nomenclature: Vertebrate Mediators of TGF $\beta$ Family Signals, Cell, 87: 173

Dittmer A, Dittmer J (2006), $\beta$-Actin is not a reliable loading control in Western blot analysis, Electrophoresis, 27(14): 2844-2845

Dong J, Albertini D F, Nishimori K, Kumar T R, Lu N, Matzuk M M (1996), Growth differentiation factor-9 is required during early ovarian folliculogenesis, Letters to Nature, 383: 531-538

Drummond A E, Dyson M, Mercer J E, Findlay J K (1996), Differential responses of postnatal rat ovarian cells to FSH and activin, Molecular and Cellular Endocrinology, 122: $21-32$ 
Drummond A E, Dyson M, Thean E, Groome N P, Robertson D M, Findlay J K (2000), Temporal and hormonal regulation of inhibin protein and subunit mRNA expression by post-natal and immature rat ovaries, Journal of Endocrinology, 166(2): 339-354

Drummond A E, Tan Le M, Ethier J-F, Dyson M, Findlay J K (2002), Expression and Localization of Activin Receptors, Smads, and Bglycan to the Postnatal Rat Ovary, Endocrinology, 143(4): 1423-1433

Dube J L, Wang P, Elvin J, Lyons K M, Celeste A J, Matzuk M M (1998), The Bone Morphogenetic Protein 15 Gene Is X-Linked and Expressed in Oocytes, Molecular Endocrinology, 12(12): 1809-1817

Dubois C M, Laprise M-H, Blanchette F, Gentry L E, Leduc R (1995), Processing of Transforming Growth Factor $\beta 1$ Precursor by Human Furin Convertase, Journal of Biological Chemistry, 270: 10618-10624

Dubois C M, Blanchette F, Laprise M-H, Leduc R, Grondin F, Seidah B G (2001), Evidence that Furin is an Authentic Tranforming Growth Factor- $\beta 1$ Converting Enzyme, American Journal of Pathology, 158(1): 305-316

Dudley A T, Lyons K M, Robertson E J (1995), A requirement for bone morphogenetic protein-7 during development of the mammalian kidney and eye, Genes Dev, 9: 2795-2807

Duffy D M (2003), Growth Differentiation Factor-9 Is Expressed by the Primate Follicle Throughout the Periovulatory Interval, Biology of Reproduction, 69(2): 725-732

Ebisawa T, Tada K, Kitajima I, Tojo K, Sampath T K, Kawabata M, Miyazono K, Imamura T (1999), Characterization of bone morphogenetic protein-6 signaling pathways in osteoblast differentiation, Journal of Cell Science, 112: 3519-3527

Ebner R, Chen R-H, Shum L, Lawler S, Zioncheck T F, Lee A, Lopez A R, Derynck R (1993), Cloning of a Type I TGF- $\beta$ Receptor and Its Effect on TGF- $\beta$ Binding to the Type II Receptor, Science, 260, 1344-1348

Edson M A, Nalam R L, Clementi C, Franco H L, DeMayo F J, Lyons K M, Pangas S A, Matzuk M M (2010), Granulosa Cell-Expressed BMPR1A and BMPR1B Have Unique Functions in Regulating Fertility but Act Redundantly to Suppress Ovarian Tumor Development, Molecular Endocrinology, 24(6): 1251-1266

Edwards S J, Reader K L, Lun S, Western A, Lawrence S, McNatty K P, Juengel J L (2008), The Cooperative Effect of Growth and Differentiation Factor- 9 and Bone Morphogenetic Protein (BMP)-15 on Granulosa Cell Function is Modulated Primarily through BMP Receptor II, Endocrinology, 149(3): 1026-1030

Engel M E, McDonnel M A, Law B K, Moses H L (1999), Interdependent SMAD and JNK Signaling in Transforming Growth Factor- $\beta$-mediated Transcription, Journal of Biological Chemistry, 274: 37413-37420

Eppig J J, Wigglesworth K, Pendola F, Hirao Y (1997), Murine oocytes suppress expression of luteinising hormone receptor messenger ribonucleic acid by granulosa cells, Biol Reprod, 56: 976-984

Ergin K, Gursoy E, Koca Y B, Basaloglu H, Seyrek K (2008), Immunohistochemical detection of insulin-like growth factor-I, transforming growth factor- $\beta 2$, basic 
fibroblast growth factor and epidermal growth factor-receptor expression in developing rat ovary, Cytokine, 43: 209- 214

Erickson G F, Shimasaki S (2003), The spatiotemporal expression pattern of the bone morphogenetic protein family in rat ovary cell types during the estrous cycle, Reproductive Biology and Endocrinology, 1: 9

Feary E S, Juengel J L, Smith P, French M C, C'Connel A R, Lawrence S B, Galloway S M, Davis G H, McNatty K P (2007), Patterns of Expression of Messenger RNAs Encoding GDF9, BMP15, TGFBR1, BMPR1B, and BMPR2 During Follicular Development and Characterization of Ovarian Follicular Populations in Ewes Carrying the Woodlands FecX22 Mutation, Biology of Reproduction, 77(6): 990998

Fenwick M A, Mora J M, Mansour Y T, Baithun C, Franks S, Hardy K (2013), Investigations of TGF- $\beta$ Signaling in Preantral Follicles of Female Mice Reveal Differential Roles for Bone Morphogenetic Protein 15, Endocrinology, 154(9): 3423-3426

Galloway S M, McNatty K P, Cambridge L M, Laitinen M P E, Juengel J L, Jokiranta T S, McLaren R J, Luiro K, Dodds K G, Montgomery G W, Beattie A E, Davis G H, Ritvos $O$ (2000), Mutations in an oocyte derived growth factor gene (BMP15) cause increased ovulation rate and infertility in dosage-sensitive manner, Nature Genetics, 25:279-283

Gao Y, Duran S, Lydon J P, DeMayo F J, Burghardt R C, Bayless K J, Bartholin L, Li Q (2015), Constitutive activation of transforming growth factor Beta receptor 1 in the mouse uterus impairs uterine morphology and function, Biology of Reproduction, 92(2): 34

Gilchrist R B, Ritter L J, Cranfield M, Jeffery L A, Amato F, Scott S J, Myllymaa S, Kaivo-Oja N, Lankinen H, Mottershead D G, Groome N P, Ritvos 0 (2004), Immunoneutralization of Growth Differentiation Factor 9 Reveals It Partially Accounts for Mouse Oocyte Mitogenic Activity, Biology of Reproduction, 71(3): 732-739

Gilchrist R B, Ritter L J, Myllymaa S, Kaivo-Oja N, Dragovic R A, Hickey R E, Ritvos O, Mottershead D G (2006), Molecular basis of oocyte-paracrine signaling that promotes granulosa cell proliferation, Journal of Cell Science, 119: 3811-3821

Gilchrist R B, Thompson M L, Thompson J G (2008), Oocyte-secreted factors: regulators of cumulus cell function and oocyte quality, Human Reproduction Update, 14(2): $159-177$

Gilchrist R B (2011), Recent insights into oocyte-follicle cell interactions provide opportunities for the development of new approaches to in vitro maturation, Reproduction, Fertility and Development, 23(1): 23-31

Gingery A, Bradley E W, Pederson L, Ruan M, Horwood N J, Oursler M J (2008), TGF- $\beta$ coordinately activates TAK1/MEK/AKT/NFkB and SMAD pathways to promote osteoclast survival, Experimental Cell Research, 314(15): 2725- 2738

Glister C, Kemp C F, Knight P G (2004), Bone morphogenetic protein (BMP) ligands and receptors in bovine ovarian follicle cells: actions of BMP4, 6 and 7 on granulosa 
cells and differential modulation of Smad1 phosphorylation by follistatin, Reproduction, 127(2): 239-254

Gospodarowicz D, Ill C R, Birdwell C R (1977), Effects of fibroblast and epidermal growth factors on ovarian cell proliferation in vitro. I. Characterization of the response of granulosa cells to FGF and EGF, Endocrinology, 100(4): 1108-1120

Gouedard L, Chen Y G, Thevenet L, Racine C, Borie S, Lamarre I, Josso N, Massague J, di Clemente N (2000), Engagement of bone morphogenetic protein type IB receptor and Smad1 signaling by anti-Mullerian hormone and its type II receptor, The Journal of Biological Chemistry, 275(36): 27973-27978

Goumans M-J, Valdimarsdottir G, Itoh S, Lebrin F, Larsson J, Mummery C, Karlsson S, ten Dijke P (2003), Activin Receptor-like Kinase (ALK)1 Is an Antagonistic Mediator of Lateral TGF $\beta$ /ALK5 Signaling, Molecular Cell, 12(4): 817-828

Grasa P, Ploutarchou P, Williams S A (2015), Oocytes lacking O-glycans alter follicle development and increase fertility by increasing follicle FSH sensitivity, decreasing apoptosis, and modifying GDF9: BMP15 expression, The FASEB Journal, 29(2): 525-539

Gray A M, Mason A J (1990), Requirement for activin A and transforming growth factor$\beta 1$ pro-regions in homodimer assembly, Science, 247(4948): 1328-1330

Guiness F, Lincoln G A, Short R V (1971), The Reproductive Cycle of the Female Red Deer, Cervus Elaphus L., Journal of Reproduction and Fertility, 27: 427-438

Guo X, Wang X-F (2009), Signaling cross-talk between TGF- $\beta$ /BMP and other pathways, Cell Research, 19(1): 71-88

Guéripel X, Benahmed M, Gougeon A (2004), Sequential Gonadotropin Treatment of Immature Mice Leads to Amplification of Transforming Growth Factor $\beta$ Action, Via Upregulation of Receptor-Type 1, Smad 2 and 4, and Downregulation of Smad 6, Biology of Reproduction, 70: 640- 648

Hanrahan J P, Gregan S M, Mulsant P, Mullen M, Davis G H, Powell R, Galloway S M (2004), Mutations in the Genes for Oocyte-Derived Growth Factors GDF9 and BMP15 Are Associated with Both Increased Ovulation Rate and Sterility in Cambridge and Belclare Sheep (Ovis aries), Biology of Reproduction, 70: 900-909

Hart P J, Deep S, Taylor A B, Shu Z, Hinck C S, Hinck A P (2002), Crystal structure of the human T $\beta R 2$ ectodomain-TGF- $\beta 3$ complex, Nature Structural Biology, 9: 203-208

Hashimoto O, Moore R K, Shimasaki S (2005), Posttranlational processing of mouse and human BMP-15: Potential implication in the determination of ovulation quota, Proceedings of the National Academy of Sciences USA, 102(15): 5426-5431

Hata A, Seoane J, Lagna G, Montalvo E, Hemmati-Brivanlou A, Massagué J (2000), OAZ Uses Distinct DNA- and Protein-Binding Zinc Fingers in Separate BMP-Smad and Olf Signaling Pathways, Cell, 100L 229-240

Hayashi H, Abdollah S, Qiu Y, Cai J, Xu Y Y, Grinnell B W, Richardson M A, Topper J N, Gimbrone M A, Wrana J L, Falb D (1997), The MAD-related protein Smad7 associates with the TGF $\beta$ receptor and functions as an antagonist of TGF $\beta$ signaling, Cell, 89(7): 1165-1173

Hayashi M, McGee E A, Min G, Klein C, Rose U M, Van Duin M, Hsueh A J W (1999), 
Recombinant Growth Differentiation Factor-9 (GDF-9) Enhances Growth and Differentiation of Cultured Early Ovarian Follicles, Endocrinology, 140(3): 12361244

Heldin C-H, Miyazono K, Dijke P (1997), TGF- $\beta$ signaling from cell membrane to nucleus through SMAD proteins, Nature, 390: 465- 471

Henricks D M, Guthrie H D, Handlin D L (1972), Plasma Estrogen, Progesterone and Luteinizing Hormone Levels During the Estrous Cycle in Pigs, Biology of Reproduction, 6: 210- 218

Hoshiya Y, Gupta V, Segev D L, Hoshiya M, Carey J L, Sasur L M, Tran T T, Ha T U, Maheswaran S (2003), Mullerian Inhibiting Substance induces NFkB signaling in breast and prostate cancer cells, Molecular and Cellular Endocrinology, 211: 4349

Hosoya T, Otsuka F, Nakamura E, Terasaka T, Inagaki K, Tsukamoto-Yamauchi N, Hara T, Toma K, Komatsubara M, Makino H (2015), Regulatory role of BMP-9 in steroidogenesis by rat ovarian granulosa cells, Journal of Steroid Biochemistry and Molecular Biology, 147: 85-91

Hoy C A, Lewis E D, Schimke R T (1990), Perturbation of DNA Replication and Cell Cycle Progression by Commonly Used [3H]Thymidine Labeling Protocols, Molecular and Cellular Biology, 10(4): 1584- 1592

Hu J, Zhang Y-Q, Liu X-P, Wang R-A, Jin Y, Xu R-J (2003), Expression and localization of Smad1, Smad2, and Smad4 proteins in rat testis during postnatal development, Asian Journal of Andrology, 5: 51-55

Hu V W, Black G E, Torres-Duarte A, Abramson F P (2002), 3H-thymidine is a defective tool with which to measure rates of DNA synthesis, The FASEB Journal, 16(11): 1456-1457

Huet C, Pisselet C, Mandon-Pépin B, Monget P, Monniaux D (2001), Extracellular matrix regulates ovine granulosa cell survival, proliferation and steroidogenesis: relationships between cell shape and function, Journal of Endocrinology, 169: 347360

Hung W-T, Wu F-J, Wang C-J, Luo C-W (2012), DAN (NBL1) Specifically Antagonizes BMP2 and BMP4 and Modulates the Actions of GDF9, BMP2, and BMP4 in the Rat Ovary, Biology of Reproduction, 86(5): 1-9

Huse M, Chen Y-C, Massagué J, Kuriyani J (1999), Crystal Structure of the Cytoplasmic Domain of the Type I TGF $\beta$ Receptor in Complex with FDBP12, Cell, 96: 425- 436

Hussein T S, Froiland D A, Amato F, Thompson J G, Gilchrist R B (2005), Oocytes prevent cumulus cell apoptosis by maintaining a morphogenic paracrine gradient of bone morphogenetic proteins, Journal of Cell Science, 118(22): 5257- 5268

Imamura T, Takase M, Nisihara A, Oeda E, Hanai J, Kawabata M, Miyazono K (1997), Smad6 inhibits signaling by the TGF $\beta$ superfamily, Nature, 389(6651): 622- 626

Incerti B, Dong J, Borsani G, Matzuk M M (1994), Structure of the mouse growth/differentiation factor 9 gene, Biochimica et Biophysica Acta, 1222(1): 125128

Ingman W V, Robker R L, Woittiez K, Robertson S A (2006), Null Mutation in 
Transforming Growth Factor $\beta 1$ Disrupts Ovarian Function and Causes Oocyte Incompetence and Early Embryo Arrest, Endocrinology, 147(2): 835-845

Inoue Y, Itoh Y, Abe K, Okamoto T, Daitoku H, Fukamizu A, Onozaki K, Hayashi H (2007), Smad3 is acetylated by p300/CPB to regulate its transactivation activity, Oncogene, 26: 500- 508

Jaatinen R, Laitinen M P, Vuojolainen K, Altonen J, Louhio H, Heikinheimo K, Lehtonen E, Ritvos $O$ (1999), Localisation of growth differentiation factor-9 (GDF-9) mRNA and protein in rat ovaries and cDNA cloning of rat GDF-9 and its novel homolog GDF9-B (1999), Molecular and Cellular Endocrinology, 156: 189-193

Jackowska M, Kempisty B, Wozna M, Piotrowska H, Antosik P, Zawierucha P, Bukowska D, Nowicki M, Jaskowski J M, Brussow K P (2013), Differential expression of GDF9, TGFB1, TGFB3 in porcine oocytes isolated from follicles of different size before and after culture in vitro, Acta Veterinaria Hungarica, 61(1): 99-115

Jones C M, Dale L, Hogan B L M, Wright C V E, Smith J C (1996), Bone morphogenetic protein-4 (BMP-4) acts during gastrula stages to cause ventralization of Xenopus embryos, Development, 122: 1545-1554

Joo S, Oh S-H, Sittadjody S, Opara E C, Jackson J D, Lee S J, Yoo J J, Atala A (2016), The effect of collagen hydrogen on 3D culture of ovarian follicles, Biomedical Materials, 11(6): 065009

Juengel J L, Hudson N L, Heath D A, Smith P, Reader K L, Lawrence S B, O'Connell A R, Laitinen M P E, Cranfield M, Groome N G, Ritvos O, McNatty K P (2002), Growth Differentiation Factor 9 and Bone Morphogenetic Protein 15 Are Essential for Ovarian Follicular Development in Sheep, Biology of Reproduction, 67: 1777-1789

Juengel J L, Bibby A H, Reader K L, Lun S, Quirke L D, Haydon L J, McNatty K P (2004a), The role of transforming growth factor-beta (TGF-beta) during ovarian follicular development in sheep, Reproductive Biology and Endocrinology, 2: 78

Juengel J L, Hudson N L, Whiting L, McNatty K P (2004b), Effects of Immunization Against Bone Morphogenetic Protein 15 and Growth Differentiation Factor 9 on Ovulation Rate, Fertilization and Pregnancy in Ewes, Biology of Reproduction, 70: 557- 561

Juengel J L, Reader K L, Bibby A H, Lun S, Ross I, Haydon L J, McNatty K P (2006), The role of bone morphogenetic proteins 2, 4, 6 and 7 during ovarian follicular development in sheep: contrast to rat, Reproduction, 131(3): 501-513

Juengel J L, Hudson N L, Berg M, Hamel K, Smith P, Lawrence S B, Whiting L, McNatty K P (2009), Effects of active immunization against growth differentiation factor 9 and/or bone morphogenetic protein 15 on ovarian function in cattle, Reproduction, 138(1): 107- 14

Kaivo-Oja N, Mottershead D G, Mazerbourg S, Myllymaa S, Duprat S, Gilchrist R B, Groome N P, Hsueh A J, Ritvos $O$ (2005), Adenoviral Gene Transfer Allows SmadResponsive Gene Promoter Analyses and Delineation of Type I Receptor Usage of Transforming Growth Factor- $\beta$ Family Ligands in Cultured Human Granulosa Luteal Cells, Journal Clinical Endocrinology, 90(1): 271-278

Kaivo-Oja N, Jeffery L A, Ritvos O, Mottershead D G (2006), Smad signaling in the ovary, Reprod Biol Endocrinol, 4: 21 
Kannampuzha-Francis J, Tribulo P, Hansen P J (2016), Actions of activin A, connective tissue growth factor, hepatocyte growth factor and teratocarcinoma-derived growth factor 1 on the development of the bovine preimplantation embryo, Reproduction, Fertility and Development, in press.

Kayasari O R, Valojerdi M R, Farrokhi A, Ebrahimi B (2012), Expression of maturation genes and their receptors during in vitro maturation of sheep COCs in the presence and absence of somatic cells of cumulus origin, Theriogenology, 77(1): $12-20$

Kempisty , Piotrowska H, Rybska M, Wozna M, Antosik P (2015), Expression of INH $\beta A$ and INH $\beta$ B proteins in porcine oocytes cultured in vitro is dependent on the follicle size, Zygote, 23(1): 204- 211

Kingsley D M (1994), The TGF $\beta$ superfamily: new members, new receptors, and new genetic tests of function in different organisms, Genes and Development, 8: 133146

Kirkbride K C, Townsend T A, Bruinsma M W, Barnett J V, Blobe G C (2008), Bone Morphogenetic Proteins Signal through the Transforming Growth Factor- $\beta$ Type III Receptor, Journal of Biological Chemistry, 283(12): 7628-7637

Knapczyk-Stwora K, Grzesiak M, Duda M, Koziorowski M, Galas J, Slomczynska M (2014), TGF $\beta$ superfamily members and their receptors in the fetal porcine ovaries: effect of prenatal flutamide treatment, Folia Histochemica et Cytobiologica, 52(4): 317325

Knight P G, Glister C (2006), TGF- $\beta$ superfamily members and ovarian follicle development, Reproduction, 132: 191-206

Kolena J, Kiss A, Channing C P (1983), Purification of porcine granulosa cells by continuous Percoll gradient, Experientia, 39(8): 908-909

Korchynskyi O, ten Dijke P (2002), Identification and Functional Characterization of Distinct Critically Important Bone Morphogenetic Protein-specific Response Elements in the Id1 Promoter, Journal of Biological Chemistry, 277(7): 4883-4891

Kretzschmar M, Doody J, Massagué J (1997), Opposing BMP and EGF signaling pathways converge on the TGF- $\beta$ family mediator Smad1, Nature, 389: 618-622

Kretzschmar M, Doody J, Timokhina I, Massagué J (1999), A mechanism of repression of TGF $\beta /$ Smad signaling by oncogenic Ras, Genes and Development, 13: 804-816

Kristensen S G, Andersen K, Clement C A, Franks S, Hardy K, Andersen C Y (2014), Expression of TGF-beta superfamily growth factors, their receptors, the associated SMADs and antagonists in five isolated size-matched populations of pre-antral follicles from normal human ovaries, Molecular Human Reproduction, 20(4): 293-308

Ku M, Howard S, Ni W, Lagna G, Hata A (2005), OAZ Regulates Bone Morphogenetic Protein Signaling through Smad6 Activation, Journal of Biological Chemistry, 281: 5277- 5287

Kusakabe M, Cheong P-L, Nikfar R, McLennan I S, Koishi K (2007), The structure of the TGF latency associated peptide region determines the ability of the proprotein convertase furin to cleave TGF $\beta$, Journal of Cellular Biochemistry, 103(1): 311320 
Kwintkiewicz J, Nishi Y, Yanase T, Giudice L C (2010), Peroxisome Proliferator-Activated Receptor- $\gamma$ Mediates Bisphenol A Inhibition of FSH-Stimulated IGF-1, Aromatase, and Estradiol in Human Granulosa Cells, Environmental Health Perspectives, 118(3): 400- 406

Kyasari O R, Valojerdi M R, Farrokhi A, Ebrahim B (2012), Expression of maturation genes and their receptors during in vitro maturation of sheep COCs in the presence and absence of somatic cells of cumulus origin, Theriogenology, 77(1): $12-20$

Laissue P, Christin-Maitre S, Touraine P, Kuttenn F, Ritvos O, Aittomaki K, Bourcigaux N, Jacquesson L, Bouchard P, Frydman R, Dewailly D, Reyss A-C, Jeffery L, Bachelot A, Massin N, Fellous M, Veitia R A (2006), Mutations and sequence variants in GDF9 and BMP15 in patients with premature ovarian failure, European Journal of Endocrinology, 154: 739- 744

Laitinen M, Vuojolainen K, Jaatinen R, Ketola I, Aaltonen J, Lehtonen E, Heikinheimo M, Ritvos $O$ (1998), A novel growth differentiation factor-9 (GDF-9) related factor is co-expressed with GDF-9 in mouse oocytes during folliculogenesis, Mechanisms of Development, 78: 135- 140

Lawrence D A, Pircher R, Jullien P (1985), Conversion of a high molecular weight latent $\beta$-TGF from chicken embryo fibroblasts into a low molecular weight active $\beta$-TGF under acidic conditions, Biochemical and Biophysical Research Communications, 133(3): 1026-1034

Lee S-J (1990), Identification of a Novel Member (GDF-1) of the Transforming Growth Factor- $\beta$ Superfamily, Molecular Endocrinology, 4(7): 1034-1040

Lee W-S, Otsuka F, Moore R K, Shimasaki S (2001), Effect of Bone Morphogenetic Protein-7 on Folliculogenesis and Ovulation in the Rat, Biology of Reproduction, 65: 994-999

Lei X, Cui K, Li Z, Su J, Jiang J, Zhang H, Liu Q, Shi D (2016), BMP-1 participates in the selection and dominance of buffalo follicles by regulating the proliferation and apoptosis of granulosa cells, Theriogenology, 85(5): 999-1012

Lei X, Cui K, Cai X, en X, Liu Q, Shi D (2017), Bone morphogenetic protein 1 is expressed in porcine ovarian follicles and promotes oocyte maturation and early embryonic development The Journal of Veterinary Medical Science, 79(2): 258- 266

Leoni G G, Bebbere D, Succu S, Berlinguer F, Mossa F, Galioto M, Bogliolo L, Ledda S, Naitana S (2007), Relations Between Relative mRNA Abundance and Developmental Competence of Ovine Oocytes, Molecular Reproduction and Development, 74: 249-257

Lewis K A, Gray P C, Blount A L, MacConell L A, Wiater E, Bilezikjian L M, Vale W (2000), Betaglycan binds inhibin and can mediate functional antagonism of activin signaling, Nature, 404: 411-414

Li J-J, Sugimara S, Mueller T D, White M A, Martin G A, Ritter L J, Liang X-Y, Gilchrist R B, Mottershead D G (2014), Modifications of Human Growth Differentiation Factor 9 to Improve the Generation of Embryos From Low Competence Oocytes, $\mathrm{Mol}$ Endocrinol, 29(1): 40- 52 
Liao W X, Moore R K, Otsuka F, Shimasaki S (2003), Effect of Intracellular Interactions on the Processing and Secretion of Bone Morphogenetic Protein-15 (BMP-15) and Growth and Differentiation Factor-9, Journal of Biological Chemistry 278(6): 3713- 3719

Lin H-K, Bergmann S, Pandolfi P P (2004), Cytoplasmic PML function in TGF- $\beta$ signalling, Nature, 431: 205- 211

Lin H Y, Wang X-F, Ng-Eaton E, Weinberg R A, Lodish H F (1992), Expression Cloning of the TGF- $\beta$ Type II Receptor, a Functional Transmembrane Serine/Threonine Kinase, Cell, 68: 775- 785

Lin J Y, Pitman-Crawford J L, Bibby A H, Hudson N L, McIntosh C J, Juengel J L, McNatty K P (2012), Effects of species differences on oocyte regulation of granulosa cell function, Reproduction: 144: 557 - 567

Lin X, Liang M, Feng X-H (2000), Smurf2 is a ubiquitin E3 ligase mediating proteasomedependent degradation of Smad 2 in Transforming Growth Factor- $\beta$ signaling, Journal of Biological Chemistry, 275(47): 36818- 36822

Liu X, Qin D, Cui Y, Chen L, Li H, Zhen C, Gao L, Li Y, Liu J (2010), The effect of calcium phosphate nanoparticles on hormone production and apoptosis in human granulosa cells, Reproductive Biology and Endocrinology, 8: 32

Liu J, Yao W, Yao Y, Du X, Zhou J, Ma B, Liu H, Li Q, Pan Z (2014), MiR-92a inhibits porcine ovarian granulosa cell apoptosis by targeting Smad7 gene, FEBS Letters, 588(23): 4497-4503

Livak K J, Schmittgen T D (2001), Analysis of relative gene expression data using realtime quantitative PCR and the 2(-Delta Delta C(T)) Method, Methods, 25: 402-408

Lowery J W, Amich J M, Andonian A, Rosen (2014), N-linked glycosylation of the Bone Morphogenetic Protein Receptor Type 2 (BMPR2) enhances ligand binding, Cellular and Molecular Life Sciences, 71(16): 3165-3172

Lundy T, Smith P, O’Connell A, Hudson N L, McNatty K P (1999), Populations of granulosa cells in small follicles of the sheep ovary, Journal of Reproduction and Fertility, 115: 251-262

Luo G, Jofmann C, Bronckers A L J J, Sohocki M, Bradley A, Karsenty G (1995), BMP-7 is an inducer of nephrogenesis, and is also required for eye development and skeletal patterning, Genes \& Development, 9: 2808-2920

MacConell L A, Leal A M O, Vale W W (2002), The Distribution of Betaglycan Protein and mRNA in Rat Brain, Pituitary, and Gonads: Implication for a Role for Betaglycan in Inhibitin-Mediated Reproductive Functions, Endocrinology, 143(3): 8707

Mace P D, Cutfield J F, Cutfield S M (2006), High resolution structures of the bone morphogenetic protein type II receptor in two crystal forms: Implications for ligand binding, Biochemical and Biophysical Research Communications, 351: 831838

Mao J, Smith M F, Rucker E B, Wu G M, McCauley T C, Cantley T C, Prather R S, Didion B A, Day B N (2004), Effect of epidermal growth factor and insulin-like growth factor I on porcine preantral follicular growth, antrum formation, and stimulation of granulosal cell proliferation and suppression of apoptosis in vitro, Journal of Animal Science, 82(7): 1967-1975 
Massagué J (1998), TGF- $\beta$ Signal Transduction, Annual Review of Biochemistry, 67:753 91

Massagué J, Wotton D (2000), Transcriptional control by the TGF- $\beta$ /Smad signaling system, The EMBO Journal, 19(8): 1745-1754

May J V, Stephenson L A, Turzcynski C J, Fong H W, Mau Y H, Davis J S (1996), Transforming growth factor $\beta$ expression in the porcine ovary: evidence that theca cells are the major secretory source during antral follicle developmet, Biology of Reproduction, 54: 485-496

Mazerbourg S, Klein C, Roh J, Kaivo-O N, Mottershead D G, Korchynskyi O, Ritvos O, Hsueh A J W (2004), Growth Differentiation Factor-9 Signaling is Mediated by the Type I Receptor, Activin Receptor-Like Kinase 5, Molecular Endrocrinology, 18(3): 653-665

Mazerbourg S, Sangkuhl K, Luo C-W,Sudo S, Klein C, Hsueh A J W (2005), Identification of Receptors and Signaling Pathways for Orphan Bone Morphogenetic Protein/Growth Differentiation Factor Ligands Based on Genomic Analyses, Journal of Biological Chemistry, 280: 32122-32132

McIntosh C J, Lun S, Lawrence S, Western A H, McNatty K P, Juengel J L (2008), The Proregion of Mouse BMP15 Regulates the Cooperative Interactions of BMP15 and GDF9, Biology of Reproduction, 79: 889-896

McMahon H E, Hashimoto S, Mellon P L, Shimasaki S (2008a), Oocyte-Specific Overexpression of Mouse Bone Morphogenetic Protein-15 Leads to Accelerated Folliculogenesis and an Early Onset of Acyclicity in Transgenic Mice, Endocrinology, 149(6): 2807- 2815

McMahon H E, Sharma S, Shimasaki S (2008b), Phosphorylation of Bone Morphogenetic Protein-15 and Growth Differentiation Factor-9 Plays a Critical Role in Determining Agonistic or Antagonistic Functions, Endocrinology, 149(2): 812817

McNatty K P, Galloway S M, Wilson T, Smith P, Hudson N L, O'Connel A, Bibby A H, Heath D A, Davis G H, Hanrahan J P, Juengel J L (2005a), Physiological effects of major genes affecting ovulation rate in sheep, Genetics Selection Evolution, 37: 25-38

McNatty K P, Juengel J L, Reader K L, Lun S, Myllymaa S, Lawrence S B, Western A Meerasahib M F, Mottershead D G, Groome N P, Ritvos O, Laitinen M P E (2005b), Bone morphogenetic protein 15 and growth differentiation factor 9 cooperate to regulate granulosa cell function, Reproduction, 129: 473-480

McNatty K P, Juengel J L, Reader K L, Lun S, Myllymaa S, Lawrence S B, Western A, Meerasahib M F, Mottershead D G, Groome N P, Ritvos O, Laitinen M P E (2005c), Bone morphogenetic protein 15 and growth differentiation factor 9 co-operate to regulate granulosa cell function in ruminants, Reproduction, 129: 481-487

McNatty K P, Hudson N L, Whiting L, Reader K L, Lun S, Western A, Heath D A, Smith P, Moore L G, Juengel J L (2007), The Effects of Immunizing Sheep with Different BMP15 or GDF9 Peptide Sequences on Ovarian Follicular Activity and Ovulation Rate, Biology of Reproduction, 76: 552-560 
McNatty K P, Heath D A, Hudson N L, Lun S, Juengel J L, Moore L G (2009), Gonadotrophin-responsiveness of granulosa cells from bone morphogenetic protein 15 heterozygous mutant sheep, Reproduction, 138: 545-551

McNatty K P, Heath D A, Hudson N L, Reader K L, Quirke L, Lun S, Juengel J L (2010), The conflict between hierarchical ovarian follicular development and superovulation treatment, Reproduction, 140: 287-294

Mester B, Ritter L J, Pitman J L, Bibby A H, Gilchrist R B, McNatty K P, Juengel J L, McIntosh C J (2014), Oocyte expression, secretion and somatic cell interaction of mouse bone morphogenetic protein 15 during the peri-ovulatory period, Reproduction, Fertility and Development, 10: 1336-1348

Meunier H, Cajander S B, Roberts V J, Rivier C, Sawchenko P E, Hsueh A J W, Vale W (1988), Rapid Changes in the Expression of Inhibin $\alpha-, \beta A-$, and $\beta B$ - Subunits in Ovarian Cell Types During the Rat Estrous Cycle, Molecular Endocrinology, 2(12): 1352-63

Middlebrook B S, Eldin K, Li X, Shivasankaran S, Pangas S A (2009), Smad1-Smad5 Ovarian Conditional Knockout Mice Develop a Disease Profile Similar to the Juvenile Form of Human Granulosa Cell Tumors, Endocrinology, 150(12): 52085217

Miyazono K, Hellman U, Wernstedt C, Heldin C-H (1988), Latent High Molecular Weight Complex of Transforming Growth Factor $\beta 1$, Journal of Biological Chemistry, 263(13): 6407-6415

Mohan R R, Kim W-J, Mohan R R, Chen L, Wilson S E (1998), Bone Morphogenic Proteins 2 and 4 and Their Receptors in the Adult Human Cornea, Investigative Ophthalmology \& Visual Science, 39(13): 2626-2636

Montgomery G W, Crawford A M, Penty J M, Dodds K G, Ede A J, Henry H M, Pierson C A, Lord E A, Galloway S M, Schmack A E (1993), The ovine Booroola fecundity gene (FecB) is linked to markers from a region of human chromosome 4q, Natue Genetics, 4(4): 410-414

Montgomery G W, Zhao Z Z, Marsh A J, Mayne R, Treloar S A, James M, Martin N G, Boomsma D I, Duffy D L (2004), A Deletion Mutation in GDF9 in Sisters with Spontaneous DZ Twins, Twin Research, 7(6): 548-555

Moore R K, Otsuka F, Shimasaki S (2003), Molecular Basis of Bone Morphogenetic Protein-15 Signaling in Granulosa Cells, Journal of Biological Chemistry, 278(1): 304-310

Mottershead D G, Pulkki M M, Muggalla P, Pasternack A, Tolonen M, Myllymaa S, Korchynskyi O, Nishi Y, Yanase T, Lun S, Juengel J L, Laitinen M, Ritvos O (2008), Characterization of recombinant human growth differentiation factor-9 signaling in ovarian granulosa cells, Molecular and Cellular Endocrinology, 283(1-2): 58-67

Mottershead D G, Ritter L J, Gilchrist R B (2012), Signalling pathways mediating specific synergistic interactions between GDF9 and BMP15, Molecular Human Reproduction, 18(3): 121-128

Mottershead D G, Harrison C A, Mueller T D, Stanton P G, Gilchrist R B, McNatty K P (2013), Growth differentiation factor 9:bone morphogenetic protein 15 (GDF9:BMP15) synergism and protein heterodimerisation, PNAS, 110(25): 2257 
Mueller T D, Nickel J (2012), Promiscuity and specificity in BMP receptor activation, FEBS Letters, 586(14): 1846-1859

Mulheron G W, Schomberg D W (1990), Rat granulosa cells express transforming growth factor-beta 2 messenger ribonucleic acid which is regulated by folliclestimulating hormone in vitro, Endocrinology, 126(3): 1777- 9

Mulsant P, Lecerf F, Fabre S, Laurent S, Monget P, Lanneluc I, Pisselet C, Riquet J, Monniaux D, Callebaut I, Cribiu E, Thimonier J, Teyssier J, Bodin L, Cognie Y, Chitour N, Elsen J-M (2001), Mutation in bone morphogenetic protein receptor-IB is associated with increased ovulation rate in Booroola Merino ewes, Proceedings of the National Academy of Sciences USA, 98(9): 5104- 5109

Nahar-Gohad P, Gohad N, Tsai C-C, Bordia R, Vyavahare N (2015), Rat Aortic Smooth Muscle Cells Cultured on Hydroxyapatite Differentiate into Osteoblast-Like Cells via BMP-2-SMAD-5 Pathway, Calcified Tissue International, 96(4): 359-369

Naito K, Skog S, Tribukait B, Andersson L, Hisazumi H (1987), Cell cycle related $\left[{ }^{3} \mathrm{H}\right]$ thymidine uptake and its significance for the incorporation into DNA, Cell and Tissue Kinetics, 20(4): 447-57

Nakao A, Imamura T, Souchelnytskyi S, Kawabata M, Ishisaki A, Oeda E, Tamaki K, Hanai J-I, Hledin C-H, Miyazono K, ten Dijke P (1997), TGF $\beta$ receptor-mediated signaling through Smad2, Smad3 and Smad4, The EMBO Journal, 16(17): 5353- 5362

Nickel J, Dreyer M K, Kirsch T, Sebald W (2001), The crystal structure of the BMP2:BMPR-IA complex and the generation of BMP-2 antagonists, Journal of Bone \& Joint Surgery, 83(1): 7-14

Nickel J, Kotzsch A, Sebald W, Mueller T D (2005), A Single Residue of GDF-5 Defines Binding Specificity to BMP Receptor IB, Journal of Molecular Biology, 349(5): 933947

Nishitoh J, Ichijo H, Kimura M, Matsumoto T, Makishima F, Yamaguchi A, Yamashita H, Enomoto S, Miyazono K (1996), Identification of Type I and Type II Serine/Threonine Kinase Receptors for Growth/Differentiation Factor-5, Journal of Biological Chemistry, 271(35): 21345-21352

Nohno T, Ishikawa T, Saito T, Hosokawa K, Noji S, Wolsing D H, Rosenbaum J S (1995), Identification of a human type II receptor for bone morphogenetic protein- 4 that forms differential heteromeric complexes with bone morphogenetic protein type I receptors, Journal of Biological Chemistry, 270(38): 22522-22526

Nordin K, Labonne C (2014), Sox5 is a DNA binding co-factor for BMP R-Smads that directs target specificity during patterning of the early ectoderm, Developmental Cell, 31(3): 374-382

Ogawa K, Kurohmaru M, Shiota K, Takahashi M, Nishida T, Hayashi Y (1991), Histochemical Localization of Inhibin and Activin $\alpha, \beta$ A and $\beta B$ Subunits in Rat Gonads, Journal of Veterinary Medical Science, 53(2): 207-212

Oh S P, Yeo C-Y, Lee Y, Schrewe H, Whitman M, Li E (2002), Activin type IIA and IIB receptors mediate Gdf11 signaling in axial vertebral patterning, Genes \& Development, 16(21): 2749-2754

Omori Y, Nakamura K, Yamashita S, Matsuda H, Mizutani T, Miyamoto K, Minegishi T (2005), Effect of Follicle-Stimulating Hormone and Estrogen on the Expression of 
Betaglycan Messenger Ribonucleic Acid Levels in Cultured Rat Granulosa Cells, Endocrinology, 146(8): 3379-3386

Onichtchouk D, Chen Y-G, Dosch R, Gawantka V, Dellus H, Massagué J, Niehrs C (1999), Silencing of TGF- $\beta$ signaling by the pseudoreceptor BAMBI, Nature, 401: 480- 485

Orisaka M, Orisaka S, Jiang J-Y, Craig J, Wang Y, Kotsuji F, Tsang B K (2006), Growth Differentiation Factor 9 Is Antiapoptotic during Follicular Development from Preantral to Early Antral Stage, Molecular Endocrinology, 20(10): 2456-2468

Ortega I, Wong D H, Villanueva J S, Cress A B, Sokalska A, Stanley S D, Duleba A J (2012), Effects of resveratrol on growth and function of rat ovarian granulosa cells, Reproductive Biology, 98(6): 1563-1573

Otsuka F, Moore R K, Shimasaki S (2001), Biological Function and Cellular Mechanism of Bone Morphogenetic Protein-6 in the Ovary, Journal of Biological Chemistry, 276 (35): 32889-32895

Otsuka F, Shimasaki S (2002), A negative feedback system between oocyte bone morphogenetic protein 15 and granulosa cell kit ligand: Its role in regulating granulosa cell mitosis, Proceedings of the National Academy of Sciences USA, 99(12): 8060-8065

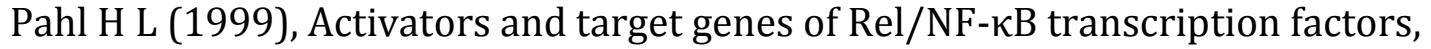
Oncogene, 18(49): 6853-6866

Palmer J S, Zhao Z Z, Hoekstra C, Hayward N K, Webb P M, Whiteman D C, Martin N G, Boomsma D I, Duffy D L, Montgomery G W (2006), Novel Variants in Growth Differentiation Factor 9 in Mothers of Dizygotic Twins, Journal of Clinical Endocrinology \& Metabolism, 91(11): 4713-4716

Pangas S A, Li X H, Robertson E J, Matzuk M M (2006), Premature luteinization and cumulus cell defects in ovarian specific Smad4 knockout mice, Molecular Endocrinology, 20(6): 1406-1422

Paradis F, Novak S, Murdoch G K, Dyck M K, Dixon W T, Foxcroft G R (2009), Temporal regulation of BMP2, BMP6, BMP15, GDF9, BMPR1A, BMPR1B, BMPR2 and TGFBR1 mRNA expression in the oocyte, granulosa and theca cells of developing preovulatory follicles in the pig, Reproduction, 138: 115-129

Pasquale E D, Beck-Peccoz P, Persani L (2004), Hypergonadotropic Ovarian Failure Associated with an Inherited Mutation of Human Bone Morphogenetic Protein-15 (BMP15) American Journal of Human Genetics, 75: 106- 111

Picton H M, Campbell B K, Hunter M G (1999), Maintenance of oestradiol production and expression of cytochrome P450 aromatase enzyme mRNA in long-term serumfree cultures of pig granulosa cells, Journal of Reproduction and Fertility, 115: 6777

Pierre A, Pisselet C, Dupont J, Bontoux M, Monget P (2005), Bone Morphogenetic Protein 5 Expression in the Rat Ovary: Biological Effects on Granulosa Cell Proliferation and Steroidogenesis, 73(6): 1102- 1108

Pierre A, Estienne A, Racine C, Picard J-Y, Fanchin R, Lahoz B, Alabart J L, Folch J, Jarrier P, Fabre S, Monniaux D, di Clements N (2016), The Bone Morphogenetic Protein 15 Up-Regulates the Anti-Mullerian Hormone Receptor Expression in Granulosa Cells, Theriogenology, 86(5): 1353-60 
Pircher R, Lawrence D A, Julien P (1984), Latent $\beta$-Transforming Growth Factor in Nontransformed and Kirsten Sarcoma Virus-transformed Normal Rat Kidney Cells, Clone 49F¹, Cancer Research, 44: 5538-5543

Pircher R, Jullien P, Lawrence D A (1986), $\beta$-Transforming Growth Factor is stored in human blood platelets as a latent high molecular weight complex, Biochemical and Biophysical Research Communications, 136(1): 30-37

Prapa E, Vasilaki A, Dafopoulos K, Katsiani E, Georgoulias P, Messini C I, Anifandis G, Messinis I E (2015), Effect of Anti-Mullerian hormone (AMH) and bone morphogenetic protein 15 (BMP-15) on steroidogenesis in primary-cultured human luteinizing granulosa cells through Smad5 signalling, Journal of Assisted Reproduction and Genetics, 32: 1079-1088

Prochazka R, Nemcova L, Nagyova E, Kanka J (2004), Expression of Growth Differentiation Factor 9 Messenger RNA in Porcine Growing and Preovulatory Ovarian Follicles, Biology of Reproduction, 71: 1290-1295

Pulkki M M, Mottershead D G, Pasternack A H, Muggalla P, Ludlow H, van Dinther M, Myllymaa S, Koli K, ten Dijke P, Laitinen M, Ritvos $O$ (2012) A Covalently Dimerized Recombinant Human Bone Morphogenetic Protein-15 Variant Identifies Bone Morphogenetic Protein Receptor Type 1B as a Key Cell Surface Receptor on Ovarian Granulosa Cells, Endocrinology, 153(3): 1509-1518

Quin R L, Shuttleworth G, Hunter M G (2004), Immunohistochemical localization of the bone morphogenetic protein receptors in the porcine ovary, Journal of Anatomy, 205: $15-23$

Rajkovic A, Pangas S A, Ballow D, Suzumori B, Matzuk M M (2004), NOBOX Deficiency Disrupts Early Folliculogenesis and Oocyte-Specific Gene Expression, Science, 305: 1157-1159

Rak Z, Drwal E, Wróbel A, Gregoraszczuk E L (2015), Resistin is a survival factor for porcine ovarian follicular cells, Reproduction, 150: 343-355

Reader K L, McIntosh C J, Juengel J L (2008), Signalling pathways involved in mouse GDF9 and BMP15 stimulated thymidine by rat granulosa cells, Reproduction, Fertility and Development, 20: 72

Reader K L, Heath D A, Lun S, McIntosh C J, Western A H, Littlejohn R P, McNatty K P, Juengel J L (2011), Signalling pathways involved in the cooperative effects of ovine and murine GDF9 + BMP15-stimulated thymidine uptake by rat granulosa cells, Reproduction, 142: 123- 131

Reader K L, Mottershead D G, Martin G A, Gilchrist R B, Heath D A, McNatty K P, Juengel J $L$ (2016), Signaling pathways involved in the synergistic effects of human growth differentiation factor 9 and bone morphogenetic protein 15, Reproduction, Fertility and Development, 28(4): 491-498

Rebbapragada A, Benchabane H, Wrana J L, Celeste A J, Attisano L (2003), Myostatin Signals through a Transforming Growth Factor $\beta$-Like Signaling Pathway To Block Adipogenesis, Molecular and Cell Biology, 23(20): 7230-7242

Regan S L P, Knight P G, Yovich J L, Stanger J D, Leung Y, Arfuso F, Dharmarajan A, Almahbobi G (2016), Dysregulation of granulosal bone morphogenetic protein 
receptor $1 \mathrm{~B}$ density is associated with reduced ovarian reserve and age-related decline in human fertility, Molecular and Cellular Endocrinology, 425: 84-93

Rich S, Seelig M, Lee H M, Lin J (1995), Transforming growth factor beta 1 costimulated growth and regulatory function of staphylococcal enterotoxin B-responsive CD8+ T cells, Journal of Immunology, 155(2): 609-18

Sadatsuki M, Tsutsumi O, Yamada R, Muramatsu M, Taketani Y (1993), Local Regulatory Effects of Activin A and Follistatin on Meiotic Maturation of Rat Oocytes, Biochemical and Biophysical Research Communications, 196(1): 388-395

Sasseville M, Ritter L J, Nguyen T M, Liu F, Mottershead D G, Russel D L, Gilchrist R B (2010), Growth differentiation factor 9 signaling requires ERK1/2 activity in mouse granulosa and cumulus cells, Journal of Cell Science, 123(18): 3166-3176

Savage C, Das P, Finelli A L, Townsend S R, Sun C-Y, Baird S E, Padgett R W (1996), Caenorhabditis elegans genes sma-2, sma-3, and sma-4 define a conserved family of transforming growth factor $\beta$ pathway components, Proceedings of the National. Academy of Sciences. USA, 93: 790-794

Scharpfenecker M, van Dinther M, Liu Z, van Bezooijen R L, Zhao Q, Pukac L, Lowik C W, ten Dijke P (2007), BMP-9 signals via ALK1 and inhibits bFGF-induced endothelial cell proliferation and VEGF-stimulated angiogenesis, Journal of Cell Science, 120(6): 964-972

Scheufler C, Sebald W, Hulsmeyer M (1999), Cyrstal structure of human bone morphogenetic protein-2 at 2.7 A resolution, Journal of Molecular Biology, 287(1) 103-115

Schmierer B, Hill C S (2005), Kinetic Analysis of Smad Nucleocytoplasmic Shuttling Reveals a Mechanism for Trnaforming Growth Factor $\beta$-Dependent Nuclear Accumulation of Smads, Molecular and Cellular Biology, 25(22): 9845-9858

Schmierer B, Tournier A L, Bates P A, Hill C S (2008), Mathematical modeling identifies Smad nucleocytoplasmic shuttling as a dynamic signal-interpreting system, Proceedings of the National Academy of Sciences USA, 105(18): 6608-6613

Sefat F, Denyer M C, Youseffi M (2014), Effects of different transforming growth factor beta (TGF- $\beta$ ) isomers on wound closure of bone cell monolayers, Cytokine, 69(1): 75- 86

Sekelsky J J, Newfeld S J, Raftery L A, Chartoff E H, Gelbart W M (1995), Genetic Characterization and Cloning of Mothers against dpp, a Gene Required for decapentaplegic Function in Drosophila melanogaster, Genetics, 139: 1327-1358

Shi F-T, Cheung A P, Leung P C K (2009), Growth Differentiation Factor 9 Enhances Activin A-Induced Inhibin B Production in Human Granulosa Cells, Endocrinology, 150(8): 3520-3546

Shi M, Zhu J, Wang R, Chen X, Mi L, Walz T, Springer T A (2011), Latent TGF- $\beta$ structure and activation, Nature, 474(7351): 343-349

Shimasaki S, Zachow R J, Li D, Kim H, Iemura S, Ueno N, Sampath K, Chang J, Erickson G F (1999), A functional bone morphogenetic protein system in the ovary, Proceedings of the National Academy of Sciences USA 96: 7282- 
Shimasaki S, Moore R K, Otsuka F, Erickson G F (2004), The bone morphogenetic protein system in mammalian reproduction, Endocr Rev, 25(1): 72- 101

Silva J R V, van den Hurk R, Costa S H F, Andrade E R, Nunes A P A, Ferreira F V A, Lobo R N B, Figueiredo J R (2004), Survival and growth of goat primordial follicles after in vitro culture of ovarian cortical slices in media containing coconut water, Animal Reproduction Science, 81(3-4): 273-286

Silva J R V, van den Hurk R, van Tol H T A, Roelen B A J, Figueiredo J R (2005), Expression of growth differentiation factor 9 (GDF9), bone morphogenetic protein 15 (BMP15), and BMP receptors in the ovaries of goats, Molecular Reproduction and Development, 70(1): 11-19

Silva P V, Guimaraes S E, Guimaraes J D, Neto J B, Lopes P S, do Nascimento C S, de Campos C F, Weller M M, Botelho M E, Faria V R (2011), Gene expression in swine granulosa cells and ovarian tissue during the estrous cycle, Genet Mol Res, 10(3): 2258- 2267

Simonsson M, Kanduri M, Gronroos E, Heldin C-H, Ericsson J (2006), The DNA Binding Activities of Smad2 and Smad3 Are Regulated by Coactivator-mediated Acetylation, Journal of Biological Chemistry, 281: 39870-39880

Singh B, Armstrong D T (1995), Transforming growth factor $\alpha$ gene expression and peptide localization in porcine ovarian follicles, Biology of Reproduction, 53: 1429-1435

Solary E, Bertrand R, Jenkins J, Pommier Y (1992), Radiolabeling of DNA can induce its fragmentation in HL-60 human promyelocytic leukemic cells, Exp Cell Res, 203(2): 495- 498

Souchelnytskyi S, ten Dijke P, Miyazono K, Heldin C-H (1996), Phosphorylation of Ser165 in TGF- $\beta$-induced cellular responses, The EMBO Journal, 15(22): 62316240

Souza C J, Campbell B K, McNeilly A S, Baird D T (2002), Effect of bone morphogenetic protein 2 (BMP2) on oestradiol and inhibin A production by sheep granulosa cells, and localisation of BMP receptors in the ovary by immunohistochemistry, Reproduction, 123(3): 362- 369

Soyun E Y, LaPolt P S, Yoon B S, Chen J Y-C, Lu J K H, Lyons K M (2001), The type I BMP receptor BmprIB is essential for female reproductive function, Proceedings of the National Academy of Sciences USA, 98(14): 7994- 7999

Spicer L J, Aad P Y, Allen D, Mazerbourg S, Hsueh A J (2006), Growth differentiation factor-9 has divergent effects on proliferation and steroidogenesis of bovine granulosa cells, Journal of Endocrinology, 189: 329- 339

Sriperumbudur R, Zorrilla L, Gadsby J E (2010), Transforming growth factor- $\beta$ (TGF $\beta$ ) and its signaling compoenents in peri-ovulatory pig follicles, Animal Reproduction Science, 120 (1-4): 84-94

Steffl M, Schweiger M, Amselgruber W M (2009), Expression of transforming growth factor- $\beta 3$ (TGF- $\beta 3$ ) in the porcine ovary during oestrus cycle, Histology and Histopathology, 23: 665- 671

Su Y-Q, Wigglesworth K, Pendola F L, O’Brien M J, Eppig J J (2002), Mitogen-Activated Protein kinase Activity in Cumulus Cells Is Essential for Gonadotropin-Induced 
Oocyte Meiotic Resumption and Cumulus Expansion in the Mouse, Endocrinology, 143(6): 2221-2232

Su Y-Q, Sugiura K, Eppig J J (2008), Mouse Oocytes License Induction of Oocyte Maturation and Cumulus Expansion: BMP15 and GDF9 Promote Epidermal Growth Factor Receptor (EGFR) Expression in Cumulus Cells, Biology of Reproduction, 78(1): 58

Sun R Z, Lei L, Cheng L, Jin Z F, Zu S J, Shan Z Y, Wang Z D, Zhang J X, Liu Z H (2010), Expression of GDF-9, BMP-15 and their receptors in mammalian ovary follicles, Journal of Molecular Histology, 41(6): 325-332

Sun Y, Liu W-Z, Liu T, Feng X, Yang N, Zhou H-F (2015), Signaling pathway of MAPK/ERK in cell proliferation, differentiation, migration, senescence and apoptosis, Journal of Receptors and Signal Transduction, 35(6): 600-604

Swinerd G (2016), The molecular forms of BMP15 in a range of mammalian species. Master Thesis, Victoria University of Wellington.

Takai S, Tokuda H, Matsushima-Nishiwaki R, Saio M, Takami T, Kozawa O (2010), TGFbeta superfamily enhances the antigen-induced TFN-gamma production be effector/memory CD8+ T cells, International Journal of Molecular Medicine, 25(1): 105-11

Taylor N A, Van de Ven W J M, Creemers J W M (2003), Curbing activation: proprotein convertases in homeostasis and pathology, The FASEB Journal, 17(10): 1215-1227

Teerds K J, Dorrington J H (1992), Immunohistochemical localisation of transforming growth factor- $\beta 1$ and $\beta 2$ during follicular development in the adult rat ovary, Molecular and Cellular Endocrinology, 84(1-2): 7-13

ten Dijke P, Goumans M J, Itoh F, Itoh S (2002), Regulation of Cell Proliferation by Smad Proteins, Journal of Cellular Physiology, 191: 1-16

ten Dijke P, Yamashita H, Sampath T K, Reddi A H, Estevez M, Riddle D L, Ichijo H, Heldin C H, Miyazono K (1994), Identification of type I receptors for osteogenic protein1 and bone morphogenetic protein-4, Journal of Biological Chemistry, 269(25): 16985-16988

Tiemessen M M, Kunzmann S, Schmidt-Weber C B, Garssen J, Bruijnzeel-Koomen C A, Knol E F, van Hoffen E (2003), Transforming growth factor-beta inhibits human antigen-specific CD4+ T cell proliferation without modulating the cytokine response, International Immunology, 15(12): 1495-1504

Tisdall D J, Hudson N, Mith P, McNatty K P (1994), Localization of ovine follistatin and ainhibin and $\beta(\mathrm{A})$-inhibin Messenger-RNA in the sheep ovary during the estrouscycle, Journal of Molecular Endocrinology, 12(2): 181-193

Tomic D, Brodie S G, Deng C, Hickey R J, Babus J K, Malkas L H, Flaws J A (2002), Smad 3 May Regulate Follicular Growth in the Mouse Ovary, Biology of Reproduction, 66: 917-923

Townsend T A, Robinson J Y, Deig C R, Hill C R, Misfeldt A, Blobe G C, Barnett J V (2011), BMP-2 and TGF $\beta 2$ Shared Pathways Regulate Endocardial Cell Transformation, Cells Tissues Organs, 194: 1-12 
Tsukazaki T, Chiang T A, Davison A F, Attisano L, Wrana J L (1998), SARA, a FYVE Domain Protein that Recruits Smad2 to the TGF $\beta$ Receptor, Cell, 95(6): 7790791

Tu A W, Luo K (2007), Acetylation of Smad2 by the Co-activator p300 Regulates Activin and Transforming Growth Factor $\beta$ Response, Journal of Biological Chemistry, 282: 21187-21196

Ueno S, Takahashi M, Manganaro T F, Ragin R C, Donahoe P K (1989), Cellular localization of mullerian inhibiting substance in the developing rat ovary, Endocrinology, 124(2): 1000-1006

Van den Hurk R, van de Pavert S A (2001), Localization of an Activin/Activin Receptor System in the Porcine Ovary, Molecular Reproduction and Development, 60: 463471

Vigo D, Villani S, Faustini M, Accorsi P A, Galeati G, Spinaci M, Munari E, Russo V, Asti A, Conte U, Torre M L (2005), Follicle-Like Model by Granulosa Cell Encapsulation in a Barium Alginate-Protamine Membrane, Tissue Engineering, 11: 709-714

Vitt U A, Hayashi M, Klein C, Hsueh A J W (2000), Growth Differentiation Factor-9 Stimulates Proliferation but Suppresses the Follicle-Stimulating HormoneInduced Differentiation of Cultured Granulosa Cells from Small Antral and Preovulatory Rat Follicles, Biology of Reproduction, 62(2): 370-377

Vitt U A, Hsu S Y, Hueh A J W (2001), Evolution and Classification of Cysteine KnotContaining Hormones and Related Extracellular Signaling Molecules, Molecular Endocrinology, 15(5): 681-694

Vitt U A, Mazerbourg S, Klein C, Hsueh A J W (2002), Bone Morphogenetic Protein Receptor II Is a receptor for Growth Differentiation Factor-9, Biology of Reproduction, 67: 473-480

Wakefield L M, Smith D M, Flanders K C, Sporn M B (1988), Latent Transforming Growth Factor- $\beta$ from Human Platelets. A high molecular weight complex containing precursor sequences, J Biol Chem, 263(16): 7646- 54

Walton K L, Makanji Y, Wilce M C, Chan K L, Robertson D M, Harrison C A (2009), A Common Biosynthetic Pathway Governs the Dimerization and Secretion of Inhibin and Related Transforming Growth Factor $\beta$ (TGF $\beta$ ) Ligands, Journal of Biological Chemistry, 284: 9311-9320

Wang C, Li C, Li H, Ma W, Chen S, Zhao Y, Rao J, Zhou X (2015), Downregulation of the expression of inhibin $\alpha$ subunit and betaglycan in porcine cystic follicles, The Journal of Veterinary Medical Science, 77(11): 1419- 1425

Wang H, Jiang J-Y, Zhu C, Peng C, Tsang B K (2006), Role and Regulation of Nodal/Activin Receptor-Like Kinase 7 Signaling Pathway in the Control of Ovarian Follicular Atresia, Molecular Endocrinology, 20(10): 2469- 2482

Wang X-L, Wang K, Zhao S, Wu Y, Gao H, Zeng S-M (2013a), Oocyte-Secreted Growth Differentiation Factor 9 Inhibits BCL-2-Interacting Mediator of Cell Death-Extra Long Expression in Porcine Cumulus Cell, Biology of Reproduction, 89(3): 1-9

Wang C, Ma W, Su Y (2013b), NF-кB Pathway Contributes to Cadmium-Induced Apoptosis of Porcine Granulosa Cells, Biological Trace Element Research, 153(1): 403- 410 
Westwood F R (2008), The Female Rat Reproductive Cycle: A Practical Histological Guide to Staging, Toxicologic Pathology, 36(3): 375-384

Wiater E, Vale W (2003),Inhibin Is an Antagonist of Bone Morphogenetic Protein Signaling, Journal of Biological Chemistry, 278(10): 7934-7941

Wieser R, Wrana J L, Massagué (1995), GS domain mutations that constitutively activate $\mathrm{T} \beta \mathrm{R}-\mathrm{I}$, the downstream signaling component in the TGF- $\beta$ receptor complex, The EMBO Journal, 14(10): 2199-2208

Williams S A, Stanley P (2008), Mouse fertility is enhanced by oocyte-specific loss of core 1-derived 0 glycans, The FASEB Journal, 22(7): 2273-2284

Wilson T, Wu X-Y, Juengel J L, Ross I K, Lumsden J M, Lord E A, Dodds K G, Walling G A, McEwan J C, O'Connell A R, McNatty K P (2001), Highly Prolific Booroola Sheep Have a Mutation in the Intracellular Kinase Domain of Bone Morphogenetic Protein IB Receptor (ALK-6) That Is Expressed in Both Oocytes and Granulosa Cells, Biology of Reproduction, 64: 1225-1235

Winnier G, Blessing M, Labosky P A, Hogan B L M (1995), Bone morphogenetic protein-4 is required for mesoderm formation and patterning in the mouse, Genes and Development, 9: 2105-2116

Woodruff T K, Meunier H, Jones P B C, Hsueh A J W, Mayo K E (1987), Rat Inhibin: Molecular Cloning of $\alpha$ - and $\beta$-Subunit Complementary Deoxyribonucleic Acids and Expression in the Ovary, Molecular Endocrinology, 1: 561-568

Woody C O, First N L, Pope A L (1967), Effect of Exogenous Progesterone on Estrous Cycle Length, Journal of Animal Science, 26(1): 139-141

Wrana J L, Attisano L, Wieser R, Ventura F, Massagué J (1994), Mechanism of activation of the TGF- $\beta$ receptor, Nature, 370: 341-346

Wu J, Dent P, Jelinek T, Wolfman A, Weber M J, Sturgill T W (1993), Inhibition of the EGFActivated MAP Kinase Signaling Pathway by Adenosine 3',5'-Monophosphate, Science, 262: 1065-1069

Wu J-W, Fairman R, Penry J, Shi Y (2001a), Formation of a Stable Heterodimer between Smad2 and Smad4, Journal of Biological Chemistry, 276(23): 20688-20694

Wu J-W, Hu M, Chai J, Seoane J, Huse M, Li C, Rigotti D J, Kyin S, Muir T W, Fairman R, Massagué J, Shi Y (2001b), Crystal Structure of a Phosphorylated Smad2: Recognition of Phosphoserine by the MH2 Domain and Insights on Smad Function in TGF $\beta$ Signaling, Molecular Cell, 8(6): 1277-1289

Xu J, Kimball T R, Lorenz J N, Brown D A, Bauskin A R, Klevitsky R, Hewett T E, Breit S N, Molkentin J D (2006), GDF15/MIC-1 functions as a protective and antihypertrophic factor released from the myocardium in association with SMAD protein activation, Circulation Research, 98(3): 342-50

Yamamoto N, Christensen L K, McAllister J M, Strauss J F (2002), Growth Differentiation Factor-9 Inhibits 3'5'-Adenosine Monophosphate-Simulated Steroidogenesis in Human Granulosa and Theca Cells, The Journal of Clinical Endocrinology \& Metabolism, 87(6): 2849-2856

Yan C, Wang P, DeMayo J, DeMayo FJ, Elvin JA, Carino C, Prasad SV, Skinner SS, Dunbar BS, Dube JL, Celeste AJ, Matzuk MM (2001), Synergistic roles of bone 
morphogenetic protein 15 and growth differentiation factor 9 in ovarian function, Molecular Endocrinology, 15(6): 854-866

Yang P, Roy S K (2006), Transforming Growth Factor B1 Stimulated DNA Synthesis in the Granulosa Cells of Preantral Follicles: Negative Interaction with Epidermal Growth Factor, Biology of Reproduction, 75(1): 140-148

Yang Y H, Hsieh T L, Ji A T, Hsu W T, Liu C Y, Lee O K, Ho J H (2016), Stromal Tissue Rigidity Promotes Mesenchymal Stem Cell-Mediated Corneal wound Healing Through the Transforming Growth Factor $\beta$ Signaling Pathway, Stem Cells, 34(20): 2525- 2535

Yoon S-J, Wills A E, Chuong E, Gupta R, Baker J C (2011), HEB and E2A function as SMAD/FOXH1 cofactors, Genes and Development, 25(15): 1654-1661

Yuan S, Wen J, Cheng J, Shen W, Zhou S, Yan W, Shen L, Luo A, Wang S (2016), Ageassociated up-regulation of EGR1 promotes granulosa cell apoptosis during follicle atresia in mice through the NF- $\kappa B$ pathway, Cell Cycle, 15(21): 2895-2905

Zamah A M, Hassis M E, Albertolle M E, Williams K E (2015), Proteomic analysis of human follicular fluid from fertile women, Clinical Proteomics, 12(1): 5

Zawel L, Dai J L, Buckhaults P, Zhou S, Kinzler K W, Vogelstein B, Kern S E (1998), Human Smad3 and Smad4 Are Sequence-Specfic Transcription Activators, Molecular Cell, 1: $611-617$

Zhai B, Liu H Y, Li X, Dai L S, Gao Y, Li C H, Zhang L J, Yu X F, Zhang J B (2013), BMP15 Prevents Cumulus Cell Apoptosis Through CCL2 and FBN1 in Porcine Ovaries, Cellular Physiology and Biochemistry, 32(2): 264-278

Zhang H, Tian S, Klausen C, Zhu H, Liu R, Leung P C K (2016), Differential activation of noncanonical SMAD2/SMAD3 signaling by bone morphogenetic proteins causes disproportionate induction of hyaluronan production in immortalised human granulosa cells, Molecular and Cellular Endocrinology, 428: 17-27

Zhao Z Z, Painter J N, Palmer J S, Webb P M, Hayward N K, Whiteman D C, Boomsma D I, Martin N G, Duffy D L, Montgomery G W (2008), Variation in bone morphogenetic protein 15 is not associated with spontaneous human dizygotic twinning, Human Reproduction, 23(10): 2372-2379

Zhu G, Guo B, Pan D, Mu Y, Feng S (2008), Expression of bone morphogenetic proteins and receptors in porcine cumulus-oocyte complexes during in vitro maturation, Animal Reproduction Science, 104(2-4): 275- 283

Zhu H, Kavsak P, Abdollah S, Wrana J L, Thomsen G H (1999), A SMAD ubiquitin ligase targets the BMP pathway and affects embryonic pattern formation, Nature, 400: 687-693 


\section{Appendices}

\section{Appendix 1 - Solutions and reagents}

\subsection{Solutions for dissection}

\section{Saline solution}

$9 \mathrm{~g}$ of sodium chloride was dissolved in $1 \mathrm{~L}$ of $\mathrm{dH}_{2} \mathrm{O}$ to make a $0.9 \%$ solution, autoclaved and stored at room temperature.

\section{Dissection media}

One jar of Medium 199 and $4.766 \mathrm{~g}$ of HEPES (20 mM) buffer were dissolved in $800 \mathrm{~mL}$ of distilled water and Penicillin-streptamycin was added. This solution was $\mathrm{pH}$ adjusted to 7.3 with $\mathrm{NaOH}$ and distilled water added for a total volume of $1 \mathrm{~L}$. The media was then filtered and stored at $4{ }^{\circ} \mathrm{C}$.

\section{Incubation media}

Polyvinyl alcohol $(0.3 \mathrm{mg} / \mathrm{mL})$, sodium bicarbonate $(2.2 \mathrm{~g} / \mathrm{L})$ and penicillinstreptamycin (100IU/mL) were added to McCoy's 5A (Modified) Medium. The media was filtered and stored at $4{ }^{\circ} \mathrm{C}$.

\subsection{Reagents for qPCR}

\section{MasterPure RNA Purification Kit}

Epicentre, an Illumina company, Catalog number MCR85102

RNASe-Free DNase I, Proteinase K stored at $-20^{\circ} \mathrm{C}$; remainder of the kit stored at room temperature

\section{SuperScript VILO cDNA Synthesis Kit}

Life technologies, Catalog number 11754-250 
Aliquoted and stored at $-20^{\circ} \mathrm{C}$

Brilliant Multiplex QPCR Master Mix

Agilent technologies, Catalog number 600553

Stored at $4{ }^{\circ} \mathrm{C}$

\section{Brilliant II SYBR Green QPCR Master Mix}

Agilent technologies, Catalog number 600828

Stored at $4{ }^{\circ} \mathrm{C}$

\subsection{Solutions for Western Blots}

\section{$10 \mathrm{X}$ Protease inhibitor stock}

1 tablet of complete EDTA-free protease inhibitor cocktail (Ref \# 04693159001, Roche) was dissolved in $5 \mathrm{~mL}$ of distilled water, and stored at $-20^{\circ} \mathrm{C}$.

\section{Phosphatase inhibitor}

1 tablet of phosphatase inhibitor (Ref \# 04906845001, Roche) was dissolved in 1mL of distilled water for a $10 \mathrm{x}$ solution, and stored at $4{ }^{\circ} \mathrm{C}$.

\section{Cell lysis buffer}

The following compounds were added:

\section{Compound}

Sodium chloride

Sodium deoxycholate

Sodium dodecyl sulfate (SDS)

Tris (pH 8.0)

\section{Amount}

$150 \mathrm{mM}$

$0.5 \%$

$0.1 \%$

$50 \mathrm{mM}$ 


\subsection{Tris HCl}

$6.06 \mathrm{~g}$ of Tris base was dissolved in $80 \mathrm{ml}$ of distilled water and $\mathrm{pH}$ adjusted to 6.8 with $\mathrm{HCl}$, and then made up to a total volume of $100 \mathrm{ml}$.

\section{$1 \mathrm{M}$ Tris HCl}

$30.29 \mathrm{~g}$ of Tris base was dissolved in $150 \mathrm{ml}$ of distilled water and $\mathrm{pH}$ adjusted to 8.5 with $\mathrm{HCl}$, and then made up to a total volume of $250 \mathrm{ml}$.

\subsection{Tris HCl}

$36.34 \mathrm{~g}$ of Tris base was dissolved in $160 \mathrm{ml}$ of distilled water and $\mathrm{pH}$ adjusted to 8.8 with $\mathrm{HCl}$, and then made up to a total volume of $200 \mathrm{ml}$.

\section{0x Sodium dodecyl sulfate (SDS)}

$20 \mathrm{~g}$ of SDS was dissolved in $200 \mathrm{ml}$ of distilled water.

\section{5x Running Buffer}

Compound Amount

Glycine

Tris

SDS

$60 \mathrm{~g}$

$15 \mathrm{~g}$

$5 g$

These chemical compounds were combined with distilled water at a volume below $1 \mathrm{~L}$ and $\mathrm{pH}$ adjusted to 8.3 with $\mathrm{HCl}$ in a total volume of $1 \mathrm{~L}$. Running buffer was stored at room temperature and diluted to $1 \mathrm{x}$ concentration prior to use.

\section{0x Tris-glycine stock}

\begin{tabular}{ll} 
Compound & Amount \\
\hline Tris base & $30.3 \mathrm{~g}$ \\
Glycine & $144 \mathrm{~g}$
\end{tabular}


These chemical compounds were combined with distilled water in a total volume of $1 \mathrm{~L}$ and stored at room temperature.

\section{Membrane washing buffer}

\begin{tabular}{ll} 
Compound & Amount \\
\hline $1 \mathrm{M}$ Tris $\mathrm{HCl}$ & $20 \mathrm{ml}$ \\
Sodium chloride & $8.76 \mathrm{~g}$ \\
Tween 20 & $1 \mathrm{ml}$
\end{tabular}

These chemical compounds were combined with distilled water in a total volume of $1 \mathrm{~L}$ and stored at room temperature.

\section{Membrane storage solution}

0.05\% Sodium azide was combined with $20 \mathrm{ml}$ of membrane washing buffer and membranes were stored in this solution at $4^{\circ} \mathrm{C}$.

\section{2x Reducing loading buffer}

\begin{tabular}{ll} 
Compound & Amount \\
\hline $0.5 \mathrm{M}$ Tris $\mathrm{HCl} \mathrm{pH} 6.8$ & $1.0 \mathrm{~mL}$ \\
Glycerol & $4.5 \mathrm{~mL}$ \\
$10 \%$ SDS & $4.6 \mathrm{~mL}$ \\
$1 \%(\mathrm{w} / \mathrm{v}$ ) bromophenol blue & $0.4 \mathrm{~mL}$ \\
$\mathrm{dH}_{2} \mathrm{O}$ & $4.5 \mathrm{~mL}$ \\
DTT & $80 \mathrm{mg}$ \\
2-Mercaptoethanol (2-ME) & $1.66 \mathrm{~mL}$
\end{tabular}

These compounds were combined and aliquoted, to be stored at $-20^{\circ} \mathrm{C}$ prior to use (up to 3 months). 2-ME was added fresh prior to use (10\% of total volume). 


\section{Stripping buffer}

\section{Compound}

$10 \%$ SDS

$0.5 \mathrm{M}$ Tris $\mathrm{HCl} \mathrm{pH} 6.8$

2-Mercaptoethanol (2-ME)

$\mathrm{dH}_{2} \mathrm{O}$
Amount

$20 \mathrm{~mL}$

$12.5 \mathrm{~mL}$

$0.7 \mathrm{~mL}$

$66.8 \mathrm{~mL}$

These compounds were combined, and made fresh prior to use.

\section{Transfer buffer}

Compound Amount

10x Tris-glycine stock

$300 \mathrm{ml}$

Methanol

$600 \mathrm{ml}$

These compounds were combined with distilled water in a total volume of 3L and stored at $4^{\circ} \mathrm{C}$. 


\section{Appendix 2 - Reagents}

\begin{tabular}{|c|c|c|}
\hline Reagent & Lot/Cat number and Company & Storage conditions \\
\hline 2-Mercaptoethanol (2-ME) & 46496KMV, Sigma & Room temperature \\
\hline $30 \%$ Acrylamide/Bis solution & 161-0158, BioRad & $4^{\circ} \mathrm{C}$ \\
\hline${ }^{3} \mathrm{H}$-Thymidine & $\begin{array}{l}\text { NET35501MC, Perkin Elmer, Boston, } \\
\text { MA, USA }\end{array}$ & $4^{\circ} \mathrm{C}$ \\
\hline$\beta$-scintillation fluid & $\begin{array}{l}\text { SC/9200.21, Perkin Elmer, Sci-Med, } \\
\text { Auckland, New Zealand }\end{array}$ & \\
\hline Bovine albumin & ABRE, MP Biomedicals & $4^{\circ} \mathrm{C}$ \\
\hline Bromophenol blue sodium salt & B8026, Sigma-Aldrich & Room temperature \\
\hline $\begin{array}{l}\text { Complete EDTA-free protease } \\
\text { inhibitor cocktail tablets }\end{array}$ & 04693159001, Roche & $4^{\circ} \mathrm{C}$ \\
\hline Glycine & AC04041000, Scharlau & Room temperature \\
\hline $\begin{array}{l}\text { HEK-293 deer BMP15 } \\
\text { recombinant conditioned media }\end{array}$ & $\mathrm{N} / \mathrm{A}$ & $-80^{\circ} \mathrm{C}$ \\
\hline $\begin{array}{l}\text { HEK-293 deer GDF9 } \\
\text { recombinant conditioned media }\end{array}$ & $\mathrm{N} / \mathrm{A}$ & $-80^{\circ} \mathrm{C}$ \\
\hline HEPES & SLBL4126B, Sigma & Room temperature \\
\hline $\begin{array}{l}\text { Ladder - Precision Plus Protein } \\
\text { Dual Color Standards }\end{array}$ & 1610374, Bio-Rad & $-20^{\circ} \mathrm{C}$ \\
\hline McCoy's 5A modified medium & $\begin{array}{l}\text { 16600082, Gibco (Thermo Fisher } \\
\text { Scientific) }\end{array}$ & $4^{\circ} \mathrm{C}$ \\
\hline Medium 199 & 1001954622, Sigma Aldrich & $4^{\circ} \mathrm{C}$ \\
\hline Methanol & ME03162500, Scharlau & Room temperature \\
\hline Penicillin-Streptomycin & $\begin{array}{l}\text { 15140122, Gibco (Thermo Fisher } \\
\text { Scientific) }\end{array}$ & $-20^{\circ} \mathrm{C}$ \\
\hline Phosphate buffered saline (PBS) & 1694258, Gibco (Life Technologies) & $4^{\circ} \mathrm{C}$ \\
\hline Protease inhibitor & 04693159001, Roche & $4^{\circ} \mathrm{C}$ \\
\hline Polyvinyl alcohol & 9002895, Sigma & Room temperature \\
\hline Sodium azide & 26628228, Scharlau & Room temperature \\
\hline Sodium bicarbonate & SLBF0769V, Sigma & Room temperature \\
\hline Sodium chloride & 7647145, Fisher Scientific & Room temperature \\
\hline $\begin{array}{l}\text { Sodium Dodecyl Sulfate (SDS) } \\
\text { dust free pellets }\end{array}$ & STBG2637V, Sigma & Room temperature \\
\hline Tris base & BP1521, Fisher Scientific & Room temperature \\
\hline Tween20 & 115125, Fisher Scientific & Room temperature \\
\hline $\begin{array}{l}\text { WesternBright ECL-Spray } \\
\text { Western Blotting Detection }\end{array}$ & K-12049-D50, Advantsa & Room temperature \\
\hline
\end{tabular}




\section{Primary antibodies}

\begin{tabular}{|c|c|c|c|}
\hline Antibody & $\begin{array}{c}\text { Brand and Lot } \\
\text { Number }\end{array}$ & $\begin{array}{c}\text { Storage } \\
\text { conditions }\end{array}$ & Target site/s \\
\hline $\begin{array}{l}\text { SMAD 2/3 (E-20) SC- } \\
\text { 6033, goat polyclonal } \\
\text { IgG }\end{array}$ & $\begin{array}{l}\text { Santa Cruz: } \\
\text { Lot\#B1313 }\end{array}$ & $4^{\circ} \mathrm{C}$ & $\begin{array}{l}\text { Raised against a peptide } \\
\text { which maps to the N-terminus } \\
\text { of Smad1 of human origin }\end{array}$ \\
\hline $\begin{array}{c}\text { SMAD 1/5/8 (N-18) - R } \\
\text { SC-6031-R, rabbit } \\
\text { polyclonal IgG }\end{array}$ & $\begin{array}{l}\text { Santa Cruz: } \\
\text { Lot\# C2216 }\end{array}$ & $4^{\circ} \mathrm{C}$ & $\begin{array}{l}\text { Raised against a peptide } \\
\text { which maps to the } C \text {-terminus } \\
\text { of Smad3 of human origin }\end{array}$ \\
\hline $\begin{array}{c}\text { p-SMAD 2/3 } \\
\text { (Ser423/425)-R SC- } \\
\text { 11769-R, rabbit } \\
\text { polyclonal IgG }\end{array}$ & $\begin{array}{l}\text { Santa Cruz: } \\
\text { Lot\# D1216 }\end{array}$ & $4^{\circ} \mathrm{C}$ & $\begin{array}{l}\text { Recognises Ser } 423 \text { and Ser } \\
425 \text { phosphorylated Smad } 3 \\
\text { and correspondingly } \\
\text { phosphorylated Smad } 2 \text { of } \\
\text { mouse, rat and human origin. } \\
\text { Raised against an amino acid } \\
\text { sequence containing Ser } 423 \\
\text { and Ser } 425 \text { phosphorylated } \\
\text { Smad3 of human origin }\end{array}$ \\
\hline $\begin{array}{c}\text { p-SMAD } \\
\text { 1/5(S463/465)/9(S465/ } \\
\text { 467) (D5B10), rabbit } \\
\text { monoclonal IgG }\end{array}$ & $\begin{array}{l}\text { Cell Signaling: } \\
\text { Lot\#13820 }\end{array}$ & $-20^{\circ} \mathrm{C}$ & $\begin{array}{l}\text { Recognises Smad1 and Smad5 } \\
\text { pro-protein when } \\
\text { phosphorylated at } \\
\text { Ser463/465 and Smad8 } \\
\text { protein when phosphorylated } \\
\text { at Ser } 465 / 467\end{array}$ \\
\hline
\end{tabular}

\section{Secondary Antibodies}

\begin{tabular}{cccc}
\hline Antibody & $\begin{array}{c}\text { Brand and Lot } \\
\text { Number }\end{array}$ & $\begin{array}{c}\text { Storage } \\
\text { conditions }\end{array}$ & Target site/s \\
\hline $\begin{array}{c}\text { Peroxidase- } \\
\text { conjugated } \\
\text { AffiniPure Rabbit } \\
\text { Anti-Goat IgG }\end{array}$ & $\begin{array}{c}\text { Jackson } \\
\text { Immunoresearch: }\end{array}$ & $-20^{\circ} \mathrm{C}$ & $\begin{array}{c}\text { Reacts with whole molecule } \\
\text { goat IgG in addition to the } \\
\text { light chains of other goat } \\
\text { immunoglobulins }\end{array}$ \\
\hline $\begin{array}{c}\text { Goat polyclonal Ab } \\
\text { to Rabbit IgG (HRP) }\end{array}$ & Abcam: & $4^{\circ} \mathrm{C}$ & $\begin{array}{c}\text { Reacts with rabbit IgG in } \\
\text { addition to the light chains } \\
\text { common to other rabbit } \\
\text { immunoglobulins }\end{array}$ \\
\hline
\end{tabular}




\section{Blocking peptides}

\begin{tabular}{ccc}
\hline Blocking peptide & Brand and Lot Number & Storage conditions \\
\hline p-Smad 2/3 & Santa Cruz: Lot\# J0716 & $4^{\circ} \mathrm{C}$ \\
Smad 2/3 & Santa Cruz: Lot\# D2205 & $4^{\circ} \mathrm{C}$ \\
Smad 1/5/8 & Santa Cruz: Lot\# E2214 & $4^{\circ} \mathrm{C}$ \\
\hline
\end{tabular}

